\title{
Molecular oxides of high-valent actinides
}

\section{Attila Kovács ${ }^{1}$ (D)}

Received: 13 March 2020 / Accepted: 4 May 2020 / Published online: 29 May 2020

(C) The Author(s) 2020

\begin{abstract}
The past decade has been very productive in the field of actinide (An) oxides containing high-valent An. Novel gas-phase experimental and an impressive number of theoretical studies have been performed, mostly on pure oxides or oxides extended with other ligands. The review covers the structural properties of molecular $\mathrm{An}$ oxides with high $\left(\mathrm{An}^{\geq \mathrm{V}}\right)$ oxidation states. The presented compounds include the actinide dioxide cations $\left[\mathrm{AnO}_{2}\right]^{+}$and $\left[\mathrm{AnO}_{2}\right]^{2+}$, neutral and ionic $\mathrm{AnO}_{x}(x=3-6)$, oxides with more than one An atom like neutral dimers, trimers and dimers from cation-cation interactions, as well as large U-oxide clusters observed very recently in the gaseous phase.
\end{abstract}

Keywords Review $\cdot$ Actinide oxides $\cdot$ High valency $\cdot$ Quantum chemical calculations $\cdot$ Gas-phase experiments

\section{Introduction}

The actinide (An) group contains the heaviest chemical elements occurring in nature (Th, $\mathrm{U}$ ) and produced in appreciable quantities in nuclear reactors $(\mathrm{Pu}, \mathrm{Am})$ for important practical applications. The other actinides of the group are mostly used only for research purposes, where the required amounts are produced in nuclear reactors or particle accelerators [1].

The actinides occur most frequently in the form of oxides, these compounds being also often the products of the synthesis. Accordingly, the oxides are the best characterized actinide compounds. Best known are the physical and chemical properties of the solid Th, $\mathrm{U}$, and Pu oxides. In contrast, considerably less information is available on the gas-phase properties of actinide oxides. The main reasons are the extraordinary challenges in the gas-phase studies like the required special experimental setups due to the high evaporation temperatures, and the extreme safety requirements in handling radioactive materials. Consequently, such experiments require enormous costs. In addition, further complications in the experiments are caused by the complexity of the vapors, by the variety of accessible oxidation states of An and the very high reactivity of atomic An with oxygen and moisture. The above

Attila Kovács

attila.kovacs@ec.europa.eu

1 European Commission, Joint Research Centre, Postfach 2340, 76125 Karlsruhe, Germany difficulties are absent in quantum chemical modelling, which technique developed considerably due to the progress of both hardware and software in the past decades. On the other hand, the modelling also has its own challenges caused by the relativistic effects and high density of electronic states in An. Therefore, sophisticated theoretical levels have to be applied and the results have to be analyzed carefully and critically. Nevertheless, nowadays the majority of new chemical data on molecular actinide compounds are provided by modelling.

Experimental and theoretical data on binary oxides have been reviewed in several publications in the past [2-14] Since the latest comprehensive review [14], a considerable progress has been achieved in the field of oxides containing high-valent actinides $\left(\mathrm{An}^{\mathrm{ZV}}\right)$, deserving an overview of the structural and other molecular properties of these interesting and exotic molecules. The grouping of compounds covered by the present review is the following:

1. Actinide dioxide cations $\left[\mathrm{AnO}_{2}\right]^{+}$and $\left[\mathrm{AnO}_{2}\right]^{2+}$

2. Neutral and ionic $\mathrm{AnO}_{3}$

3. Neutral and ionic $\mathrm{AnO}_{4}$

4. Neutral and ionic $\mathrm{AnO}_{5}$

5. Neutral and ionic $\mathrm{AnO}_{6}$

6. Neutral dimers and trimers

7. Dimers from cation-cation interactions (CCIs)

8. Large U-oxide clusters observed in the gaseous phase

The present review focuses on the structural properties of the above compounds. They can vary considerably due to the 
flexible An electronic structure, facilitating different coordination environments [15]. In them, however, a frequent motif is the $\mathrm{AnO}_{2}$ moiety appearing in most known An multioxides.

Note that an introduction of the advanced experimental and theoretical methods used in modern actinide research is omitted here. For interested readers, recent compilations $[14,16]$ are recommended.

\section{Actinide dioxide cations $\left[\mathrm{AnO}_{2}\right]^{+}$and $\left[\mathrm{AnO}_{2}\right]^{2+}$}

Due to the small size and simple structure of these cations, they have been subjected to numerous experimental and theoretical studies in the past. The molecular data on the geometry, electronic structure, vibrational, and other properties have been compiled in detail in a recent review [14] and are therefore omitted here. In the present work, only two new comprehensive studies are added, which investigated the stabilities of these species across the actinide row by means of high-level ab initio calculations.

Systematic computations on $\mathrm{AnO}_{2}{ }^{+}$cations for $\mathrm{An}=$ Pa-Lr were performed at the $\operatorname{CCSD}(\mathrm{T})$ level elucidating the stabilities and structural preferences [17]. According to these calculations, actinides in the first half of the row have actinyl(V)-type $[\mathrm{O}=\mathrm{An}=\mathrm{O}]^{+}$ground-state structures, while $\mathrm{Cm}$ and actinides beyond Es prefer the triangular structure with side-on bonded $\eta^{2}-\mathrm{O}_{2}$. The high stability of $\left[\mathrm{Cm}\left(\eta^{2}-\mathrm{O}_{2}\right)\right]^{+}$is in agreement with the $5 \mathrm{f}^{7}$ configuration of $\mathrm{Cm}^{\mathrm{III}}$. In the triangular structures $\mathrm{Cm}, \mathrm{Bk}, \mathrm{Cf}$, and $\mathrm{Lr}$ appeared as $\mathrm{An}^{\mathrm{III}}$ peroxides with a formal charge distribution of $\left[\mathrm{An}^{3+}\left(\mathrm{O}_{2}{ }^{2-}\right)\right]^{+}$while Es, Fm, Md, and No as $\mathrm{An}^{\mathrm{II}}$ superoxides with a formal charge distribution of $\left[\mathrm{An}^{2+}\left(\mathrm{O}_{2}{ }^{-}\right)\right]^{+}$. The two oxidation states could be well distinguished by the considerably longer An-O bond distances in the superoxides (cf. Fig. 1). In the $\mathrm{r}(\mathrm{An}-\mathrm{O})$ bond distances of the actinyl forms notable trends included the slight gradual decrease from $\mathrm{Pa}$ to $\mathrm{Pu}$ and the significant increase from $\mathrm{Md}$ to $\mathrm{Lr}$. The latter feature is in agreement with oxidation states $\mathrm{No}^{\mathrm{IV}}$ and $\mathrm{Lr}^{\mathrm{III}}$. In fact, this $\mathrm{LrO}_{2}{ }^{+}$ species is non-actinyl and is bent with a bond angle of $107^{\circ}$.

Dau et al. reported in this paper also the first preparation and observation of $\mathrm{BkO}_{2}{ }^{+}$and $\mathrm{CfO}_{2}{ }^{+}$by electrospray ionization mass spectrometry, confirming experimentally the high stabilities of $\mathrm{Bk}^{\mathrm{V}}$ and $\mathrm{Cf}^{\mathrm{V}}$ in these oxides [17]. The dissociation energies demonstrated a gradual decrease from $\mathrm{Pa}$ to $\mathrm{Cm}$. The high stability of $\mathrm{Cf}^{\mathrm{V}}$ (in the actinyl structure) is due to its $5 \mathrm{f}^{7}$ configuration. Somewhat unexpected was, however, the comparable stability of $\mathrm{Bk}^{\mathrm{V}}$. The increasing stability of the $\left[\mathrm{An}\left(\eta^{2}-\mathrm{O}_{2}\right)\right]^{+}$forms for the late actinides was explained by the increased stabilization of the $5 \mathrm{f}$ electrons, letting the bonding activities to the (other valence) $6 \mathrm{~d}$ and $7 \mathrm{~s}$ subshells.

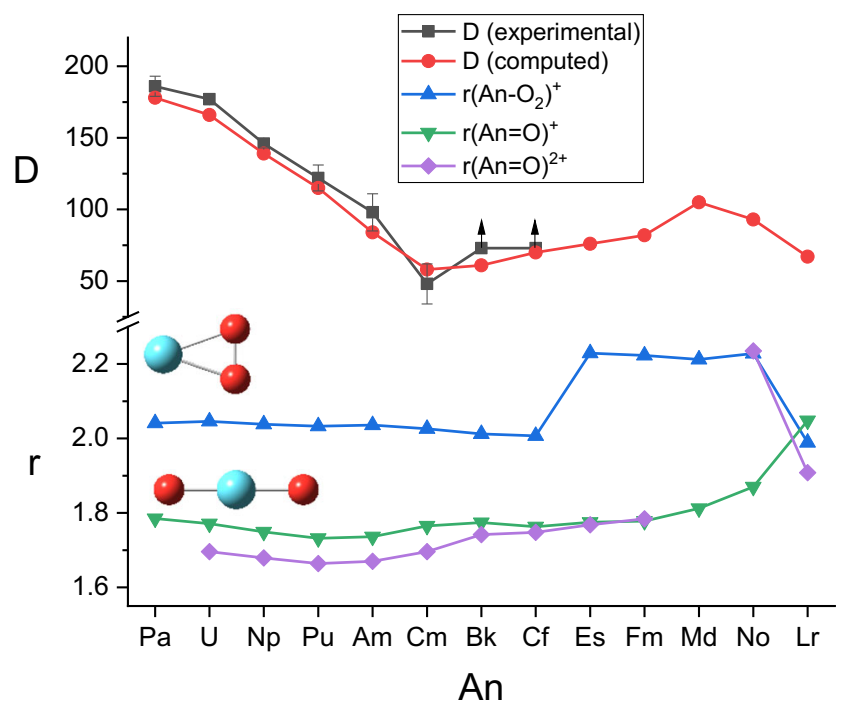

Fig. 1 Bond dissociation energies for the reaction $\mathrm{AnO}_{2}{ }^{+} \rightarrow \mathrm{AnO}^{+}+\mathrm{O}$ (D, kcal $/ \mathrm{mol})$ and An-O bond distances $(\mathrm{r}, \AA)$ for the $\left[\mathrm{An}\left(\eta^{2}-\mathrm{O}_{2}\right)\right]^{+}$and $[\mathrm{O}=\mathrm{An}=\mathrm{O}]^{+}$structures from $\operatorname{CCSD}(\mathrm{T})[17]$ and for the $[\mathrm{O}=\mathrm{An}=\mathrm{O}]^{2+}$ structures from B3LYP [18] calculations. The experimental dissociation energy values for $\mathrm{BkO}_{2}{ }^{+}$and $\mathrm{CfO}_{2}{ }^{+}$could be determined only as lower limits (indicated by the arrows)

Dixon et al. performed CCSD(T) energy calculations on geometries optimized by density functional theory (DFT) of $\mathrm{AnO}_{2}{ }^{2+}$ dications of twelve actinides ( $\mathrm{An}=\mathrm{U}-\mathrm{Lr}$ ) [18]. The (incidentally) multiconfigurational nature of the compounds was taken into account using starting orbitals from the DFT calculations. In the study, all the relevant spin multiplicities and actinide oxidation states were considered. The effect of spin-orbit coupling on the relative stabilities was also investigated. Altogether eight structural isomers were found on the potential energy surface (Fig. 2). The largest number of different dication species (7) were found for $U$; the number of species decreased along the actinide row.

The relative energies of the various structures are depicted in Fig. 3. The main conclusions from the study include the superiority of oxidation state $\mathrm{VI}$ for the $\mathrm{U}, \mathrm{Np}$, and $\mathrm{Pu}$ oxide dications with the linear $[\mathrm{O}=\mathrm{An}=\mathrm{O}]^{2+}$ structure. Oxidation state III is preferred for $\mathrm{An}=\mathrm{Cm}, \mathrm{Bk}$ and $\mathrm{Lr}$ with a $\left[\mathrm{An}\left(\mathrm{\eta}^{2}\right.\right.$ $\left.\left.\mathrm{O}_{2}\right)\right]^{2+}$ superoxide $\mathrm{C}_{2 \mathrm{v}}$ structure. The other six actinides prefer oxidation state II in $\left[\mathrm{An}\left(\eta^{1}-\mathrm{O}_{2}\right)\right]^{2+}$ containing a physisorbed $\mathrm{O}_{2}$ in a $\mathrm{C}_{\mathrm{s}}$ or $\mathrm{C}_{\infty \mathrm{v}}$ arrangement (cf. Fig. 2). The preference of low oxidation states for transplutonium actinides is the consequence of the stabilization of the $5 \mathrm{f}$ orbitals. The $\mathrm{f}^{14}$ configuration explains the remarkably high stability of divalent No.

The computed $\mathrm{An}=\mathrm{O}$ bond distances of the linear $[\mathrm{O}=\mathrm{An}=\mathrm{O}]^{2+}$ structures can be compared with those of the linear $[\mathrm{O}=\mathrm{An}=\mathrm{O}]^{2+}$ cations in Fig. 1 . The trends (while obtained at different theoretical levels) agree very well from $U$ to $\mathrm{Fm}$. A notable feature is the drastic bond distance increase in $[\mathrm{O}=\mathrm{No}=\mathrm{O}]^{2+}$, caused by the reduction of the oxidation state of No from IV in $[\mathrm{O}=\mathrm{No}=\mathrm{O}]^{+}$to II. 


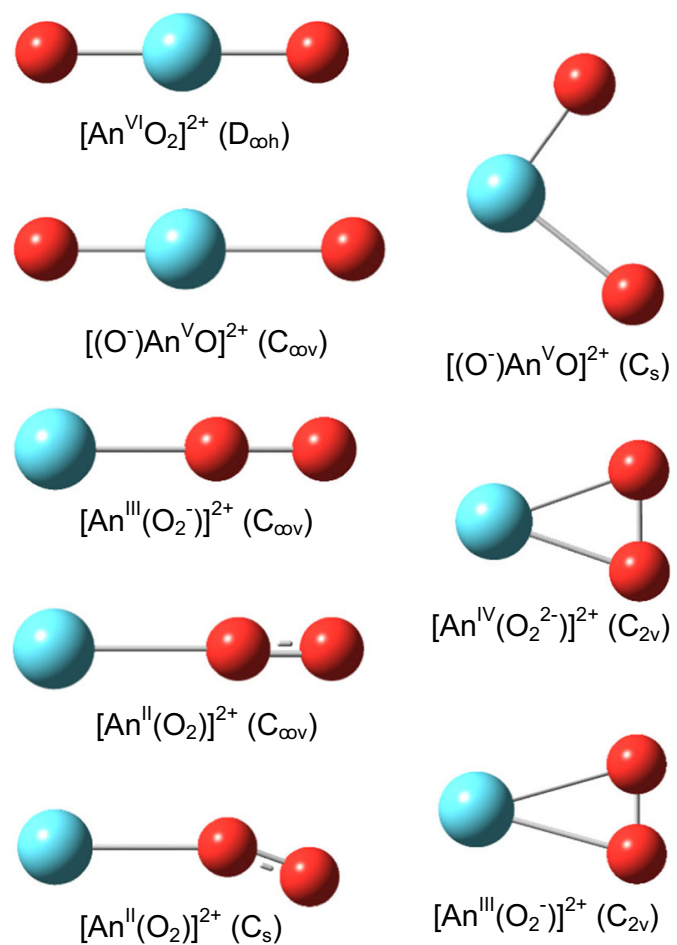

Fig. 2 Plausible minimum structures of $\mathrm{AnO}_{2}{ }^{2+}$ ions [18]. An atoms are depicted in cyan, $\mathrm{O}$ in red. The most frequent oxidation states of $\mathrm{An}$ in the characteristic structures and the symmetries are given too

\section{Neutral and ionic $\mathrm{AnO}_{3}$}

The three characteristic isomers of $\mathrm{AnO}_{3}$ are presented in Fig. 4 , while selected computed geometrical data are compared in Table 1.

\section{$\mathrm{ThO}_{3}$ and $\mathrm{ThO}_{3}{ }^{-}$}

The $\mathrm{ThO}_{3}{ }^{-}$anion obtained by laser vaporization of solid $\mathrm{ThO}_{2}$ was studied by photoelectron spectroscopy in combination



Fig. $3 \mathrm{AnO}_{2}{ }^{2+}$ relative energies from spin-orbit-free $\operatorname{CCSD}(\mathrm{T})$ calculations [18]
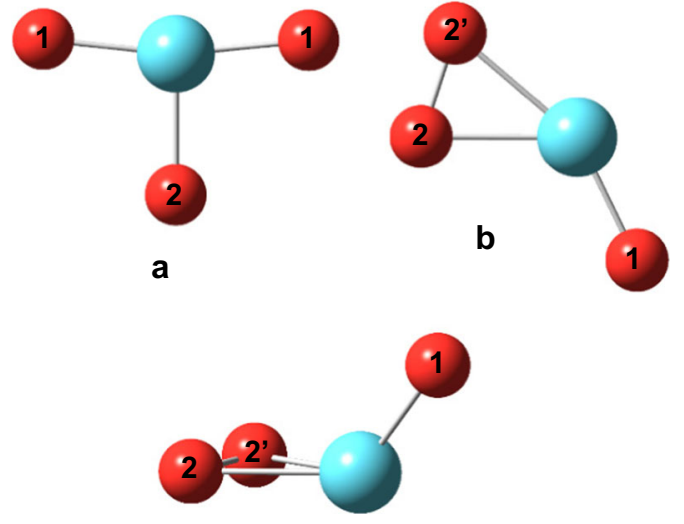

C

Fig. $4 \mathrm{AnO}_{3}$ isomers: a $\mathrm{T}$ - or $\mathrm{Y}$-shaped $\left(\mathrm{C}_{2 \mathrm{v}}, \mathrm{C}_{3 \mathrm{v}}\right)$, b oxoperoxide $\left(\mathrm{C}_{\mathrm{s}}\right)$, c oxosuperoxide $\left(\mathrm{C}_{\mathrm{s}}\right)$. An atoms are depicted in cyan, $\mathrm{O}$ in red

with DFT and $\operatorname{CCSD}(\mathrm{T})$ calculations [19]. Photoinduced electron loss of $\mathrm{ThO}_{3}{ }^{-}$resulted in neutral $\mathrm{ThO}_{3}$. The measured adiabatic detachment energy (ADE, $3.31 \mathrm{eV}$ ) was in good agreement with the $\operatorname{CCSD}(\mathrm{T})$ value of $3.26 \mathrm{eV}$. The structure of ground-state $\mathrm{ThO}_{3}$ can be derived by a side-on $\left(\eta^{2}\right)$ attachment of ThO to an $\mathrm{O}_{2}$ molecule (Fig. 4c). The trioxide Tshaped form with $\mathrm{C}_{2 \mathrm{v}}$ symmetry (Fig. 4a) was calculated to be higher in energy by $51 \mathrm{~kJ} / \mathrm{mol}$. In contrast, the ground-state $\mathrm{ThO}_{3}{ }^{-}$molecule proved to have a T-shaped structure, and the $\eta^{2}$ form (Fig. 4c) was found to be higher in energy by $118 \mathrm{~kJ} /$ mol. Bond order and natural population analyses were performed to clarify the bonding in the studied species. The hybridization of $6 \mathrm{~d}$ and $5 \mathrm{f}$ orbitals resulted in seven bonding molecular orbitals for $\mathrm{ThO}_{3}$ and $\mathrm{ThO}_{3}{ }^{-}$which, however, does not mean that each of them corresponds to a single bond. The oxidation state of Th does not exceed IV in these oxides.

\section{$\mathrm{PaO}_{3}{ }^{-}$}

$\mathrm{PaO}_{3}{ }^{-}$was part of a theoretical study on $\mathrm{d}$ and $\mathrm{f}$ elements with five valence electrons [20]. The scalar relativistic PBE calculations confirmed the stability of the $\mathrm{Pa}^{\mathrm{V}}$ oxidation state in a $\mathrm{C}_{3 \mathrm{v}}$ trioxo structure (Fig. 4a) of singlet $\mathrm{PaO}_{3}{ }^{-}$. The triplet $\mathrm{PaO}_{3}{ }^{-}$was found to have a similar structure but with $\mathrm{C}_{2 \mathrm{v}}$ symmetry and calculated to be higher in energy by $174 \mathrm{~kJ} /$ mol. The bond distances of the two structures were quite similar being in the expected range of $\mathrm{Pa}=\mathrm{O}$ double bonds. The authors assigned oxidation state $\mathrm{Pa}^{\mathrm{IV}}$ in triplet $\mathrm{PaO}_{3}{ }^{-}$; a reasoning was not given. Additional reported molecular data included the vibrational frequencies.

De Jong et al. computed $\mathrm{PaO}_{3}{ }^{-}$using the PBE0 functional [21]. The data (computed energies, structures, vibrational frequencies) deposited in the Supporting Information without discussion in the text supported the singlet ground electronic state. 
Table 1 Optimized geometrical parameters of the ground and selected other states of $\mathrm{AnO}_{3}$ molecules

\begin{tabular}{|c|c|c|c|c|c|c|c|c|}
\hline $\mathrm{AnO}_{3}$ & Fig. $4^{\mathrm{a}}$ & Method $^{\mathrm{b}}$ & State & $\mathrm{An}-\mathrm{O}_{1}$ & $\mathrm{An}-\mathrm{O}_{2}$ & $\mathrm{O}_{2}-\mathrm{O}_{2}{ }^{\prime}$ & $\mathrm{O}_{1} \mathrm{AnO}_{1}{ }^{\mathrm{c}}$ & Reference \\
\hline \multirow[t]{2}{*}{$\mathrm{ThO}_{3}$} & $\mathrm{c}$ & $\operatorname{CCSD}(\mathrm{T}) / \mathrm{A}$ & ${ }^{1} A^{\prime}$ & 1.891 & 2.132 & 1.514 & n.a. & [19] \\
\hline & $\mathrm{a}$ & & ${ }^{1} \mathrm{~A}_{1}$ & 1.934 & 1.968 & - & n.a. & \\
\hline \multirow[t]{2}{*}{$\mathrm{ThO}_{3}{ }^{-}$} & $\mathrm{a}$ & $\operatorname{CCSD}(\mathrm{T}) / \mathrm{A}$ & ${ }^{2} \mathrm{~A}_{1}$ & 2.007 & 2.021 & - & n.a. & [19] \\
\hline & $\mathrm{c}$ & & ${ }^{2} A^{\prime}$ & 1.929 & 2.176 & 1.514 & n.a. & \\
\hline \multirow[t]{3}{*}{$\mathrm{PaO}_{3}^{-}$} & $\mathrm{a}$ & $\mathrm{PBE} / \mathrm{B}$ & ${ }^{1} \mathrm{X}$ & 1.940 & 1.940 & - & n.a. & {$[20]$} \\
\hline & $\mathrm{a}$ & & ${ }^{3} \mathrm{X}$ & 1.904 & 1.951 & - & n.a. & \\
\hline & a & PBE0/A & ${ }^{1} \mathrm{X}$ & 1.953 & 1.953 & - & 120 & {$[21]$} \\
\hline \multirow[t]{7}{*}{$\mathrm{UO}_{3}$} & $\mathrm{a}$ & CASPT2/B & ${ }^{1} \mathrm{~A}_{1}$ & 1.789 & 1.838 & - & 161.3 & {$[34]$} \\
\hline & $\mathrm{a}$ & B3LYP/A & ${ }^{1} \mathrm{~A}_{1}$ & 1.80 & 1.85 & - & 160 & {$[32]$} \\
\hline & $\mathrm{a}$ & $\mathrm{HF} / \mathrm{C}$ & ${ }^{1} \mathrm{~A}_{1}$ & 1.75 & 1.83 & - & 161 & [29] \\
\hline & $\mathrm{a}$ & B3LYP/A & ${ }^{1} \mathrm{~A}_{1}$ & 1.810 & 1.853 & - & 158.8 & {$[27]$} \\
\hline & $\mathrm{a}$ & $\mathrm{HF} / \mathrm{A}$ & ${ }^{1} \mathrm{~A}_{1}$ & 1.745 & 1.828 & - & 165.2 & {$[30]$} \\
\hline & $\mathrm{a}$ & SO-PBE0/A & n.a. & 1.771 & 1.786 & - & 161 & {$[31]$} \\
\hline & $\mathrm{a}$ & SO-B3LYP/A & n.a. & 1.808 & 1.849 & - & 157 & \\
\hline \multirow[t]{3}{*}{$\mathrm{UO}_{3}^{-}$} & $\mathrm{a}$ & SO-PBE0/A & n.a. & 1.879 & 1.914 & - & 155 & [31] \\
\hline & $\mathrm{a}$ & SO-B3LYP/A & n.a. & 1.902 & 1.931 & - & 150 & \\
\hline & $\mathrm{a}$ & B3LYP/A & ${ }^{2} \mathrm{~B}_{2}$ & 1.90 & 1.93 & - & 150 & {$[32]$} \\
\hline $\mathrm{NpO}_{3}$ & $\mathrm{a}$ & CASPT2/B & ${ }^{2} \mathrm{~A}_{2}$ & 1.766 & 1.836 & - & 166.6 & [34] \\
\hline \multirow[t]{7}{*}{$\mathrm{PuO}_{3}$} & $\mathrm{a}$ & CASPT2/B & ${ }^{3} \mathrm{~B}_{2}$ & 1.763 & 1.842 & - & 171.0 & [34] \\
\hline & a & B3LYP/A & ${ }^{3} \mathrm{~B}_{2}$ & 1.767 & 1.934 & - & 172.3 & {$[42]$} \\
\hline & $\mathrm{a}$ & SO-PBE0/A & ${ }^{3} \mathrm{X}$ & 1.749 & 1.853 & - & 170 & {$[40]$} \\
\hline & $\mathrm{a}$ & SO-B3LYP/A & ${ }^{3} \mathrm{X}$ & 1.749 & 1.858 & - & 169 & \\
\hline & $\mathrm{a}$ & B3LYP/A & ${ }^{1} \mathrm{~A}_{1}$ & 1.752 & 1.811 & - & n.a. & {$[38]$} \\
\hline & $\mathrm{a}$ & B3LYP/C & ${ }^{7} \mathrm{~B}_{1}$ & 2.206 & 1.914 & - & 102.2 & [39] \\
\hline & $\mathrm{b}$ & SO-PBE0/A & n.a. & 1.806 & $2.101 / 2.027$ & 1.454 & 125 & [49] \\
\hline \multirow[t]{3}{*}{$\mathrm{PuO}_{3}^{-}$} & $\mathrm{a}$ & PBE0/A & ${ }^{2} \mathrm{X}$ & $1.814 / 1.832$ & 1.897 & - & 168.2 & {$[46]$} \\
\hline & $\mathrm{a}$ & & ${ }^{4} X$ & 1.855 & 1.892 & - & 161.0 & \\
\hline & $\mathrm{a}$ & & ${ }^{6} \mathrm{X}$ & 1.794 & 2.153 & - & 177.0 & \\
\hline \multirow[t]{4}{*}{$\mathrm{AmO}_{3}$} & $\mathrm{a}$ & CASPT2/B & ${ }^{6} \mathrm{~B}_{2}$ & 1.721 & 2.101 & - & 180.0 & [34] \\
\hline & $\mathrm{a}$ & SO-PBE0/A & n.a. & 1.747 & 2.067 & - & 179 & [49] \\
\hline & $\mathrm{b}$ & & n.a. & 1.809 & $2.118 / 2.022$ & 1.432 & 118 & \\
\hline & $\mathrm{c}$ & & n.a. & 1.827 & 2.280 & 1.327 & 74 & \\
\hline \multirow[t]{4}{*}{$\mathrm{CmO}_{3}$} & $\mathrm{a}$ & CASPT2/B & ${ }^{7} \mathrm{~A}_{2}$ & 1.746 & 2.115 & - & 173.1 & {$[34]$} \\
\hline & $\mathrm{a}$ & SO-PBE0/A & n.a. & 1.768 & 2.069 & - & 176 & [49] \\
\hline & $\mathrm{b}$ & & n.a. & 1.819 & $2.097 / 2.047$ & 1.443 & 118 & \\
\hline & $\mathrm{c}$ & & n.a. & 1.840 & 2.281 & 1.318 & 76 & \\
\hline \multirow[t]{3}{*}{$\mathrm{BkO}_{3}$} & $\mathrm{a}$ & SO-PBE0/A & n.a. & 1.774 & 2.053 & - & 171 & [49] \\
\hline & $\mathrm{b}$ & & n.a. & 1.809 & $2.089 / 2.025$ & 1.448 & 123 & \\
\hline & $\mathrm{c}$ & & n.a. & 1.831 & 2.276 & 1.323 & 71 & \\
\hline \multirow[t]{3}{*}{$\mathrm{CfO}_{3}$} & a & SO-PBE0/A & n.a. & 1.763 & 2.047 & - & 173 & [49] \\
\hline & $\mathrm{b}$ & & n.a. & 1.804 & $2.111 / 2.021$ & 1.422 & 117 & \\
\hline & $\mathrm{c}$ & & n.a. & 1.818 & 2.285 & 1.321 & 71 & \\
\hline
\end{tabular}

Bond distances are given in angstroms, bond angles in degrees

${ }^{\text {a }}$ Structures from Fig. 4

${ }^{\mathrm{b}}$ The abbreviations of basis sets $\mathrm{A}, \mathrm{B}$, and $\mathrm{C}$ mean relativistic small-core pseudopotential, all-electron, and relativistic large-core pseudopotential, respectively

${ }^{\mathrm{c}} \mathrm{O}_{1} \mathrm{AnO}_{2}$ bond angle in the peroxide and superoxide structures 


\section{$\mathrm{UO}_{3}$ and $\mathrm{UO}_{3}{ }^{-}$}

The neutral $\mathrm{UO}_{3}$ molecule was detected in matrix-isolation IR spectra of mixtures of uranium oxides [22-27]. Several studies were performed in solid $\operatorname{Ar}$ [22-27] reporting five from the six fundamentals of $\mathrm{U}^{16} \mathrm{O}_{3}$. Experiments using mixture of ${ }^{16} \mathrm{O}$ and ${ }^{18} \mathrm{O}$ isotopes coupled with normal coordinate analysis pointed out the $\mathrm{T}$-shaped $\mathrm{C}_{2 \mathrm{v}}$ molecular geometry with a near-linear OUO moiety (Fig. 4a) [24, 28]. The structure and the vibrational assignments were confirmed by quantum chemical calculations [27, 29-33]. The $\mathrm{U}^{\mathrm{VI}}$ oxidation state was confirmed by DFT-based adaptive natural density partitioning (AdNDP) analysis resulting in three 2-center-2electron $\sigma$ and six 2-center-2-electron $\pi \mathrm{U}-\mathrm{O}$ bonds [32].

Already early quantum chemical calculations on $\mathrm{UO}_{3}$ using Hartree-Fock (HF) theory and relativistic large-core pseudopotentials [29] predicted the ${ }^{1} \mathrm{~A}_{1}$ ground electronic state and reasonable geometrical parameters. Later DFT calculations provided more accurate structural data and a good agreement between the computed and experimental frequencies (taking into account both the matrix shift and anharmonicity) [27, 31]. The electronic structure and excited states of $\mathrm{UO}_{3}$ were investigated by multireference CASPT2 calculations [34] confirming the ${ }^{1} \mathrm{~A}_{1}$ spin-orbit-free (SF) ground electronic state and its closed-shell character. It forms exclusively the spin-orbit (SO) ground state. Triplet states were predicted at very high energies, above $160 \mathrm{~kJ} / \mathrm{mol}$ [34]. High-energy triplet structures include the T-shaped one (Fig. 4a) as well as forms with peroxide motif (Fig. 4b) [33].

The $\mathrm{UO}_{3}{ }^{-}$anion was detected early in a secondary ion mass spectrometric investigation of uranium oxides using a cesium sputter source [35]. Its presence was confirmed by Fourier transform ion cyclotron resonance (FT-ICR) mass spectrometry in the vapor above solid $\mathrm{UO}_{3}$ and $\left(\mathrm{NH}_{4}\right)_{2} \mathrm{U}_{2} \mathrm{O}_{7}$ upon laser ablation [36]. In recent laser vaporization experiments of $\mathrm{Su}$ et al., $\mathrm{UO}_{3}{ }^{-}$was formed from surface oxide impurities on a uranium disk target [32]. In the latter work, the mass-selected anion was subjected to a photoelectron spectroscopic (PES) analysis using laser beams operating at various wavelengths. Upon laser irradiation well-resolved electron detachment transitions occurred from the anionic electronic ground state to the ground and low-lying excited states of neutral $\mathrm{UO}_{3}$. Combined with Franck-Condon simulations, the electron affinity of $\mathrm{UO}_{3}$ was determined to be $1.12 \pm 0.03 \mathrm{eV}$. In addition, the vibrational resolution of the spectra facilitated the experimental determination of the symmetric stretching frequency of $\mathrm{UO}_{3}\left(850 \pm 30 \mathrm{~cm}^{-1}\right)$. Five low-lying excited states with geometries similar to that of $\mathrm{UO}_{3}{ }^{-}$were observed and vertical detachment energies between 3.2 and $6.3 \mathrm{eV}$ were determined. Regarding neutral $\mathrm{UO}_{3}$, a large energy separation of $1.8 \mathrm{eV}$ was measured between the ground and first excited states, pointing to a large HOMO-LUMO gap in agreement with the closed-shell nature of the molecule [32].
Theoretical studies of the $\mathrm{UO}_{3}{ }^{-}$anion include the DFT one by Zaitsevskii for evaluation of the adiabatic electron affinity of $\mathrm{UO}_{3}$ [31]. The effects of the excess electron on the geometry (Fig. 4a) are manifested in considerably (by ca. $0.1 \AA$ ) lengthened $\mathrm{U}-\mathrm{O}$ bond distances and a slightly smaller $\mathrm{O}_{1}-\mathrm{U}$ $\mathrm{O}_{1}$ bond angle (cf. Table 1). The geometry features were confirmed by the DFT calculations of Su et al. [32]. The electronic structure of $\mathrm{UO}_{3}{ }^{-}$is similar to that of $\mathrm{UO}_{3}$, the main difference being the single occupation of a 5 f-based $\mathrm{B}_{2}$ orbital by the extra electron. The valence molecular orbitals (MOs) are of dominant $\mathrm{O}\left(2 \mathrm{p}_{\sigma, \pi}\right)$ character with ca. $20 \% \mathrm{U}(6 \mathrm{~d})$ or $\mathrm{U}(5 \mathrm{f})$ contribution. The low-energy unoccupied MOs have generally dominant $\mathrm{U}(5 \mathrm{f})$ character except for one with dominant $\mathrm{U}(7 \mathrm{~s})$ character. The assignment of the detachment band in the PES spectrum was performed on this basis to the singly occupied $\mathrm{B}_{2} \mathrm{MO}$ [32].

\section{$\mathrm{NpO}_{3}$}

The only information on the geometry and electronic structure of $\mathrm{NpO}_{3}$ comes from a CASPT2 study of the ground and lowlying excited electronic states [34]. The calculations resulted in a $\mathrm{C}_{2 \mathrm{v}}$ ground-state geometry (Fig. $4 \mathrm{a}$, Table 1). The doublet ${ }^{2} \mathrm{~A}_{2}$ SF ground state gave the main component of the SO ground state. The quartet states were predicted to appear above $100 \mathrm{~kJ} / \mathrm{mol}$.

\section{$\mathrm{PuO}_{3}, \mathrm{PuO}_{3}{ }^{+}$, and $\mathrm{PuO}_{3}{ }^{-}$}

A detection of the $\mathrm{PuO}_{3}$ molecule was reported from a mass spectrometric analysis of the sublimation products of solid $\mathrm{PuO}_{2}$ [37]. It was observed in a very low concentration; therefore, a confirmation from new experiments would be desirable. No experimental data on its molecular properties are available.

The first theoretical studies on $\mathrm{PuO}_{3}$ provided some contradicting results, reflecting the difficulties of routine quantum chemical calculations for the complex electronic structure of $\mathrm{Pu}$. The very first DFT study from 2001 reported a T-shaped structure (Fig. 4a) for the ${ }^{1} \mathrm{~A}_{1 \mathrm{~g}}$ state of $\mathrm{PuO}_{3}$ [38]. Gao et al. calculated quintet, septet, and nonet states by HF and DFT (using the less-reliable large-core pseudopotential for $\mathrm{Pu}$ ) and found a ${ }^{7} \mathrm{~B}_{1}$ ground electronic state with an Y-shaped $\mathrm{C}_{2 \mathrm{v}}$ structure (Fig. 4a) [39]. Two-component relativistic DFT calculations on triplet $\mathrm{PuO}_{3}$ predicted a T-shaped structure $[40,41]$ with geometrical parameters in good agreement with those reported by Straka et al. [38] for the ${ }^{1} \mathrm{~A}_{1 \mathrm{~g}}$ state (cf. Table 1). The ${ }^{3} \mathrm{~B}_{2}$ character of the ground electronic state was clarified recently by CASPT2 [34] and CASSCF [42] calculations. In the latter study, the most important valence orbitals for the active space in multireference ab initio calculations were also determined using the density matrix renormalization group (DMRG) algorithm [43]. 
The multireference calculations $[34,42]$ pointed out the very complex electronic structure of $\mathrm{PuO}_{3}$ (most complex from the five $\mathrm{AnO}_{3}$, where $\mathrm{An}=\mathrm{U}-\mathrm{Cm}$ [34]) with several low-lying excited electronic states. An extensive mixing was shown between the SF ground ${ }^{3} \mathrm{~B}_{2}$ and first excited ${ }^{3} \mathrm{~A}_{2}$ states forming the $\mathrm{SO}$ ground and first excited states. The singlet states appeared as notable contributions in the SO states above $130 \mathrm{~kJ} / \mathrm{mol}$, while the quintet ones above $180 \mathrm{~kJ} / \mathrm{mol}$.

After two failed studies on $\mathrm{PuO}_{3}{ }^{+}[44,45]$ Gao et al. reported a ${ }^{6} \mathrm{~B}_{2}$ ground electronic state with a $\mathrm{C}_{2 \mathrm{v}}$ Y-shaped structure (Fig. 4a) for this cation [39]. However, as the used theoretical level was the same which led to erroneous results on the neutral $\mathrm{PuO}_{3}$ molecule (vide supra), an independent confirmation of the data on $\mathrm{PuO}_{3}{ }^{+}$would be desirable.

DFT results on $\mathrm{PuO}_{3}{ }^{-}$were published in [46]: relative energies and structures of three states with doublet, quartet, and sextet spin multiplicities were deposited in the Supporting Information without discussion in the text. The geometrical parameters are included in Table 1 . From them, the T-shaped (Fig. 4a) $\mathrm{C}_{2 \mathrm{v}}$ quartet form was found to be the most stable followed by the doublet and sextet higher in energy by 47 and $68 \mathrm{~kJ} / \mathrm{mol}$, respectively.

\section{$\mathrm{AmO}_{3}$}

The geometry and bond dissociation energy of $\mathrm{AmO}_{3}$ were predicted by two-component relativistic DFT calculations without providing details on the electronic structure [41]. CASPT2 calculations predicted the SF ground state of Tshaped (Fig. 4a) $\mathrm{AmO}_{3}$ being a sextet ${ }^{6} \mathrm{~B}_{2}$, which formed almost exclusively the $\mathrm{SO}$ ground state [34]. The quartet states appeared at quite low energies, from ca. $42 \mathrm{~kJ} / \mathrm{mol}$, while the octet ones much higher, above $190 \mathrm{~kJ} / \mathrm{mol}$. The geometrical parameters from the two studies $[34,41]$ are in good agreement (cf. Table 1).

\section{$\mathrm{CmO}_{3}$}

The $\mathrm{CmO}_{3}$ molecule was indirectly inferred from a thermochromatographic measurement [47]. No molecular data are available for $\mathrm{CmO}_{3}$ from experiment.

Two-component relativistic DFT calculations [48] provided the first molecular data on $\mathrm{CmO}_{3}$ including the geometrical parameters of a T-shaped structure (Fig. 4a) and bond dissociation energy. Subsequent relativistic SO-PBE0 calculations [49] predicted the oxosuperoxide isomer (Fig. 4c) to be more stable by $31 \mathrm{~kJ} / \mathrm{mol}$ than the $\mathrm{T}$-shaped one.

The electronic structure of T-shaped $\mathrm{CmO}_{3}$ was investigated by CASPT2 calculations. The lowest-energy SF state showed a ${ }^{7} \mathrm{~A}_{2}$ character, this state forming nearly exclusively the lowest-energy SO state [34]. Compared with other $\mathrm{AnO}_{3}$ molecules $(\mathrm{An}=\mathrm{U}-\mathrm{Am})$, the neighboring (quintet and nonet) spin multiplicities appeared here at the lowest energies: the quintet ${ }^{5} \mathrm{~B}_{2}$ was the major component in the first SO excited state at $28.5 \mathrm{~kJ} / \mathrm{mol}$, while the nonet ${ }^{9} \mathrm{~B}_{1}$ appeared in the second $\mathrm{SO}$ excited state at $54 \mathrm{~kJ} /$ mol. The CASPT2 geometrical parameters were in good agreement with the DFT ones from [48].

\section{$\mathrm{BkO}_{3}, \mathrm{CfO}_{3}$}

These trioxides were investigated by Zaitsevskii by relativistic SO-PBE0 calculations [49] reporting the structures and dissociation enthalpies. For $\mathrm{BkO}_{3}$ the T-shaped structure (Fig. 4a), for $\mathrm{CfO}_{3}$ the oxosuperoxide isomer (Fig. 4c) was predicted to be the most stable.

\section{Comparison of some properties of $\mathrm{AnO}_{3}$ molecules}

This comparative analysis is facilitated by systematic calculations on $\mathrm{AnO}_{3}$ molecules performed in [34, 49].

An interesting problem is the variation of the structure across the An row. Towards the heavier actinides, the trivalent character gets stronger; consequently, the features characteristic for $\mathrm{An}^{\mathrm{VI}}$ (e.g., the trioxo T-shaped structure) become less favored. The stability of the three isomers (Fig. 4) was investigated by Zaitsevskii in the series $\mathrm{PuO}_{3}-\mathrm{CfO}_{3}$ using relativistic SO-PBE0 calculations [49]. The oxoperoxide isomer (Fig. $4 \mathrm{~b}$ ) has a formal charge distribution of $(\mathrm{AnO})^{2+}\left(\mathrm{O}_{2}\right)^{2-}$ in agreement with the oxidation state $\mathrm{An}^{\mathrm{IV}}$. The oxosuperoxide isomer (Fig. 4c) with one unpaired electron localized on the $\mathrm{O}_{2}$ fragment has a formal charge distribution of $(\mathrm{AnO})^{+}\left(\mathrm{O}_{2}\right)^{-}$, corresponding to oxidation state $\mathrm{An}^{\mathrm{III}}$.

The relative stabilities were assessed by the $\Delta H_{0}^{o}$ enthalpies of dissociation to $\mathrm{AnO}_{2}+1 / 2 \mathrm{O}_{2}$. Figure 5 shows the variation of the $\Delta H_{0}^{o}$ enthalpies from $\mathrm{Pu}$ to $\mathrm{Cf}$. The oxoperoxide form had the highest energy from the three isomers and, due to the positive $\Delta H_{0}^{o}$ values, was thermodynamically unstable. The T-shaped structure was preferred for $\mathrm{Pu}, \mathrm{Am}$, and $\mathrm{Bk}$, while the oxosuperoxide isomer was predicted to be the most stable for $\mathrm{Cm}$ and Cf.

The above characteristics were rationalized on the basis of effective atomic configurations derived using the concept "atoms in compounds" [50]. The high stability of $\mathrm{Bk}^{\mathrm{V}} \mathrm{O}_{3}$ with respect to its neighbors $\mathrm{Cm}^{\mathrm{V}} \mathrm{O}_{3}$ and $\mathrm{Cf}^{\mathrm{V}} \mathrm{O}_{3}$ is in agreement with the high number (6) of unpaired $5 \mathrm{f}$ electrons in $\mathrm{Bk}^{\mathrm{V}}$. In $\mathrm{Cf}^{\mathrm{V}}$ an enhanced $5 \mathrm{f}$ electron pairing was observed (deviating from the known high-spin $5 \mathrm{f}^{7}$ ground state of the $\mathrm{Cf}^{5+}$ ion), which can destabilize the T-shaped structure. 


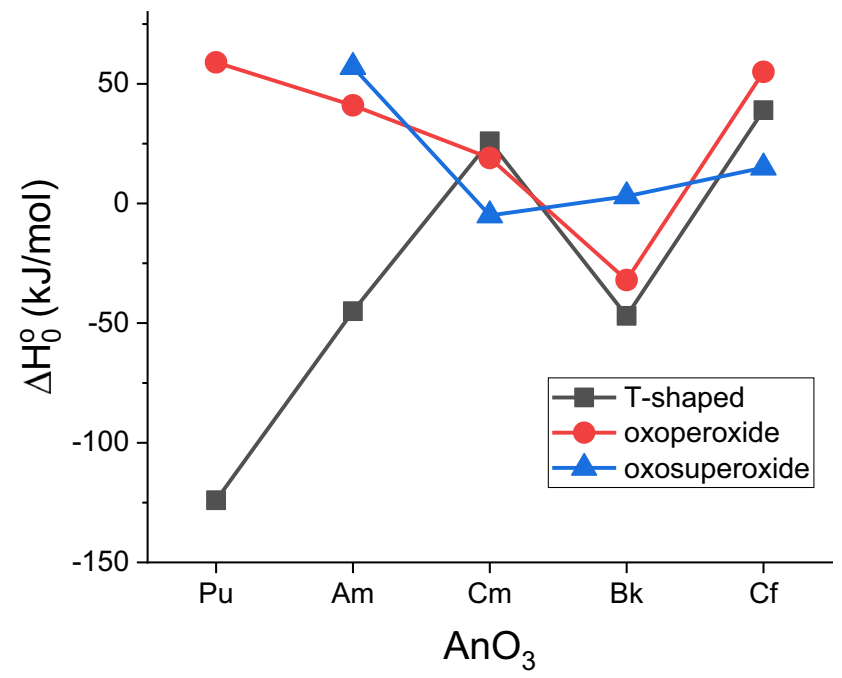

Fig. 5 Calculated $\Delta H_{0}^{o}$ enthalpies of dissociation to $\mathrm{AnO}_{2}+1 / 2 \mathrm{O}_{2}$ of the three $\mathrm{AnO}_{3}$ isomers; data from [49]. For the structures, see Fig. 4

Trends in the geometrical parameters of T-shaped $\mathrm{AnO}_{3}$ $(\mathrm{An}=\mathrm{U}, \mathrm{Pu}-\mathrm{Cf}$ ) molecules can be assessed on the basis of the SO-PBE0 results $[31,49]$ in Table 1 . The main features are the decrease of $\mathrm{An}-\mathrm{O}_{1}$ bond distances, the increase of the $\mathrm{An}-\mathrm{O}_{2}$ bond distances, and the increase of the $\mathrm{O}_{1} \mathrm{AnO}_{1}$ bond angles from $\mathrm{U}$ to Am (in agreement with CASPT2 data on $\mathrm{UO}_{3}-\mathrm{CmO}_{3}$ from [34], cf. Table 1, Fig. 6). No systematic changes can be recognized beyond Am. Particularly interesting are the two distinct ranges of the An- $\mathrm{O}_{2}$ bond distance (around $1.84 \AA$ in the lighter $\mathrm{U}, \mathrm{Np}$, and $\mathrm{Pu}$ trioxides and around $2.1 \AA$ in the heavier $\mathrm{AnO}_{3}$ molecules) in which only marginal variations occur. The considerable lengthening refers to a significant difference in the bonding, i.e., the replacement of the double bond by a single bond. On the basis of this lengthened $\mathrm{An}-\mathrm{O}_{2}$ bond and the formal charge of $\mathrm{O}_{2}$ a pentavalent character of Am and $\mathrm{Cm}$ was suggested [41, 49] in these trioxides. The considerably longer $\mathrm{Am}-\mathrm{O}_{2}$ bond with respect to the analogous $\mathrm{Pu}-\mathrm{O}_{2}$ one is in agreement with the by ca. $80 \mathrm{~kJ} / \mathrm{mol}$ smaller bond dissociation energy of the $\mathrm{Am}-\mathrm{O}_{2}$ bond [41], supporting its considerably weaker character.

The above noted long $\mathrm{An}-\mathrm{O}_{2}$ bonds in heavier $\mathrm{AnO}_{3}$ $(\mathrm{An}=\mathrm{Am}-\mathrm{Cf})$ molecules were consistent with the effective atomic configuration data [50], i.e., with the decrease of the paired $5 f$ electron population between $\mathrm{Pu}^{\mathrm{VI}} \mathrm{O}_{3}$ and $\mathrm{Am}^{\mathrm{V}} \mathrm{O}_{3}$ by ca. $1 \mathrm{e}$ and the parallel increase of the unpaired $5 \mathrm{f}$ population by ca. 2 e (Fig. 7).

A detailed analysis of the valence molecular orbitals in [34] showed a gradually increasing number of unpaired nonbonding $5 \mathrm{f}$ electrons from $\mathrm{UO}_{3}$ to $\mathrm{PuO}_{3}$ (from 0 to 2, respectively). In contrast, in T-shaped $\mathrm{AmO}_{3}$ and $\mathrm{CmO}_{3}$ the lowestenergy states were composed of four and five non-bonding unpaired $5 \mathrm{f}$ electrons, respectively, and a singly populated

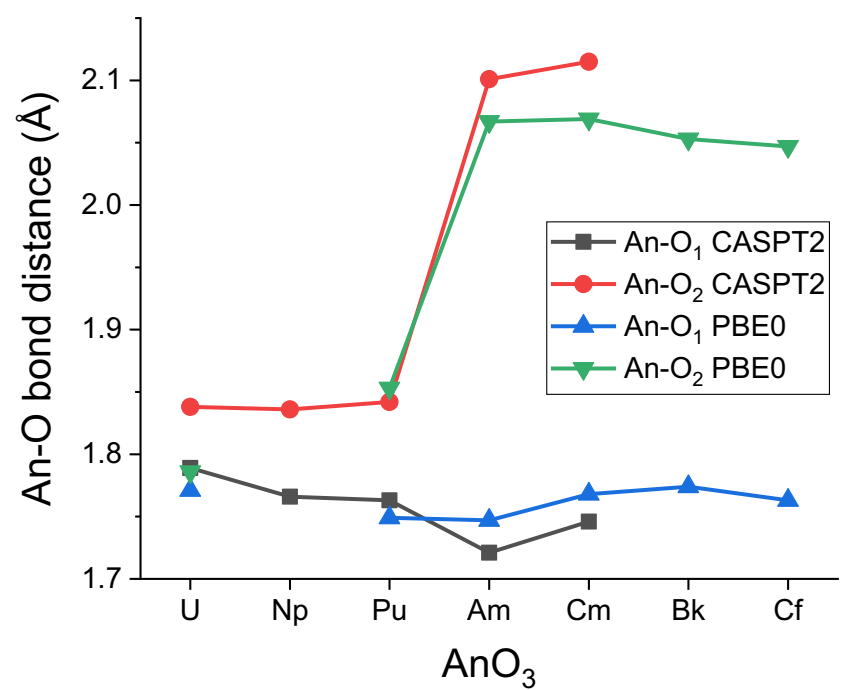

Fig. 6 Trends in the $\mathrm{An}-\mathrm{O}_{1}$ and $\mathrm{An}-\mathrm{O}_{2}$ bond distances in T-shaped $\mathrm{AnO}_{3}$ molecules from SO-PBE0 [31, 49] and SF-CASPT2 calculations [34]. For the numbering of atoms, see Fig. 4

$\mathrm{B}_{2}$ bonding $\pi$ orbital between the $\mathrm{An}$ and $\mathrm{O}_{2}$ atoms. This replaced the analogous, but doubly occupied, $\mathrm{B}_{2} \pi$ orbital in the U/Np/Pu trioxides, explaining the longer $\mathrm{Am}-\mathrm{O}_{2}$ and $\mathrm{Cm}$ $\mathrm{O}_{2}$ bonds.

\section{Neutral and anionic $\mathrm{AnO}_{4}$}

Gas-phase experimental reports were published for neutral $\mathrm{UO}_{4}$ and the $\mathrm{UO}_{4}^{-}, \mathrm{NpO}_{4}^{-}$, and $\mathrm{PuO}_{4}^{-}$anions. In addition, several theoretical studies on An tetroxides were carried out. According to them, $\mathrm{AnO}_{4}$ molecules can form numerous

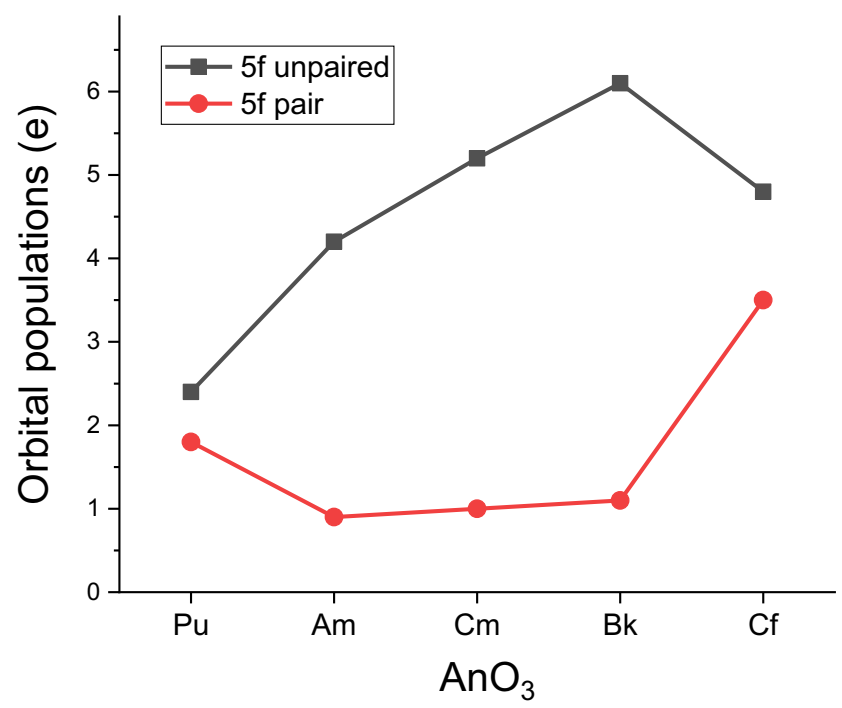

Fig. 7 Effective populations of the 5 f atomic subshells. Data from [50] 
interesting isomers as depicted in Fig. 8. From them, the $\eta^{2}$ $\mathrm{O}_{2}$-coordinated structure in Fig. 8a represents two bonding types: depending on the $\mathrm{O}-\mathrm{O}$ distance this structure can mean the peroxo form with $\mathrm{O}_{2}{ }^{2-}$-ligand (O-O bond around $1.45 \AA$ ) or the superoxo one with $\mathrm{O}_{2}{ }^{-}$-ligand (O-O bond around 1.31 $\AA)$.

\section{$\mathrm{PaO}_{4}^{-}$}

The $\mathrm{PaO}_{4}{ }^{-}$anion was investigated recently using the PBE0 hybrid functional [21]. From the various considered isomers, the lowest-energy one proved to be the structure consisting of a bent protactinyl and an $\eta^{2}$-coordinated $\mathrm{O}_{2}$ (Fig. 8a). No



a

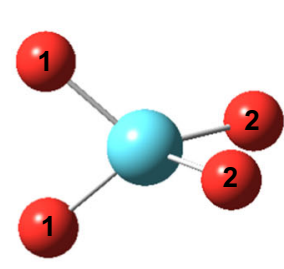

C

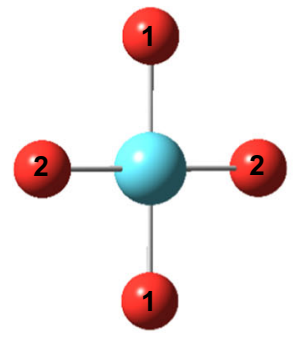

e

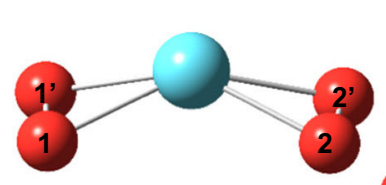

g

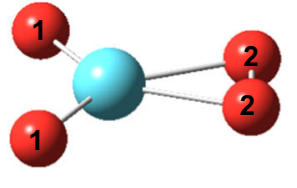

b


f

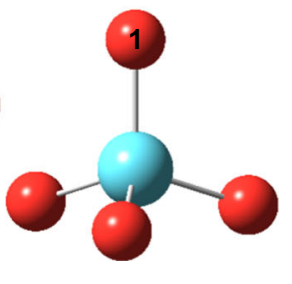

h
Fig. 8 Main structural isomers of neutral and ionic $\mathrm{AnO}_{4}$ molecules. An atoms are depicted in cyan, $\mathrm{O}$ in red. Structures with the following symmetries are discussed in the review: $\mathbf{a} \mathrm{C}_{2 \mathrm{v}} ; \mathbf{b} \mathrm{C}_{2 \mathrm{v}} ; \mathbf{c} \mathrm{D}_{2 \mathrm{~d}}, \mathrm{C}_{2 \mathrm{v}} ; \mathbf{d}$



symmetry was assigned to this species in the paper, but according to the given Cartesian coordinates, the optimized structure is very close to $\mathrm{C}_{2 \mathrm{v}}$. Characteristic on this structure is the considerable bending of the protactinyl moiety compared with the heavier actinide analogues (cf. Table 2). This is the consequence of the $\mathrm{Pa}^{\mathrm{V}}$ oxidation state in this anion (composed formally of $\mathrm{PaO}_{2}{ }^{+}$and peroxide $\mathrm{O}_{2}{ }^{2-}$ ) unlike the heavier actinides which can access higher oxidation states. In the Supporting Information of [21] the relative energies and structures of 13 additional (singlet and triplet) $\mathrm{PaO}_{4}{ }^{-}$species were given without discussion, several of them corresponding to excited electronic states. For comparison, a few selected low-energy ones are included in Table 2 . From them, the planar peroxide derivative, formed by a $90^{\circ}$ turn of $\mathrm{O}_{2}$ (Fig. $8 \mathrm{~b}$ ), is the closest is energy, being higher by $15 \mathrm{~kJ} / \mathrm{mol}$.

\section{$\mathrm{UO}_{4}, \mathrm{UO}_{4}^{-}, \mathrm{UO}_{4}{ }^{2-}$, and $\mathrm{UO}_{4}^{+}$}

Because the $\mathrm{U}$ atom reached its maximum oxidation state VI in $\mathrm{UO}_{3}$, the higher oxides can be formed incorporating either open-shell oxyl ligands (with electron holes in the $2 p$ subshell) or $\eta^{1}$ - or $\eta^{2}$-coordinated $\mathrm{O}_{2}$ ligands.

Neutral $\mathrm{UO}_{4}$ was observed in the matrix-isolation IR study of Zhou et al. [27], assigning the IR absorption band at 905.1 $\mathrm{cm}^{-1}$ in Ne matrix to the $\mathrm{UO}_{2}\left(\mathrm{O}_{2}\right)$ form on the basis of the good agreement with the computed frequency. Two other IR bands were assigned to higher $\mathrm{UO}_{2}\left(\mathrm{O}_{2}\right)_{x}$ species. DFT calculations were performed on $\mathrm{UO}_{4}$, and on the basis of the calculated wavefunction a superoxo $\left(\mathrm{UO}_{2}{ }^{+}\right)\left(\mathrm{O}_{2}{ }^{-}\right)$character (Fig. 8a) was suggested for the ${ }^{1} \mathrm{~A}_{1}$ ground state.

$\mathrm{UO}_{4}$ was also produced in laser-induced electron detachment measurements on $\mathrm{UO}_{4}{ }^{-}$by Su et al. [32] (vide infra). The experiments resulted in the electron affinity of $3.60 \pm 0.03 \mathrm{eV}$ for $\mathrm{UO}_{4}$. The $\mathrm{U}-\mathrm{O}$ symmetric stretching frequency of $\mathrm{UO}_{4}$ was measured to be $770 \pm 30 \mathrm{~cm}^{-1}$. The frequency and electron affinity of an unidentified excited state were also measured.

DFT calculations in the latter study confirmed the ${ }^{1} \mathrm{~A}_{1}$ ground electronic state of $\mathrm{UO}_{4}$ having an $\eta^{2}-\mathrm{O}_{2}$ ligand attached to the bent uranyl moiety in a $\mathrm{C}_{2 \mathrm{v}}$ arrangement (Fig. 8a). The tetrakis-oxo isomer (Fig. 8c) was higher in energy by $70 \mathrm{~kJ} / \mathrm{mol}$ according to $\mathrm{CCSD}(\mathrm{T})$ single-point calculations on the B3LYP geometry. These calculations suggested a peroxo $\mathrm{O}_{2}{ }^{2-}$ character of the $\eta^{2}$-ligand, contradicting the previously suggested [27] superoxo nature of the ground electronic state. A superoxo $\mathrm{UO}_{4}$ structure was obtained for a high-lying excited electronic state [32].

Anionic $\mathrm{UO}_{4}^{-}$was reported from several experimental studies. It was first observed by Gibson et al. using FT-ICR mass spectrometry $[36,51]$. The molecule showed a remarkable abundance in the vapor phase above solid $\mathrm{UO}_{3}$ and $\left(\mathrm{NH}_{4}\right)_{2} \mathrm{U}_{2} \mathrm{O}_{7}$ subjected to laser ablation. $\mathrm{UO}_{4}{ }^{-}$was formed also in the gas-phase oxidation reaction $\mathrm{UO}_{3}{ }^{-}+\mathrm{N}_{2} \mathrm{O}$ under 
Table 2 Selected computed geometrical parameters of ground-state neutral and ionic $\mathrm{AnO}_{4}$

\begin{tabular}{|c|c|c|c|c|c|c|c|c|c|}
\hline $\mathrm{AnO}_{4}$ & Fig. 8 & Sym & Method $^{\mathrm{a}}$ & State & $\mathrm{An}-\mathrm{O}_{1}$ & $\mathrm{An}-\mathrm{O}_{2}$ & $\mathrm{O}_{2}-\mathrm{O}_{2}$ & $\mathrm{O}_{1} \mathrm{AnO}_{1}$ & Reference \\
\hline \multirow[t]{5}{*}{$\mathrm{PaO}_{4}^{-}$} & $\mathrm{a}$ & $\sim \mathrm{C}_{2 \mathrm{v}}$ & \multirow[t]{5}{*}{ PBE0/A } & ${ }^{1} \mathrm{X}$ & 1.913 & 2.190 & 1.457 & 143.6 & \multirow[t]{5}{*}[21]{} \\
\hline & $\mathrm{a}$ & $\mathrm{C}_{2 \mathrm{v}}$ & & ${ }^{3} \mathrm{X}$ & 1.856 & 2.417 & 1.317 & 170.7 & \\
\hline & $\mathrm{b}$ & $\mathrm{C}_{2 \mathrm{v}}$ & & ${ }^{1} \mathrm{X}$ & 1.927 & 2.180 & 1.474 & 117.5 & \\
\hline & $\mathrm{c}$ & $D_{2 d}$ & & ${ }^{1} \mathrm{X}$ & 1.917 & 1.917 & - & 84.6 & \\
\hline & $\mathrm{c}$ & $\mathrm{D}_{2 \mathrm{~d}}$ & & ${ }^{3} \mathrm{X}$ & 1.964 & 1.964 & - & 132.8 & \\
\hline \multirow[t]{4}{*}{$\mathrm{UO}_{4}$} & $\mathrm{a}$ & $\mathrm{C}_{2 \mathrm{v}}$ & B3LYP/A & ${ }^{1} \mathrm{~A}_{1}$ & 1.794 & 2.108 & 1.443 & 160.0 & {$[27]$} \\
\hline & $\mathrm{a}$ & $\mathrm{C}_{2 \mathrm{v}}$ & \multirow[t]{3}{*}{ B3LYP/A } & ${ }^{1} \mathrm{~A}_{1}$ & 1.784 & 2.102 & 1.429 & 160.3 & \multirow[t]{3}{*}{ [32] } \\
\hline & $\mathrm{c}$ & $\mathrm{D}_{2 \mathrm{~d}}$ & & ${ }^{1} \mathrm{~A}_{1}$ & 1.819 & 1.819 & - & 123.8 & \\
\hline & $\mathrm{a}$ & $\mathrm{C}_{2 \mathrm{v}}$ & & ${ }^{3} \mathrm{~A}_{2}$ & 1.802 & 2.355 & 1.319 & 168.8 & \\
\hline \multirow[t]{10}{*}{$\mathrm{UO}_{4}^{-}$} & $\mathrm{d}$ & $\mathrm{C}_{2 \mathrm{v}}$ & PW91/B & ${ }^{2} \mathrm{~A}$ & 1.89 & 1.94 & & n.a. & [51] \\
\hline & $\mathrm{d}$ & $\mathrm{C}_{2 \mathrm{v}}$ & \multirow[t]{3}{*}{ B3LYP/A } & ${ }^{2} \mathrm{~B}_{1}$ & 1.861 & 1.943 & - & 154.5 & \multirow[t]{3}{*}[32]{} \\
\hline & $\mathrm{a}$ & $\mathrm{C}_{2 \mathrm{v}}$ & & ${ }^{2} \mathrm{~A}_{1}$ & 1.879 & 2.175 & 1.480 & 147.9 & \\
\hline & a & $\mathrm{C}_{2 \mathrm{v}}$ & & ${ }^{4} \mathrm{~A}_{2}$ & 1.828 & 2.431 & 1.323 & 174.2 & \\
\hline & $\mathrm{d}$ & $\mathrm{C}_{2 \mathrm{v}}$ & \multirow[t]{6}{*}{ PBE0/A } & ${ }^{2} X$ & 1.842 & 1.925 & - & 156.9 & \multirow[t]{6}{*}[21]{} \\
\hline & $\mathrm{d}$ & $\mathrm{C}_{2 \mathrm{v}}$ & & ${ }^{4} X$ & 1.893 & 1.921 & - & 139.2 & \\
\hline & d & $\mathrm{C}_{2}$ & & ${ }^{2} X$ & 1.865 & 1.865 & - & 152.3 & \\
\hline & $\mathrm{a}$ & $\mathrm{C}_{2 \mathrm{v}}$ & & ${ }^{2} X$ & 1.861 & 2.150 & 1.463 & 151.4 & \\
\hline & $\mathrm{e}$ & $\mathrm{D}_{4 \mathrm{~h}}$ & & ${ }^{4} X$ & 1.872 & 1.872 & - & 180.0 & \\
\hline & $\mathrm{g}$ & $\sim \mathrm{C}_{2 \mathrm{v}}$ & & ${ }^{4} X$ & 2.113 & 2.111 & 1.463 & $140.9^{\mathrm{b}}$ & \\
\hline \multirow[t]{2}{*}{$\mathrm{UO}_{4}{ }^{2-}$} & $\mathrm{h}$ & $\mathrm{T}_{\mathrm{d}}$ & \multirow[t]{2}{*}{$\operatorname{CCSD}(\mathrm{T}) / \mathrm{A}$} & ${ }^{1} \mathrm{X}$ & 1.99 & - & - & 109.5 & \multirow[t]{2}{*}[56]{} \\
\hline & e & $\mathrm{D}_{4 \mathrm{~h}}$ & & ${ }^{1} \mathrm{X}$ & 1.96 & - & - & 180.0 & \\
\hline \multirow[t]{4}{*}{$\mathrm{UO}_{4}^{+}$} & $\mathrm{a}$ & $\mathrm{C}_{2 \mathrm{v}}$ & \multirow[t]{2}{*}{ B3LYP/A } & ${ }^{2} \mathrm{~A}_{2}$ & 1.738 & 2.293 & 1.290 & 173.3 & \multirow[t]{2}{*}[60,61]{} \\
\hline & $\mathrm{f}$ & $\mathrm{C}_{\mathrm{s}}$ & & ${ }^{2} A^{\prime}$ & 1.764 & 2.613 & 1.205 & 177.7 & \\
\hline & $\mathrm{a}$ & $\mathrm{C}_{2 \mathrm{v}}$ & \multirow[t]{2}{*}{ PBE/A } & ${ }^{2} \mathrm{X}$ & 1.757 & 2.280 & 1.297 & n.a. & \multirow[t]{2}{*}[62]{} \\
\hline & $\mathrm{d}$ & $\mathrm{D}_{2 \mathrm{~d}}$ & & ${ }^{2} \mathrm{X}$ & 1.805 & 1.805 & - & n.a. & \\
\hline $\mathrm{NpO}_{4}^{-}$ & $\mathrm{e}$ & $\mathrm{D}_{4 \mathrm{~h}}$ & $\operatorname{CCSD}(\mathrm{T}) / \mathrm{A}$ & ${ }^{1} \mathrm{X}$ & 1.86 & - & - & 180.0 & {$[56]$} \\
\hline & $\mathrm{h}$ & $\mathrm{T}_{\mathrm{d}}$ & & ${ }^{1} \mathrm{X}$ & 1.92 & - & - & 109.5 & \\
\hline & $\mathrm{e}$ & $\mathrm{D}_{4 \mathrm{~h}}$ & $\mathrm{PBE} 0 / \mathrm{A}$ & ${ }^{1} \mathrm{X}$ & 1.820 & - & - & 180.0 & {$[46]$} \\
\hline $\mathrm{NpO}_{4}{ }^{+}$ & $\mathrm{f}$ & $\mathrm{C}_{\mathrm{s}}$ & B3LYP/A & ${ }^{1} \mathrm{X}$ & 1.742 & 2.649 & 1.204 & 179.2 & {$[61]$} \\
\hline $\mathrm{PuO}_{4}$ & $\mathrm{e}$ & $\mathrm{D}_{4 \mathrm{~h}}$ & B3LYP/A & ${ }^{1} \mathrm{X}$ & 1.766 & 1.766 & - & 180.0 & {$[38]$} \\
\hline & $\mathrm{e}$ & $\mathrm{D}_{4 \mathrm{~h}}$ & $\operatorname{CCSD}(\mathrm{T}) / \mathrm{A}$ & ${ }^{1} \mathrm{X}$ & 1.777 & 1.777 & - & 180.0 & \\
\hline & $\mathrm{e}$ & $\mathrm{D}_{4 \mathrm{~h}}$ & SO-B3LYP/A & n.a. & 1.774 & 1.774 & - & 180.0 & {$[41]$} \\
\hline & $\mathrm{e}$ & $\mathrm{D}_{4 \mathrm{~h}}$ & PBE0/A & n.a. & 1.753 & 1.753 & - & 180.0 & \\
\hline & $\mathrm{a}$ & $\mathrm{C}_{2 \mathrm{v}}$ & B3LYP/A & ${ }^{5} \mathrm{~B}_{1}$ & 1.764 & 2.331 & 1.314 & 176.3 & {$[57]$} \\
\hline & $\mathrm{e}$ & $\mathrm{D}_{4 \mathrm{~h}}$ & & ${ }^{1} \mathrm{~A}_{1}$ & 1.772 & 1.772 & - & 180.0 & \\
\hline & a & $\mathrm{C}_{2 \mathrm{v}}$ & SO-PBE0/A & n.a. & 1.747 & 2.279 & 1.306 & 176.2 & [74] \\
\hline & $\mathrm{e}$ & $\mathrm{D}_{4 \mathrm{~h}}$ & & n.a. & 1.753 & 1.753 & - & 180.0 & \\
\hline & g & $\mathrm{C}_{2 \mathrm{v}}$ & & n.a. & 2.064 & 2.064 & 1.437 & n.a. & \\
\hline & $\mathrm{a}$ & $\mathrm{C}_{2 \mathrm{v}}$ & $\mathrm{PBE} 0 / \mathrm{A}$ & ${ }^{3} \mathrm{X}$ & 1.746 & 2.273 & 1.310 & 176.6. & {$[46]$} \\
\hline & $\mathrm{a}$ & $\mathrm{C}_{2 \mathrm{v}}$ & & ${ }^{5} \mathrm{X}$ & 1.745 & 2.298 & 1.310 & 177.1 & \\
\hline $\mathrm{PuO}_{4}^{-}$ & $\mathrm{e}$ & $\mathrm{D}_{4 \mathrm{~h}}$ & PBE0/A & ${ }^{2} \mathrm{X}$ & 1.803 & 1.803 & - & 180.0 & {$[46]$} \\
\hline & $\mathrm{e}$ & $\mathrm{C}_{2 \mathrm{~h}}$ & & ${ }^{4} \mathrm{X}$ & 1.832 & 1.833 & - & 180.0 & \\
\hline & $\mathrm{a}$ & $\mathrm{C}_{2 \mathrm{v}}$ & & ${ }^{4} \mathrm{X}$ & 1.806 & 2.141 & 1.465 & 168.9 & \\
\hline & d & $\mathrm{C}_{\mathrm{s}}$ & & ${ }^{4} \mathrm{X}$ & 1.787 & $2.090 / 2.205$ & - & 173.7 & \\
\hline & $\mathrm{g}$ & $\mathrm{C}_{2}$ & & ${ }^{6} \mathrm{X}$ & 2.132 & 2.144 & 1.472 & $127.6^{\mathrm{b}}$ & \\
\hline $\mathrm{AmO}_{4}$ & $\mathrm{a}$ & $\mathrm{C}_{2 \mathrm{v}}$ & SO-PBE0/A & n.a. & 1.742 & 2.292 & 1.309 & 177.7 & {$[74]$} \\
\hline & $\mathrm{e}$ & $\mathrm{D}_{4 \mathrm{~h}}$ & & n.a. & 1.742 & 1.742 & - & 180.0 & \\
\hline & $\mathrm{g}$ & $\mathrm{C}_{\mathrm{s}}$ & & n.a. & 2.075 & 2.238 & $1.443 / 1.328$ & n.a. & \\
\hline $\mathrm{CmO}_{4}$ & $\mathrm{a}$ & $\mathrm{C}_{2 \mathrm{v}}$ & SO-PBE0/A & n.a. & 1.763 & 2.276 & 1.309 & 173.5 & {$[74]$} \\
\hline
\end{tabular}


Table 2 (continued)

\begin{tabular}{ccccccccc}
\hline $\mathrm{AnO}_{4}$ & Fig. 8 & Sym & Method $^{\mathrm{a}}$ & State & $\mathrm{An}-\mathrm{O}_{1}$ & $\mathrm{An}-\mathrm{O}_{2}$ & $\mathrm{O}_{2}-\mathrm{O}_{2}$ & $\mathrm{O}_{1} \mathrm{AnO}_{1}$ \\
\hline \\
$\mathrm{e}$ & $\mathrm{D}_{2 \mathrm{~h}}$ & & n.a. & 1.747 & 2.057 & - & 180.0 \\
$\mathrm{~g}$ & $\mathrm{C}_{1}$ & & n.a. & 2.046 & 2.298 & $1.483 / 1.323$ & n.a. \\
\hline
\end{tabular}

Bond distances are given in angstroms, bond angles in degrees. For the definition of atoms, see Fig. 8

${ }^{\mathrm{a}}$ The abbreviations of basis sets A and B mean relativistic small-core pseudopotential and all-electron, respectively

${ }^{\mathrm{b}}$ Angle between the opposite-positioned oxygens: $\mathrm{O}_{1}-\mathrm{An}-\mathrm{O}_{2}$ '

thermal conditions. Sokalska et al. obtained $\mathrm{UO}_{4}{ }^{-}$by collision induced dissociation of ions from laser desorption/ionization of various solid uranyl-salts, followed by detection by mass spectrometry [52]. Several spin states and structural isomers were probed by MP2 and DFT calculations. They predicted a doublet ground electronic state with distorted planar structures, revised later by more sophisticated calculations (vide infra).

$\mathrm{Su}$ et al. prepared $\mathrm{UO}_{4}{ }^{-}$by laser evaporation of solid uranium followed by reaction with $\mathrm{O}_{2}$ in $\mathrm{He}$ carrier gas [32]. The anion was identified by mass spectrometry and further characterized by photoelectron spectroscopy and quantum chemical calculations. De Jong et al. [21] prepared $\mathrm{UO}_{4}{ }^{-}$by gasphase reaction of $\mathrm{UO}_{2}\left(\mathrm{C}_{2} \mathrm{O}_{4}\right)^{-}$(from electrospray ionization) with $\mathrm{O}_{2}$ in an ion trap. The anion was detected by mass spectrometry and characterized by DFT computations.

The structure and bonding properties of $\mathrm{UO}_{4}^{-}$were clarified by quantum chemical calculations carried out parallel with experiments in the above studies.

The ${ }^{2} \mathrm{~B}_{1}$ ground electronic state of $\mathrm{UO}_{4}^{-}$proved to be a tetrakis-oxo structure with $\mathrm{C}_{2 \mathrm{v}}$ symmetry (Fig. 8d) [21, 32, 51] resembling the tetraoxo anions of heavy transition metals with oxidation states $\geq \operatorname{VI}[53,54]$. In this structure, the radical electron is delocalized between the two "equatorial" oxygen atoms resulting in slightly larger $\mathrm{U}-\mathrm{O}_{2}$ vs $\mathrm{U}-\mathrm{O}_{1}$ bond distances (cf. Table 2) [51]. Yet, these weakened $\mathrm{U}_{-} \mathrm{O}_{2}$ bonds are still stronger than a single bond [21]. The radical electron enters a dominantly $\mathrm{O}(2 \mathrm{p})$-type LUMO differing from the lower $\mathrm{UO}_{x}{ }^{-}$ $(x \leq 3)$ anions where this extra electron occupies an U(5f)-type LUMO. This feature is associated with a significantly higher electron affinity of $\mathrm{UO}_{4}$ compared with $\mathrm{UO}_{3}$ [32].

Important additional isomers of $\mathrm{UO}_{4}{ }^{-}$include those consisting of an $\eta^{2}-\mathrm{O}_{2}$ ligand (Fig. 8a): $\mathrm{The}^{2} \mathrm{~A}_{1}$ peroxide form with a formal $\mathrm{O}_{2}{ }^{2-}$ ligand was calculated to be higher in energy by over $130 \mathrm{~kJ} / \mathrm{mol}$ according to DFT calculations [21, 51] as well as by $\operatorname{CCSD}(\mathrm{T})$ energies on the B3LYP geometries [32]. The ${ }^{4} \mathrm{~A}_{2}$ superoxide with a formal $\mathrm{O}_{2}^{-}$ligand and considerably larger $\mathrm{U}-\mathrm{O}_{2}$ distance was even higher in energy (by $282 \mathrm{~kJ} / \mathrm{mol}$ ) [32]. In the Supporting Information of [21], the relative energies and structures of altogether 11 additional (doublet and quartet) $\mathrm{UO}_{4}^{-}$species were given, several of them corresponding to excited electronic states. Selected ones are included in Table 2. From them, the $\mathrm{C}_{2}$ (distorted $\mathrm{S}_{4}$ ) form (Fig. 8d) was the closest is energy, computed to be higher only by $7 \mathrm{~kJ} / \mathrm{mol}$. The planar (Fig. 8e) and double-peroxi (Fig. 8g) isomers were obtained very high in energy (209 and $578 \mathrm{~kJ} /$ mol, respectively).

The square planar isomer of $\mathrm{UO}_{4}{ }^{2-}$ (Fig. 8e) was investigated at the HF level by Pyykkö and Zhao [55] in a comparative study of various uranium oxide ions. Calculations by Bolvin et al. [56] a decade later using various wavefunction theory and DFT methods resulted consistently in a tetrahedral ground-state (Fig. 8h) with a flat potential energy surface around the minimum. The high symmetries of the probed $T_{d}$ and $\mathrm{D}_{4 \mathrm{~h}}$ structures (Fig. 8e, h, respectively) facilitated geometry optimizations at the highest $\operatorname{CCSD}(\mathrm{T})$ level (Table 2). The $\mathrm{D}_{4 \mathrm{~h}}$ form was found to be less stable by $91.5 \mathrm{~kJ} / \mathrm{mol}$. The study included also low-energy excited states and analysis of valence molecular orbitals.

Huang et al. [57] performed a comparative analysis of isoelectronic $\mathrm{UO}_{4}{ }^{2-}, \mathrm{NpO}_{4}{ }^{-}$, and $\mathrm{PuO}_{4}$ using the $\mathrm{B} 3 \mathrm{LYP}$ method focusing on the relative energies of the three main structures: singlet $\mathrm{T}_{\mathrm{d}}$ (Fig. $8 \mathrm{~h}$ ), singlet $\mathrm{D}_{4 \mathrm{~h}}$ (Fig. 8e), and triplet and quintet $\mathrm{C}_{2 \mathrm{v}}$ (Fig. 8a). The study supported the ground-state character of the singlet $\mathrm{T}_{\mathrm{d}}$ isomer of $\mathrm{UO}_{4}{ }^{2-}$ and the preference of $\mathrm{U}^{\mathrm{VI}}$ over $\mathrm{U}^{\mathrm{III}}$ oxide. The $\mathrm{D}_{4 \mathrm{~h}}$ and $\mathrm{C}_{2 \mathrm{v}}$ isomers proved to be low-energy structures. No geometrical parameters were published for $\mathrm{UO}_{4}{ }^{2-}$.

The free $\mathrm{UO}_{4}{ }^{+}$molecule was not observed experimentally, while in the gas phase, Groenewold et al. found $\mathrm{UO}_{2}{ }^{+}\left(\mathrm{O}_{2}\right)$ species coordinated by additional two or three electron donor ligands (acetone, $\mathrm{H}_{2} \mathrm{O}$, DMSO) [58, 59]. This observation was explained by the electron acceptor character of $\mathrm{O}_{2}$ : it requires excess electron density on the metal center which could be provided by the mentioned additional ligands.

Bryantsev et al. proposed for $\mathrm{UO}_{4}{ }^{+}$an $\left(\mathrm{UO}_{2}{ }^{2+}\right)\left(\eta^{2}-\mathrm{O}_{2}{ }^{-}\right)$ structure (Fig. 8a), corresponding to a uranyl(VI) superoxo compound on the basis of B3LYP calculations [60]. This structure, stabilized by a 2-electron-3-centered bond between the singly occupied $\mathrm{U}\left(5 \mathrm{f}_{\varphi}\right)$ orbital and the $\mathrm{O}_{2}\left(\pi^{*}\right)$ orbital in the equatorial plane, was favored by $46 \mathrm{~kJ} / \mathrm{mol}$ over the $\left(\mathrm{UO}_{2}{ }^{+}\right)\left(\eta^{1}-\mathrm{O}_{2}\right) \mathrm{C}_{\mathrm{s}}$ isomer (Fig. 8f). The calculated enthalpy 
and Gibbs-free energy for $\mathrm{O}_{2}$-addition to $\mathrm{UO}_{2}{ }^{+}$were -52 and $-20 \mathrm{~kJ} / \mathrm{mol}$, respectively [61].

$\mathrm{UO}_{4}{ }^{+}$ions complexed by a few Ar atoms were produced in a supersonic molecular beam by laser vaporization of uranium in Ar containing a few percent of $\mathrm{O}_{2}$ [62]. Such gas-phase complexes resemble matrix-isolation situations (molecules captured in a cryogenic matrix) but, due to the less Ar neighbors, they can provide better approximations of the molecular vibrations. Excitation of the $\mathrm{UO}_{4}{ }^{+} \mathrm{Ar}_{2}$ complexes with an IR$\mathrm{OPO}$ laser system in the range of the O-U-O and O-O stretching vibrations facilitated the experimental determination of these vibrational frequencies. The asymmetric O-U-O stretching of the $\mathrm{UO}_{2}$ moiety appeared as an intense band at $1015 \mathrm{~cm}^{-1}$ while the symmetric stretching as a weak one at $930 \mathrm{~cm}^{-1}$. The found infrared activity of this latter vibration (being inactive in linear OUO) is due to a slight bend of the uranyl core upon coordination of $\mathrm{O}_{2}$. The $\mathrm{O}-\mathrm{O}$ stretching band of the $\eta^{2}$-coordinated $\mathrm{O}_{2}$ appeared at $1163 \mathrm{~cm}^{-1}$. Two isomers of $\mathrm{UO}_{4}{ }^{+}$(Fig. 8a, d) were computed by DFT and the calculated frequencies of the lower-energy doublet $\mathrm{C}_{2 \mathrm{v}}$ isomer agreed very well with the experimental spectrum [62]. The calculated O-O bond distance of the $\eta^{2}-\mathrm{O}_{2}$ moiety $(1.297 \AA$ ) was close to the one in the superoxide $\mathrm{O}_{2}^{-}$ion (1.34 $\AA$ [63]).

\section{$\mathrm{NpO}_{4}{ }^{-}$and $\mathrm{NpO}_{4}{ }^{+}$}

The highest known oxidation state of $\mathrm{Np}$ is VII, reported in the gaseous phase first for $\mathrm{NpO}_{3}\left(\mathrm{NO}_{3}\right)_{2}{ }^{-}$[64]. Recently, Gibson et al. synthesized $\mathrm{NpO}_{4}{ }^{-}$by the gas-phase reaction of $\mathrm{NpO}_{2}\left(\mathrm{C}_{2} \mathrm{O}_{4}\right)^{-}$with $\mathrm{O}_{2}$ in an ion trap [46]. The detection was done by mass spectrometry while the heptavalent oxidation state was supported by reactivity studies and DFT calculations. In the experimental studies, the slow rate of water addition suggested the high stability of $\mathrm{NpO}_{4}{ }^{-}$which can happen in a structure with four $\mathrm{Np}=\mathrm{O}$ quasi-double bonds (according to $\mathrm{Np}^{\mathrm{VII}}$ ). These experimental findings were consistent with calculated reaction energies [64].

The square planar $\mathrm{D}_{4 \mathrm{~h}}$ structure of singlet $\mathrm{NpO}_{4}{ }^{-}$(Fig. 8e) was proposed by early relativistic extended Hückel calculations of Pyykkö et al. [65] and confirmed by Bolvin et al. using various wavefunction theory and DFT methods [56]. The latter authors performed geometry optimizations of the $\mathrm{D}_{4 \mathrm{~h}}$ and $\mathrm{T}_{\mathrm{d}}$ (Fig. 8e, h) isomers using 10 different methods including $\operatorname{CCSD}(\mathrm{T})$, and obtained a preference of $\mathrm{D}_{4 \mathrm{~h}}$ by 105 $\mathrm{kJ} / \mathrm{mol}$ at the latter level. Analysis of molecular orbitals revealed the determining role of $5 \mathrm{f}$ orbitals for the planar structure, because removing them from the basis set changed the structure to a tetrahedral one. The promoting role of $5 \mathrm{f}$ orbitals in the covalent bonding was associated with their relatively low energy.

The DFT calculations in [46] agreed too with the singlet square planar structure. The Mulliken atomic spin population of $\mathrm{Np}$ corresponded to $5 \mathrm{f}^{0}$ configuration, i.e., to $\mathrm{Np}{ }^{\mathrm{VII}}$.
Huang et al. performed a comparative analysis of isoelectronic $\mathrm{UO}_{4}{ }^{2-}, \mathrm{NpO}_{4}{ }^{-}$, and $\mathrm{PuO}_{4}$ with the B3LYP method [57] focusing on the relative energies of the three main structures: singlet $\mathrm{T}_{\mathrm{d}}$ (Fig. $8 \mathrm{~h}$ ), singlet $\mathrm{D}_{4 \mathrm{~h}}$ (Fig. 8e), and triplet and quintet $\mathrm{C}_{2 \mathrm{v}}$ (Fig. 8a). The study confirmed the ground-state character of the $\mathrm{D}_{4 \mathrm{~h}}$ isomer as $\mathrm{Np}^{\mathrm{VII}} \mathrm{O}_{4}^{-}$while the $\mathrm{T}_{\mathrm{d}}$ transition state and the $\mathrm{C}_{2 \mathrm{v}}$ minimum corresponded to low-energy structures. The data indicated the preference of $\mathrm{Np}^{\mathrm{VII}}$ over $\mathrm{Np}^{\mathrm{IV}}$ oxide. No geometrical parameters were published for $\mathrm{NpO}_{4}{ }^{-}$.

$\mathrm{NpO}_{4}{ }^{+}$was studied by Rios et al. [61] using B3LYP calculations. The lowest-energy open-shell singlet and quintet states were found to be practically degenerate in energy (within $4 \mathrm{~kJ} / \mathrm{mol}$ ), with the singlet state being slightly favored. The calculated enthalpy and Gibbs-free energy for $\mathrm{O}_{2}$ addition to $\mathrm{NpO}_{2}{ }^{+}$were -24 and $+2 \mathrm{~kJ} / \mathrm{mol}$, respectively. The obtained structure contained an $\mathrm{O}_{2}$ molecule in a very weak $\eta^{1}$-arrangement to $\mathrm{NpO}_{2}{ }^{+}$(Fig. 8f), the O-O bond lengths being almost the same as in the free $\mathrm{O}_{2}$ molecule. Hence, this weakly bound neptunyl-dioxygen complex retained the $\mathrm{Np}^{\mathrm{V}}$ oxidation state of $\mathrm{NpO}_{2}{ }^{+}$, in contrast to the uranyl-dioxygen superoxo complex in which $\mathrm{U}^{\mathrm{V}}$ was oxidized to $\mathrm{U}^{\mathrm{VI}}$.

\section{$\mathrm{PuO}_{4}$ and $\mathrm{PuO}_{4}^{-}$}

Neutral $\mathrm{PuO}_{4}$ molecule was inferred by Domanov et al. [66, 67] on the basis of gas thermochromatographic measurements of volatile oxidation products of $\mathrm{Pu}$. The suggested composition $\left(\mathrm{Pu}^{\mathrm{VIII}} \mathrm{O}_{4}\right)$ of the detected species with unusually low deposition temperature was based on the similar deposition zones of well-known octavalent transition metal oxides, $\mathrm{OsO}_{4}$ and $\mathrm{RuO}_{4}$, supposing an analogous tetrahedral structure [68] for $\mathrm{PuO}_{4}$. However, the formation of $\mathrm{PuO}_{4}$ could not be confirmed in a similar independent experiment [69]. The detection of $\mathrm{Pu}^{\mathrm{VIII}} \mathrm{O}_{4}$ was questioned also by Zaitsevskii et al. [41] who obtained a non-tetrahedral structure for $\mathrm{PuO}_{4}$ by DFT calculations (vide infra).

The formation of $\mathrm{PuO}_{4}$ in the gaseous phase was assumed in an ozonation treatment of $\mathrm{Pu}^{\mathrm{VI}}$ hydroxo complexes tracked by $\alpha$-spectrometry [70]. However, in another ozonation experiment on $\mathrm{Pu}^{\mathrm{VI}}$, no $\mathrm{Pu}^{\mathrm{VIII}}$ compounds could be detected by X-ray photoelectron spectroscopy [71]. A critical analysis of the experimental reports on $\mathrm{PuO}_{4}$ was published by Shilov et al. [72] with the conclusion that no unambiguous experimental proof is available for the existence of $\mathrm{Pu}^{\mathrm{VIII}}$ in the gaseous phase.

The first theoretical study of $\mathrm{PuO}_{4}$ was performed by Straka et al. [38] using wavefunction theory (HF, MP2, $\operatorname{CCSD}(\mathrm{T})$ ) methods. The geometry optimizations resulted consistently in a planar $\mathrm{D}_{4 \mathrm{~h}}$ structure (Fig. 8e, in contradiction with the tetrahedral one assumed by Domanov et al. [67]) with bond distances close to those of $\mathrm{PuO}_{2}$ and $\mathrm{PuO}_{3}$. Accordingly, this singlet planar $\mathrm{PuO}_{4}$ form was assumed to contain $\mathrm{Pu}^{\mathrm{VIII}}$. On the other hand, the calculations indicated also a 
multiconfigurational electronic structure, calling for confirmation by multiconfigurational calculations. As additional molecular data, $\mathrm{Pu}-\mathrm{O}$ stretching frequencies, the standard enthalpy of formation and the bond dissociation energy were reported [38]. The planar $\mathrm{PuO}_{4}$ structure was considered also in DFT studies of the molecular geometry and thermodynamic stability [40] as well as in modelling of solution structures with a $\mathrm{PuO}_{4}$ motif [73]. The latter study assessed the redox potential of the $\mathrm{Pu}^{\mathrm{VII}} / \mathrm{Pu}^{\mathrm{VIII}}$ couple in alkaline and acidic solutions. In acidic medium, the $\mathrm{Pu}{ }^{\mathrm{VII}} / \mathrm{Pu}^{\mathrm{VIII}}$ redox potential was found to be too high to get the $\mathrm{Pu}^{\mathrm{VIII}}$ valence state. In contrast, $\mathrm{Pu}^{\mathrm{VIII}}$ may be synthesized in strong alkaline solution, but it seems to be unstable and can easily be reduced back to $\mathrm{Pu}^{\mathrm{VII}}$ by the solvent water molecules.

In another study, Zaitsevskii et al. investigated the stability of $\mathrm{PuO}_{4}$ isomers using two-component relativistic DFT [41]. According to the calculated $\Delta \mathrm{H}^{0}{ }_{298}$ and $\Delta \mathrm{G}^{0}{ }_{298}$ data, planar $\mathrm{PuO}_{4}$ (Fig. 8e) proved to be thermodynamically less stable by ca. $70 \mathrm{~kJ} / \mathrm{mol}$ than the plutonyl superoxide, $\mathrm{PuO}_{2}\left(\mathrm{O}_{2}\right)$ (Fig. $8 a)$.

Huang et al. performed DFT, MP2, $\operatorname{CCSD}(\mathrm{T})$, and SOCASPT2 calculations on possible structural isomers of $\mathrm{PuO}_{4}$ providing details also on the electronic structure and spectroscopic properties [57]. From the two minima found on the potential energy surface, the quintet $\mathrm{PuO}_{2}\left(\mathrm{O}_{2}\right)($ Fig. 8a) was found to be superior to singlet $\mathrm{PuO}_{4}$ (Fig. $8 \mathrm{e}$ ) by $68 \mathrm{~kJ} / \mathrm{mol}$ at the $\operatorname{CCSD}(\mathrm{T})$ level. The electronic structure of the global minimum corresponded formally to $\left(\mathrm{PuO}_{2}^{+}\right)\left(\eta^{2}-\mathrm{O}_{2}^{-}\right)$, i.e., to a plutonyl(V) $\left(5 f^{3}\right)$ unit coupled to a superoxido $\mathrm{O}_{2}^{-}\left(\pi^{* 3}\right)$ ligand. Its stability indicated that it may likely be detectable as a transient species in gas-phase reactions.

A comparative analysis using the B3LYP method in the same study [57] revealed the following trends in the relative stabilities of the main structures of isoelectronic $\mathrm{UO}_{4}{ }^{2-}$, $\mathrm{NpO}_{4}{ }^{-}$, and $\mathrm{PuO}_{4}$ molecules: the singlet $\mathrm{T}_{\mathrm{d}}$ isomer, being the ground-state structure of $\mathrm{UO}_{4}{ }^{2-}$, became a gradually destabilized transition state for $\mathrm{NpO}_{4}{ }^{-}$and $\mathrm{PuO}_{4}$. The singlet $\mathrm{D}_{4 \mathrm{~h}}$ isomer, being the ground-state structure of $\mathrm{NpO}_{4}^{-}$, was found to be a low-energy isomer for $\mathrm{UO}_{4}{ }^{2-}$ and $\mathrm{PuO}_{4}$. The stability of the quintet $\mathrm{C}_{2 \mathrm{v}}$ isomer increased gradually from $\mathrm{UO}_{4}{ }^{2-}$ towards $\mathrm{PuO}_{4}$, corresponding to the ground-state structure of the latter molecule. These results further supported the preference of $\mathrm{Pu}^{\mathrm{V}}$ over $\mathrm{Pu}^{\mathrm{VIII}}$ oxide.

Zaitsevskii and Schwarz investigated the stability of $\mathrm{PuO}_{4}$ isomers [74] using two-component relativistic DFT. The considered structures were the plutonyl superoxide $\left(\mathrm{PuO}_{2}^{+}\right)\left(\eta^{2}\right.$ $\mathrm{O}_{2}{ }^{-}$), the planar tetroxide $\mathrm{PuO}_{4}$ and the peroxide derivative $\mathrm{Pu}^{4+}\left(\eta^{2}-\mathrm{O}_{2}{ }^{2-}\right)_{2}$ (Fig. 8a, e, g), corresponding to this stability order. The reported comparison with the analogous $\mathrm{AmO}_{4}$ and $\mathrm{CmO}_{4}$ isomers is presented below in the " $\mathrm{AmO}_{4}$ and $\mathrm{CmO}_{4}$ " section.

The $\mathrm{D}_{4 \mathrm{~h}}$ and $\mathrm{C}_{2 \mathrm{v}}$ isomers of $\mathrm{PuO}_{4}$ were included in two additional theoretical studies using B3LYP, $\operatorname{CCSD}(\mathrm{T})$,
CASSCF, and CASPT2 methods. The stability of $\mathrm{Pu}^{\mathrm{VIII}}$ was probed on a set of $\mathrm{PuO}_{n} \mathrm{~F}_{8-2 n}(n=0-4)$ models taking advantage of the high oxidizing nature of $\mathrm{F}$ [75]. The relevance of $\mathrm{Pu}^{\mathrm{VIII}}$ could not be confirmed, because even the decomposition of $\mathrm{PuF}_{8}$ to $\mathrm{PuF}_{6}+\mathrm{F}_{2}$ was found to be considerably exothermic $(\Delta \mathrm{E}=-377 \mathrm{~kJ} / \mathrm{mol}$ without thermal corrections). $\mathrm{A}$ subsequent comparative study on the highest oxidation states in selected $\mathrm{MO}_{4}$ molecules $(\mathrm{M}=\mathrm{Fe}, \mathrm{Ru}, \mathrm{Os}, \mathrm{Hs}, \mathrm{Sm}, \mathrm{Pu})$ [76] revealed the inferiority of f-elements to heavy d-elements. The $\mathrm{Ru}^{\mathrm{VIII}} \mathrm{O}_{4}, \mathrm{Os}^{\mathrm{VIII}} \mathrm{O}_{4}$, and $\mathrm{Hs}^{\mathrm{VIII}} \mathrm{O}_{4}$ oxides are stabilized by closed-shell electronic structures having empty metal $\mathrm{d}^{0}$ valence shells bonded to $\mathrm{O}^{2-}$ ligands. In contrast, the light d- and the f-elements prefer partial occupation of their valance shells. Accordingly, $\mathrm{Pu}$ prefers the $5 \mathrm{f}^{3}$ configuration and thus the superoxide $\left(\mathrm{Pu}^{\mathrm{V}} \mathrm{O}_{2}{ }^{+}\right)\left(\eta^{2}-\mathrm{O}_{2}{ }^{-}\right)$form. The reason for the larger stability of this electronic structure is the low energy of $5 \mathrm{f}$ orbitals, making very difficult to remove the last few $5 \mathrm{f} \mathrm{elec-}$ trons of Pu.

The electron affinity of $\mathrm{PuO}_{4}$ was estimated in the PBE0 study of $\mathrm{PuO}_{4}{ }^{-}$by Gibson et al. [46], vide infra. In the Supporting Information of [46], the relative energies and structures of six (singlet, triplet, quintet) $\mathrm{PuO}_{4}$ species were given without discussion. The triplet and quintet superoxide forms (Fig. 8a) were the lowest-energy structures (the triplet being lower by $10 \mathrm{~kJ} / \mathrm{mol}$, with marginally differing geometrical parameters, cf. Table 2), while the singlet planar form (Fig. 8e) was computed to be higher by $107 \mathrm{~kJ} / \mathrm{mol}$. These results are in reasonable agreement with the more sophisticated ones of Huang et al. ([57], vide supra).

The experimental observation of $\mathrm{PuO}_{4}^{-}$was reported recently [46]. It was synthesized by the gas-phase reaction of $\mathrm{PuO}_{2}\left(\mathrm{C}_{2} \mathrm{O}_{4}\right)^{-}$with $\mathrm{O}_{2}$ in an ion trap, detected subsequently by mass spectrometry. The slow rate of water addition suggested the high stability of $\mathrm{Pu}^{\mathrm{VII}} \mathrm{O}_{4}^{-}$in agreement with a structure containing four $\mathrm{Pu}=\mathrm{O}$ double bonds. These experimental findings were consistent with the DFT calculated structure and reaction energies. The computed reaction products of water addition indicated slightly less stability of $\mathrm{Pu}^{\mathrm{VII}}$ with respect to $\mathrm{Np}^{\mathrm{VII}}$, in agreement with the estimated difference between the $\mathrm{Pu}{ }^{\mathrm{VII}} / \mathrm{Pu}^{\mathrm{VI}}$ and $\mathrm{Np}^{\mathrm{VII}} / \mathrm{Np}^{\mathrm{VI}}$ reduction potentials [15].

The PBE0 calculations in Ref. [46] resulted in a doublet square planar ground state for $\mathrm{PuO}_{4}{ }^{-}$(Fig. 8e). The Mulliken atomic spin population of $\mathrm{Pu}$ agreed with a $5 \mathrm{f}^{1}$ configuration, i.e., with $\mathrm{Pu}^{\mathrm{VII}}$. Calculations on the conversion of $\mathrm{Pu}^{\mathrm{V}} \mathrm{O}_{4}$ to $\mathrm{Pu}^{\mathrm{VII}} \mathrm{O}_{4}{ }^{-}$by electron addition suggested an exothermic reaction with $\Delta \mathrm{E}=-247 \mathrm{~kJ} / \mathrm{mol}$, the value corresponding to the computationally predicted electron affinity of $\mathrm{PuO}_{4}$. In the Supporting Information of [46], the relative energies and structures of 18 additional (doublet, quartet, sextet) $\mathrm{PuO}_{4}{ }^{-}$species were given without discussion. For comparison, selected ones are included in Table 2. From them, the quartet peroxide (Fig. 8a) was computed to be the closest to the ground state, being 
higher in energy by $121 \mathrm{~kJ} / \mathrm{mol}$. The sextet double superoxide (Fig. 8g) was found to be higher in energy by 375 $\mathrm{kJ} / \mathrm{mol}$.

\section{$\mathrm{AmO}_{4}$ and $\mathrm{CmO}_{4}$}

Experimental information on $\mathrm{AmO}_{4}$ is not available hitherto. An assumed detection of $\mathrm{Cm}^{\mathrm{VIII}} \mathrm{O}_{4}$ in a gas thermochromatographic study was reported in [77]. Because this report was based on an analogous experience with $\mathrm{PuO}_{4}$, the reliability was strongly questioned [72].

The first theoretical study of $\mathrm{AmO}_{4}$ was published by Zaitsevskii et al. [41] using two-component relativistic DFT, reporting the structure (Table 2) and the bond dissociation energy. According to calculated gas-phase reaction energies at $298 \mathrm{~K}, \mathrm{AmO}_{4}$ was found to be thermodynamically unstable and should spontaneously decay to $\mathrm{AmO}_{2}$ and molecular $\mathrm{O}_{2}$. From the studied two minimum structures, $\mathrm{AmO}_{2}\left(\eta^{2}-\mathrm{O}_{2}\right)$ superoxide and planar $\mathrm{AmO}_{4}$ (Fig. 8a, e), the former one was energetically preferred. The Am-O bonds were found to be slightly shorter than those in the analogous $\mathrm{Pu}$ tetroxides. Comparing the energy data of $\mathrm{Pu}$ and $\mathrm{Am}$ tri- and tetraoxides, for both actinides the (formal) oxidation states VI and VII appeared to be more favorable than VIII. Am has less propensity for the higher oxidation states than $\mathrm{Pu}$ as a result of the increasing stability of the $5 \mathrm{f}$ subshell across the actinide row.

In a subsequent computational study at the same theoretical level Zaitsevskii and Schwarz investigated systematically the structures and stabilities of $\mathrm{PuO}_{4}, \mathrm{AmO}_{4}$, and $\mathrm{CmO}_{4}$ isomers [74]. Three isomers were considered: the planar tetroxide $\mathrm{AnO}_{4}$ (Fig. 8e), the actinyl superoxide $\left(\mathrm{AnO}_{2}{ }^{+}\right)\left(\eta^{2}-\mathrm{O}_{2}{ }^{-}\right)($Fig. 8a) and the double-peroxide derivative $\mathrm{An}^{\mathrm{n}+}\left(\eta^{2}-\mathrm{O}_{2}\right)_{2}{ }^{n-}(n=3$ or 4 , Fig. $8 \mathrm{~g})$. For all the three actinides, the superoxide form proved to be the most stable (Fig. 9). In this $\mathrm{C}_{2 \mathrm{v}}$ structure, the actinides are in oxidation state $\mathrm{V}$. The next in the stability order was planar $\mathrm{AnO}_{4}$ for $\mathrm{Pu}$ and $\mathrm{Am}$, in which the metals would have formally oxidation state VIII. This oxidation state did not seem to be feasible for $\mathrm{Cm}$ because the $\mathrm{CmO}_{4}$ structure had two-two $\mathrm{Cm}-\mathrm{O}$ double and single bonds $\left(\mathrm{D}_{2 \mathrm{~h}}\right.$ symmetry) corresponding to $\mathrm{Cm}^{\mathrm{VI}}$. Moreover, this structure was higher in energy than the $\mathrm{Cm}^{3+}\left(\eta^{2}-\mathrm{O}_{2}{ }^{2-}\right)\left(\eta^{2}-\mathrm{O}_{2}^{-}\right)$peroxide-superoxide form. This peroxide-superoxide isomer was the highest-energy one for $\mathrm{Am}$, while in this isomer class the tetravalent $\mathrm{Pu}$ formed a diperoxide $\mathrm{Pu}^{4+}\left(\eta^{2}-\mathrm{O}_{2}{ }^{2-}\right)_{2}$ structure with $\mathrm{C}_{2 \mathrm{v}}$ symmetry. The study supported the gradually decreasing stabilities and An oxidation states for the three actinides.

Zaitsevskii and Schwarz investigated also the reaction of $\mathrm{AnO}_{2}\left(\mathrm{O}_{2}\right)(\mathrm{An}=\mathrm{Pu}, \mathrm{Am}, \mathrm{Cm})$ molecules with $\mathrm{O}_{2}$ and concluded that they can exothermally bind a second $\mathrm{O}_{2}$ [74]. For more details of the $\mathrm{AnO}_{2}\left(\mathrm{O}_{2}\right)_{2}$ molecules, see the "Neutral and ionic $\mathrm{AnO}_{6}$ " section.

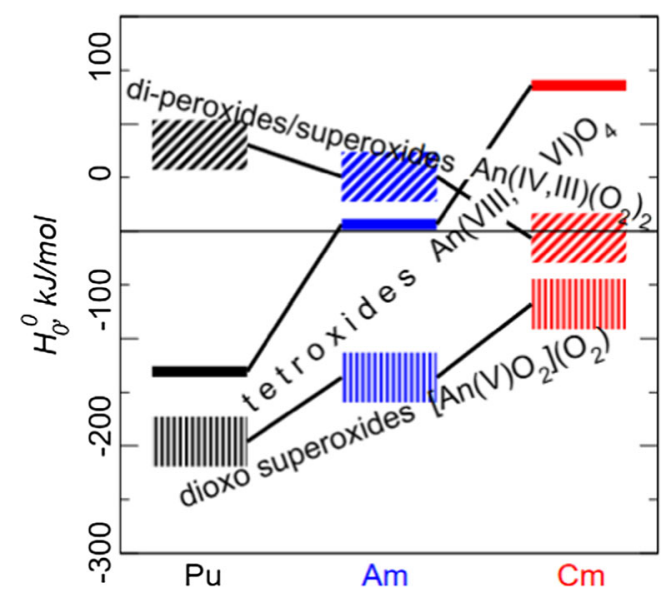

Fig. 9 Calculated dissociation enthalpies $\Delta \mathrm{H}^{\circ}{ }_{0}$ of various $\mathrm{AnO}_{4}$ isomers to $\mathrm{AnO}_{2}+\mathrm{O}_{2}$. Reproduced from [74] with permission from the PCCP Owner Societies

\section{$\mathrm{PaO}_{5}{ }^{-}, \mathrm{UO}_{5}, \mathrm{UO}_{5}{ }^{-}$, and $\mathrm{PuO}_{5}{ }^{-}$}

De Jong et al. computed $\mathrm{PaO}_{5}{ }^{-}$using the PBE0 functional and obtained a triplet ground electronic state [21]. The structure was a square-based pyramid with close to $\mathrm{C}_{2}$ symmetry (Fig. $10 \mathrm{~d}$ ). The data (computed energies, structures, vibrational frequencies) of the triplet and singlet states were given in the Supporting Information without discussion.

$\mathrm{UO}_{5}{ }^{-}$was prepared by reaction of laser vaporized uranium disk and $\mathrm{O}_{2}$ in He carrier gas and investigated using photoelectron spectroscopy and quantum chemical calculations [32]. In electron detachment experiments on $\mathrm{UO}_{5}{ }^{-}$, the neutral $\mathrm{UO}_{5}$ could be obtained, and in this way, the electron affinity of the latter molecule be measured, resulting in $4.02 \pm 0.06 \mathrm{eV}$ [32]. The electron affinities of uranium oxide molecules covered in the paper increase gradually in the $\mathrm{UO}_{3}<\mathrm{UO}_{4}<\mathrm{UO}_{5}$ row in good agreement with spin-orbit-coupled $\mathrm{CCSD}(\mathrm{T})$ energy calculations.

The structures of $\mathrm{UO}_{5}$ species were elucidated by B3LYP calculations [32]. Neutral $\mathrm{UO}_{5}$ can be derived from $\mathrm{UO}_{3}$ by $\eta^{1}$ - or $\eta^{2}$-coordination of an $\mathrm{O}_{2}$ molecule in the equatorial plane. The $\eta^{1} \mathrm{U}_{-} \mathrm{O}_{3}$ bond in the triplet global minimum structure (Fig. 10a) is very weak, as indicated both by the large U$\mathrm{O}_{3}$ and the $\mathrm{O}_{3}-\mathrm{O}_{3}$ ' bond distances, the latter being very close to that of free $\mathrm{O}_{2}$. The triplet superoxo $\left(\mathrm{UO}_{3}{ }^{+}\right)\left(\mathrm{O}_{2}{ }^{-}\right)$isomer with $\eta^{2}$-coordinated $\mathrm{O}_{2}$ molecule in the equatorial plane (Fig. 10b) was only by $24 \mathrm{~kJ} / \mathrm{mol}$ higher in energy according to $\operatorname{CCSD}(\mathrm{T})$ single-point calculations. The singlet pentakis-oxo isomer was much higher in energy (Fig. 10c, $254 \mathrm{~kJ} / \mathrm{mol}$ ) [32].

The B3LYP calculations on $\mathrm{UO}_{5}^{-}$predicted similar structures to those of the neutral $\mathrm{UO}_{5}$ molecule [32]. However, the $\operatorname{CCSD}(\mathrm{T})$ energy order of the $\eta^{1}$ - and $\eta^{2}$-isomers (Fig. 10a, b) was interchanged, where the $\eta^{1}-\mathrm{O}_{2}$ isomer was computed to be higher in energy by $71 \mathrm{~kJ} / \mathrm{mol}$. In the ${ }^{2} \mathrm{~A}^{\prime \prime}$ ground state, the unpaired electron occupies a molecular orbital of $\mathrm{O}(2 \mathrm{p})$ character in the $\eta^{2}-\mathrm{O}_{2}$ moiety. 


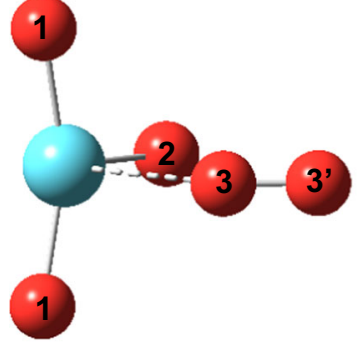

a



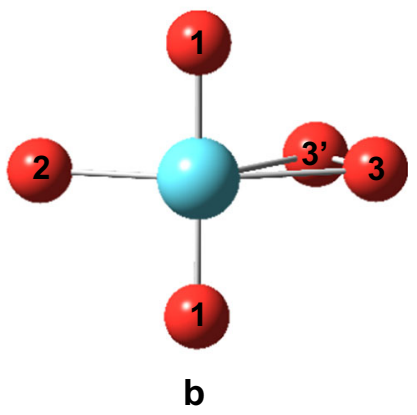

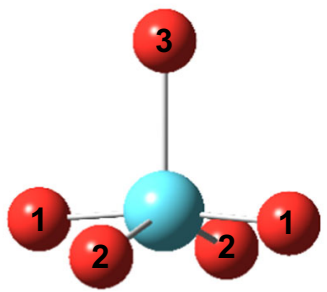

d
Fig. 10 Main structural isomers of neutral and ionic $\mathrm{AnO}_{5}$. An atoms are depicted in cyan, $\mathrm{O}$ in red

$\mathrm{Su}$ et al. performed also a comparative bonding analysis of

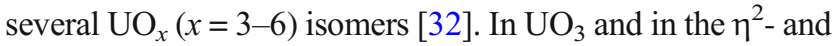
$\eta^{1}$-coordinated larger oxides, the uranyl moiety is preserved. In the tetra/penta/hexakis-oxide isomers with separate O ligands, however, the uranyl moiety is strongly deformed losing its linear character and decreasing the bond order. In the small $\mathrm{UO}_{3}{ }^{-}$anion the excess electron was found to be localized on the $\mathrm{U}$ atom, while in the larger anions $(x=4-6)$, it was localized on the $\mathrm{O}_{2}$ ligands. In all these oxides, the $\mathrm{U}$ atom had oxidation state VI.

De Jong et al. published DFT data (relative energies, geometries, vibrational frequencies) on doublet and quartet $\mathrm{UO}_{5}{ }^{-}$in the Supplementary Information of [21] without dis- cussion in the text. The optimized structure of both spin states was a square-based pyramid (Fig. 10d), differing from the $\eta^{1}$ and $\eta^{2}$-ones reported earlier by $\mathrm{Su}$ et al. [32] (vide supra). Different initial structures for the geometry optimization may be the reason for the discrepancy.

DFT data on $\mathrm{PuO}_{5}{ }^{-}$were published in [46]: relative energies and structures of three spin multiplicities (doublet, quartet, and sextet) can be found in the Supporting Information without discussion in the text. From the three states, the quartet one proved to be the most stable followed by the doublet and sextet at 3 and $21 \mathrm{~kJ} / \mathrm{mol}$, respectively. Similarly to the above results on the $\mathrm{UO}^{5-}$ ion by the same group [21], all the optimized structures correspond to square-based pyramids with $\mathrm{C}_{2 \mathrm{v}}$ symmetry (Fig. 10d). For comparison, selected geometrical parameters are given in Table 3 . The only significant difference is the considerable lengthening of the $\mathrm{Pu}-\mathrm{O}_{2}$ bond in the sextet, indicating a reduction of the $\mathrm{Pu}$ oxidation state.

\section{Neutral and ionic $\mathrm{AnO}_{6}$}

Hexacoordinated $\mathrm{U}$ is a frequent structural motif in solid $\mathrm{U}^{\mathrm{VI}}$ oxides, formally being $\mathrm{UO}_{6}{ }^{6-}$. The molecular hexakis-oxo $\mathrm{UO}_{6}{ }^{6-}$ anion (Fig. 11a) was studied using simple relativistic HF calculations by Pyykkö and Zhao [55] as part of the analysis of the trend in $\mathrm{U}-\mathrm{O}$ bond distances. The $\mathrm{UO}_{6}{ }^{6-}$ anion was found to be a minimum on the potential energy surface having cubic symmetry. The U-O bond distance is considerably increased with respect to square planar $\mathrm{UO}_{4}{ }^{2-}$ and, particularly, to $\mathrm{UO}_{2}{ }^{2+}$ calculated at the same level of theory. The study supported that the trend found in crystalline structures with different $\mathrm{UO}_{x}(x=2-6)$ coordinations is of intramolecular nature.

The octahedral isomer of neutral $\mathrm{UO}_{6}$ (Fig. 11a) seemed to be an appropriate model for the highest oxidation state of $U$

Table 3 Computed geometrical parameters of ground-state neutral and ionic $\mathrm{AnO}_{5}$ species

\begin{tabular}{|c|c|c|c|c|c|c|c|c|c|c|}
\hline $\mathrm{AnO}_{\mathrm{x}}$ & Fig. 10 & Sym & Method $^{\mathrm{a}}$ & State & $\mathrm{An}-\mathrm{O}_{1}$ & $\mathrm{An}-\mathrm{O}_{2}$ & $\mathrm{An}-\mathrm{O}_{3}$ & $\mathrm{O}_{3}-\mathrm{O}_{3}$ & $\mathrm{O}_{1} \mathrm{AnO}_{1}$ & Reference \\
\hline $\mathrm{PaO}_{5}^{-}$ & d & $\sim \mathrm{C}_{2}$ & PBE0/A & ${ }^{3} \mathrm{X}$ & $1.893 / 1.906$ & $2.205 / 2.217$ & 2.303 & - & 164.0 & {$[21]$} \\
\hline \multirow[t]{3}{*}{$\mathrm{UO}_{5}$} & $\mathrm{a}$ & $\mathrm{C}_{\mathrm{s}}$ & \multirow[t]{3}{*}{ B3LYP/A } & ${ }^{3} \mathrm{~A} "$ & 1.803 & 1.849 & 2.772 & 1.204 & 158.5 & \multirow[t]{3}{*}{ [32] } \\
\hline & $\mathrm{b}$ & $\mathrm{C}_{\mathrm{s}}$ & & ${ }^{3} \mathrm{~A}^{\prime}$ & 1.772 & 2.073 & $2.334 / 2.366$ & 1.305 & 174.0 & \\
\hline & $\mathrm{c}$ & $\mathrm{C}_{2 \mathrm{v}}$ & & ${ }^{1} \mathrm{~A}_{1}$ & 1.801 & 1.805 & 1.799 & - & 179.0 & \\
\hline \multirow[t]{4}{*}{$\mathrm{UO}_{5}^{-}$} & $\mathrm{b}$ & $\mathrm{C}_{\mathrm{s}}$ & \multirow[t]{2}{*}{ B3LYP/A } & ${ }^{2} \mathrm{~A} "$ & 1.840 & 1.892 & $2.416 / 2.466$ & 1.320 & 160.1 & \multirow[t]{2}{*}{ [32] } \\
\hline & $\mathrm{a}$ & $\mathrm{C}_{1}$ & & ${ }^{2} \mathrm{~A}$ & $1.835 / 1.837$ & 1.887 & 2.281 & 1.311 & 157.5 & \\
\hline & $\mathrm{d}$ & $\mathrm{C}_{2 \mathrm{v}}$ & \multirow[t]{2}{*}{ PBE0/A } & ${ }^{2} X$ & 1.834 & 1.868 & 2.180 & - & 169.1 & \multirow[t]{2}{*}{ [21] } \\
\hline & $\mathrm{d}$ & $\mathrm{C}_{2 \mathrm{v}}$ & & ${ }^{4} X$ & 1.795 & 2.136 & 2.220 & - & 169.3 & \\
\hline \multirow[t]{3}{*}{$\mathrm{PuO}_{5}^{-}$} & d & $\mathrm{C}_{2 \mathrm{v}}$ & \multirow[t]{3}{*}{ PBE0/A } & ${ }^{2} X$ & 1.785 & 1.789 & 2.186 & - & 176.9 & \multirow[t]{3}{*}[46]{} \\
\hline & $\mathrm{d}$ & $\mathrm{C}_{2 \mathrm{v}}$ & & ${ }^{4} X$ & 1.784 & 1.802 & 2.170 & - & 177.6 & \\
\hline & $\mathrm{d}$ & $\mathrm{C}_{2 \mathrm{v}}$ & & ${ }^{6} \mathrm{X}$ & 1.755 & 2.149 & 2.208 & - & 171.4 & \\
\hline
\end{tabular}

Bond distances are given in angstroms, bond angles in degrees. For the definition of atoms, see Fig. 10

${ }^{a}$ Basis set A means relativistic small-core pseudopotential. 


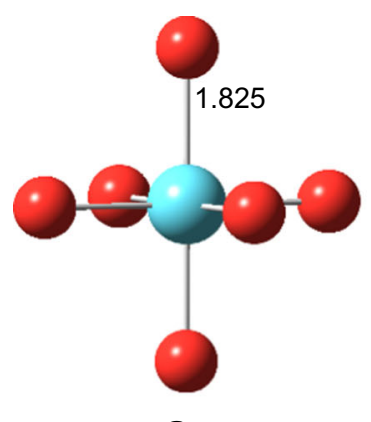

a
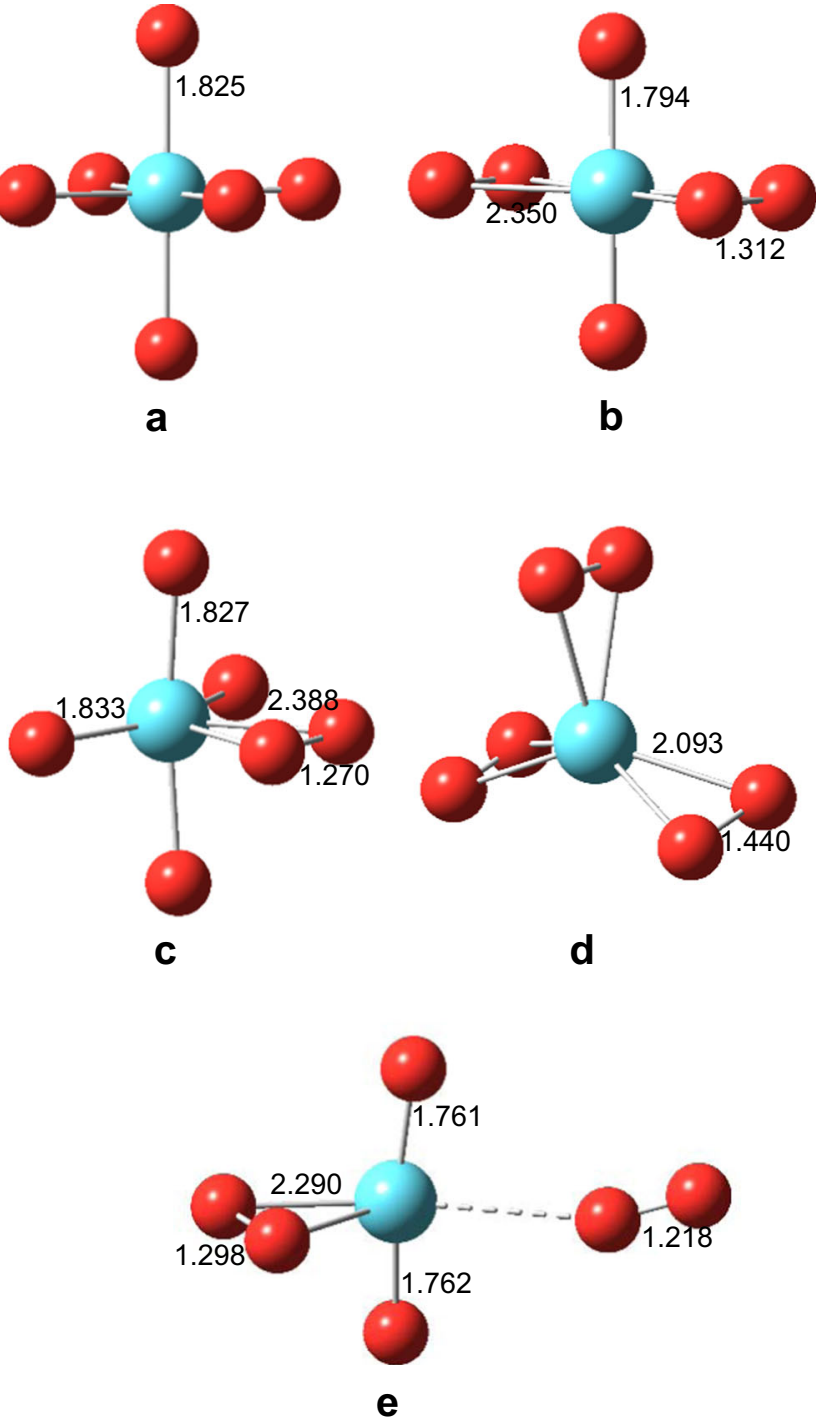

Fig. 11 Characteristic structures of neutral and ionic $\mathrm{AnO}_{6}$ with

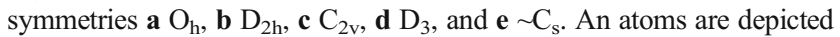
in cyan, $\mathrm{O}$ in red. $\mathrm{U}-\mathrm{O}$ bond distances $(\AA)$ from [79] $\left(\mathbf{a}-\mathbf{d}, \mathrm{UO}_{6}\right)$ and [62] $\left(\mathbf{e}, \mathrm{UO}_{6}{ }^{+}\right)$obtained by SO-PW91/B and PBE/A calculations, respectively

(probing $\mathrm{U}^{\mathrm{XII}}$ ) [78]. The computed bond distances at various quasirelativistic wavefunction theory and DFT levels agreed with U-O double bonds. However, the electronic structure was found to have some multiconfigurational character, therefore the necessity of multireference calculations was noted. Other structures were not considered in [78] but later studies showed that this hypothetical structure has no relevance.

Recent detailed relativistic DFT studies of Xiao et al. accompanied by single-point $\operatorname{CCSD}(\mathrm{T})$ energy calculations indicated the local minimum character of this ${ }^{1} \mathrm{~A}_{1 \mathrm{~g}}$ octahedral isomer lying very high (ca. $540 \mathrm{~kJ} / \mathrm{mol}$ ) in energy compared to the ${ }^{3} \mathrm{~B}_{2}$ uranyl peroxide form, $\mathrm{U}^{\mathrm{VI}} \mathrm{O}_{2}\left(\eta^{2}-\mathrm{O}_{2}\right)_{2}$ (Fig. 11b) [79]. Similar peroxide motifs exist in several uranium minerals [80]. Other high-energy isomers include the species ${ }^{3} \mathrm{~B}_{3 \mathrm{u}}$ $\mathrm{UO}_{4}\left(\eta^{2}-\mathrm{O}_{2}\right)$ and ${ }^{1} \mathrm{~A}_{1} \mathrm{U}\left(\eta^{2}-\mathrm{O}_{2}\right)_{3}$ (Fig. 11c, d) [79]. Such uranium peroxide molecules were earlier tentatively reported from experiment: two IR bands in the Ne matrix from deposition of laser ablated $\mathrm{U}$ with $\mathrm{O}_{2}$ were assigned to $\mathrm{UO}_{2}\left(\mathrm{O}_{2}\right)_{\mathrm{x}}$ species by Zhou et al. [27].

$\mathrm{UO}_{6}{ }^{+}$ions were produced in a supersonic molecular beam by laser vaporization of uranium in Ar containing a few percent of $\mathrm{O}_{2}$ [62]. In the obtained $\mathrm{UO}_{6}{ }^{+} \mathrm{Ar}_{2}$ gas-phase complex, due to the very weak effect of Ar atoms, the molecular parameters approximate well those of the isolated $\mathrm{UO}_{6}{ }^{+}$ion. The $\mathrm{UO}_{6}{ }^{+} \mathrm{Ar}_{2}$ complexes were excited with an IR-OPO laser system in the ranges of the O-U-O and O-O stretching vibrations. In the IR spectrum, three characteristic bands were observed, providing important clues on the structure of $\mathrm{UO}_{6}^{+}$: they were the asymmetric O-U-O stretching, the O-O stretching band of an $\eta^{2}$-coordinated $\mathrm{O}_{2}$, and that of an $\mathrm{O}_{2}$ interacting weakly with the $\mathrm{UO}_{2}\left(\eta^{2}-\mathrm{O}_{2}\right)^{+}$ion. The lack of the symmetric OUO stretching band suggested an O-U-O core closer to linear than in $\mathrm{UO}_{2}\left(\mathrm{O}_{2}\right)^{+}$. DFT calculations supported the end-on attachment of an $\mathrm{O}_{2}$ bonded by van der Waals forces to $\mathrm{U}$ (Fig. 11e) in the quartet electronic state.

The enthalpies of formation of $\mathrm{AnO}_{2}\left(\eta^{2}-\mathrm{O}_{2}\right)_{2}(\mathrm{An}=\mathrm{Pu}$, $\mathrm{Am}, \mathrm{Cm}$ ) molecules (Fig. 11b) from $\mathrm{AnO}_{2}\left(\eta^{2}-\mathrm{O}_{2}\right)$ were calculated using two-component relativistic DFT to be $-38,-44$, and $-19 \mathrm{~kJ} / \mathrm{mol}$, respectively. Other molecular data were not reported in [74].

\section{Neutral dimers and trimers}

In the solid phase, the actinides have generally high coordination numbers. In oxygen-containing inorganic and metalorganic compounds, $\mathrm{Th}^{\mathrm{IV}} \mathrm{O}_{x}$ polyhedra were found with $4 \leq$ $x \leq 12$ [81], while $\mathrm{U}^{\mathrm{VI}} \mathrm{O}_{x}$ polyhedra with $5 \leq x \leq 9$ [82]. Np and $\mathrm{Pu}$ in various (III, IV, V, VI, VII) oxidation states form $\mathrm{AnO}_{x}$ coordination polyhedra with $6 \leq x \leq 12$ [83,84]. The coordination of the heavier $\mathrm{Am}, \mathrm{Cm}, \mathrm{Bk}, \mathrm{Cf}$, and Es atoms in crystal structures amounts to $6 \leq x \leq 9[85,86]$. This high coordination occurs usually in the form of bridging An-O-An bonds.

Molecules with An-O-An bridging include the small neutral and cation-cation clusters. Such molecules have not been detected in the gaseous phase, yet the molecular parameters of various species were predicted by quantum chemical calculations. Their analysis at adequate theoretical levels revealed important information on the characteristics of An-O-An bonding.

\section{U-oxide clusters}

Yang et al. carried out a detailed survey of the potential energy surfaces of $\mathrm{U}_{2} \mathrm{O}_{n}(n=1-6)$ and $\mathrm{U}_{3} \mathrm{O}_{m}(m=1-9)$ clusters [33]. The calculations were performed with the VASP code developed for periodic systems [87], but with appropriate parameter settings able to model isolated molecular systems too. The 
paper lacked calculated Hessians or vibrational frequencies; therefore, the results of [33] should be treated with caution until confirmation of the minimum characters. Nevertheless, the geometries of the monomer $\mathrm{UO}, \mathrm{UO}_{2}$ and $\mathrm{UO}_{3}$ molecules were reproduced well by the DFT calculations using the HSE06 functional. As the present review covers $\mathrm{An}^{2 \mathrm{~V}}$ oxidation states, only the most stable dimer $\mathrm{U}_{2} \mathrm{O}_{n}(n=5-6)$ and trimer $\mathrm{U}_{3} \mathrm{O}_{m}(m=7-9)$ structures are presented. They were reproduced by B3LYP calculations (using the Gaussian09 code) in the present work and the calculated vibrational frequencies confirmed their minimum characters.

The discussed low-energy structures do not have any U-U bonding (cf. Figs. 12, 13, 14, 15, and 16), the $U$ atoms are connected by U-O-U bridges with U-O distances between 1.9 and $2.4 \AA$. Particularly interesting are the terminal oxo groups with U-O bonds of around $1.8 \AA$ : they are mostly involved in quasilinear uranyl moieties where the bridging U-O components have bond distances increased to ca. $1.9 \AA$.

All the found most stable dimer structures have at least two U-O-U bridges [33]. The lowest-energy structure of $\mathrm{U}_{2} \mathrm{O}_{5}$ has $\mathrm{C}_{2}$ symmetry with three $\mathrm{U}-\mathrm{O}-\mathrm{U}$ bridges and one terminal oxo group on each $\mathrm{U}$ atom (Fig. 12a). The double-bridged $\mathrm{C}_{\mathrm{s}}$ structure with a terminal oxo group and a perpendicular uranyl moiety (Fig. 12b) proved to be a local minimum somewhat higher (by $28 \mathrm{~kJ} / \mathrm{mol}$ ) in energy.

The double-bridged lowest-energy structure of $\mathrm{U}_{2} \mathrm{O}_{6}[33]$ has $\mathrm{D}_{2 \mathrm{~h}}$ symmetry and has two quasi-linear terminal uranyl moieties perpendicular to the bridging U-O-U plane (Fig. 13a). It can be derived from $\mathrm{T}$-shaped $\mathrm{UO}_{3}$ molecules by bonding through the

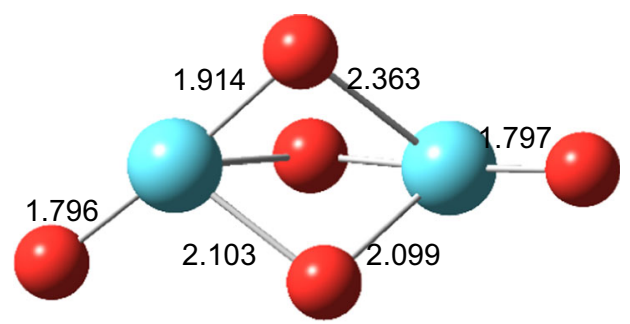

a

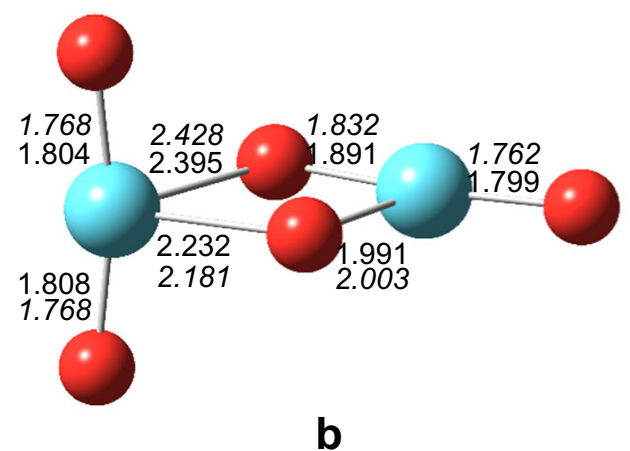

Fig. 12 Characteristic structures of $\mathrm{An}_{2} \mathrm{O}_{5}$ with symmetries $\mathbf{a} \mathrm{C}_{2}$ and $\mathbf{b}$ $\mathrm{C}_{\mathrm{s}}$. An atoms are depicted in cyan, $\mathrm{O}$ in red. Bond distances $(\AA)$ from SOHSE06 calculations in [33] (U) and [88] (Pu, italics)

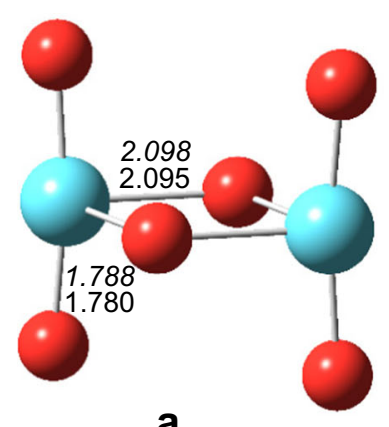

a
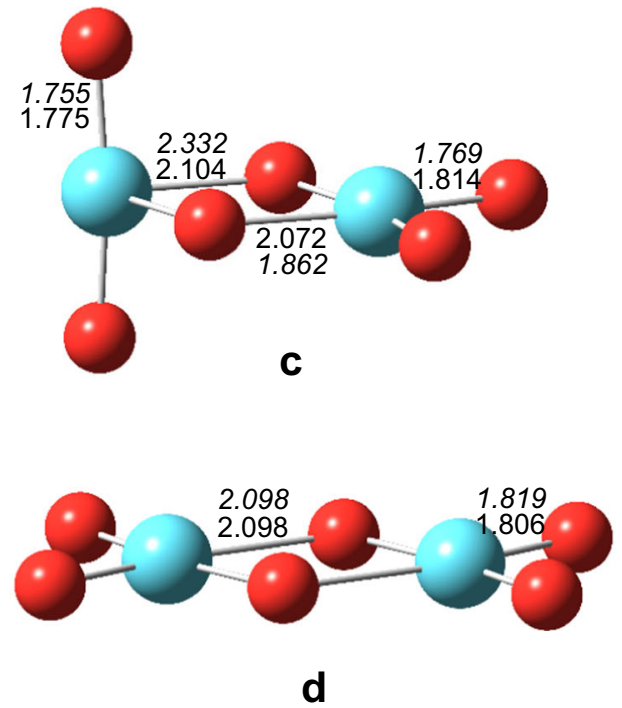

Fig. 13 Characteristic structures of $\mathrm{An}_{2} \mathrm{O}_{6}$ with symmetries a $\mathrm{D}_{2 \mathrm{~h}}, \mathrm{C}_{2 \mathrm{v}} ; \mathbf{b}$ $\mathrm{C}_{2 \mathrm{v}} ; \mathbf{c} \mathrm{C}_{2 \mathrm{v}}$; and $\mathbf{d} \mathrm{C}_{2 \mathrm{~h}}$. An atoms are depicted in cyan, $\mathrm{O}$ in red. Bond distances $(\AA)$ in structures a, c, and $\mathbf{d}$ from SO-HSE06 calculations in [33] $(\mathrm{U})$ and $[88](\mathrm{Pu}$, italics). Bond distances in structure $\mathbf{b}$ from SO-PBE0/A calculations in [49] (Am plain, Bk italics)

equatorial oxygens. The monomeric equatorial U-O bond distance of ca. $1.85 \AA$ was increased to ca. $2.1 \AA$ in the bridge. Interesting (symmetric) low-energy minima are formed by turning the terminal uranyl moieties into the U-O-U plane (Fig. $13 \mathrm{c}, \mathrm{d})$ accompanied by a drastic decrease of the ca. $165^{\circ}$ terminal uranyl bond angles to ca. $100^{\circ}$, the latter resembling those of the planar $\mathrm{UO}_{4}$ species. These changes, however, had marginal effect on the U-O bond distances (cf. Fig. 13).

The lowest-energy $\mathrm{U}_{3} \mathrm{O}_{m}(m=7-9)$ structures have compact character in which the three $U$ atoms are arranged as peaks of a triangle connected by three or four bridging oxygens [33]. In $\mathrm{U}_{3} \mathrm{O}_{7}$ (slightly deformed from $\mathrm{C}_{3}$ symmetry), each $\mathrm{U}$ atom has one terminal oxo group (Fig. 14a), in the triple-bridged $\mathrm{U}_{3} \mathrm{O}_{9}$ with $\mathrm{C}_{2 \mathrm{v}}$ symmetry each $\mathrm{U}$ atom is involved in quasilinear O-U-O moieties (Fig. 14c), while in the four-bridged asymmetric $\mathrm{U}_{3} \mathrm{O}_{8}$, an intermediate situation with two oxo groups and one quasilinear terminal O-U-O moiety is formed (Fig. 14b). The terminal oxo groups in these structures can be 




a

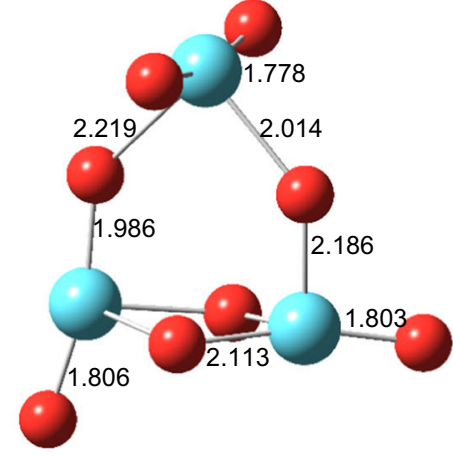

b

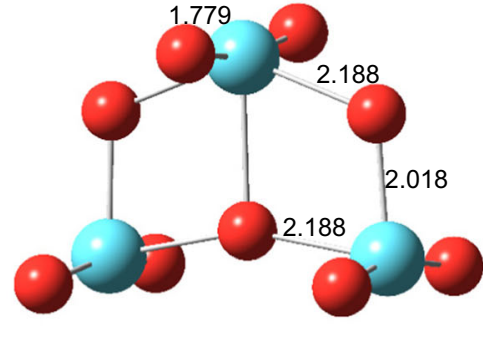

C

Fig. 14 Characteristic structures of $\mathbf{a} \mathrm{U}_{3} \mathrm{O}_{7}\left(\sim \mathrm{C}_{3}\right), \mathbf{b} \mathrm{U}_{3} \mathrm{O}_{8}\left(\mathrm{C}_{1}\right)$, and $\mathbf{c} \mathrm{U}_{3} \mathrm{O}_{9}\left(\mathrm{C}_{2 \mathrm{v}}\right)$. $\mathrm{U}$ atoms are depicted in cyan, $\mathrm{O}$ in red. Bond distances $(\AA)$ from $\mathrm{SO}-$ HSE06 calculations in [33]

considered as components of quasilinear uranyl moieties with lengthened bridging U-O distances. The above structures have several low-energy $(2-100 \mathrm{~kJ} / \mathrm{mol})$ isomers (see [33]) with three or four U-O-U bridges.

The shown lowest-energy dimer and trimer structures had singlet spin multiplicities except for $\mathrm{U}_{3} \mathrm{O}_{7}$, which was triplet. (Note that the $\mathrm{M}$ values in the figure captions of [33] correspond to spin polarization instead of spin multiplicity.) Most low-lying states were singlets too, the triplets were characteristic only on the low-energy $\mathrm{U}_{3} \mathrm{O}_{7}$ and $\mathrm{U}_{3} \mathrm{O}_{8}$ species, which consist of formally mixed-valence $\mathrm{U}$ atoms. The calculated dissociation energies of the clusters were between 200 and $380 \mathrm{~kJ} / \mathrm{mol}$. Clusters with U/O ratios between 2 and 2.5 were computed to be the most stable, in agreement with the solidphase experience that the $\mathrm{UO}_{2+x}$ hyperoxides are energetically

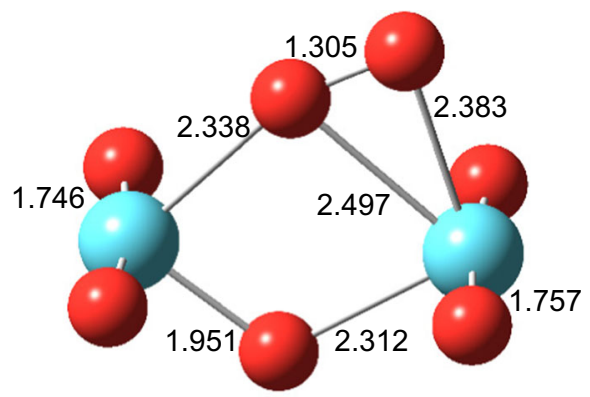

a

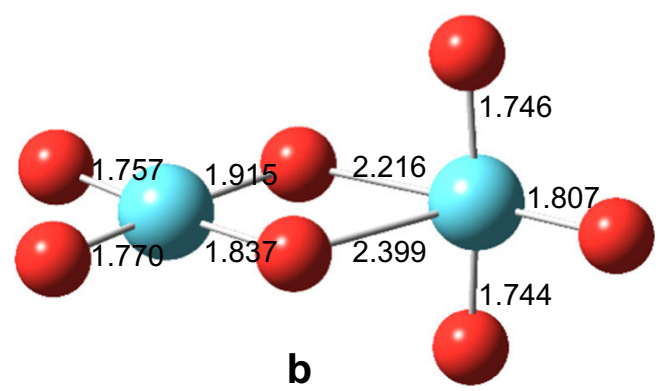

Fig. 15 Characteristic structures of $\mathrm{An}_{2} \mathrm{O}_{7}(\mathrm{An}=\mathrm{Pu}, \mathrm{Am})$ with $\mathrm{C}_{\mathrm{s}}$ symmetry. An atoms are depicted in cyan, $\mathrm{O}$ in red. The bond distances of $\mathrm{Pu}_{2} \mathrm{O}_{7}(\AA)$ are from SO-HSE06 calculations in [88] stable. In the study [33], electronic energy levels were also determined using the orbital-resolved projected density of states model.



a


Fig. 16 Characteristic structures of $\mathrm{An}_{2} \mathrm{O}_{8}$ with symmetries $\mathbf{a}, \mathbf{b} \mathrm{C}_{2 \mathrm{~h}}$ and c $\mathrm{C}_{2 \mathrm{v}}$. An atoms are depicted in cyan, $\mathrm{O}$ in red. The bond distances of $\mathrm{Pu}_{2} \mathrm{O}_{8}(\AA)$ are from SO-HSE06 calculations in [88] 


\section{Dimers of Pu and Am oxides}

Symmetric dimer structures of neutral $\mathrm{Pu}$ and $\mathrm{Am}$ oxides with compositions $\mathrm{Pu}_{2} \mathrm{O}_{6}, \mathrm{Am}_{2} \mathrm{O}_{6}, \mathrm{Pu}_{2} \mathrm{O}_{7}, \mathrm{Am}_{2} \mathrm{O}_{7}, \mathrm{Pu}_{2} \mathrm{O}_{8}$, and mixed ones $\mathrm{PuAmO}_{6}, \mathrm{PuAmO}_{7}$, and $\mathrm{PuAmO}_{8}$ were first computed by Zaitsevskii et al. [40, 41]. The ground-state character was checked by swapping higher occupied and lower virtual orbitals, while the minimum character of the structures was confirmed by calculation of the Hessian matrices. However, no spin multiplicities and other details of the electronic structure were reported, which can make a comparison with other related studies difficult.

In all of these structures the actinide atoms are connected by two bridging oxygens. Computation of the $\mathrm{AnO}_{3}$ and $\mathrm{AnO}_{4}$ monomers in the same study [41] facilitated a straightforward assessment of the geometrical changes upon dimer formation. A common feature of most studied dimer structures was that the $\mathrm{AnO}_{2}$ actinyl moieties of the monomers were retained, only slight changes in these $\mathrm{O}-\mathrm{An}-\mathrm{O}$ angles and An-O distances were observed.

The $\mathrm{D}_{2 \mathrm{~h}}$ structures of $\mathrm{Pu}_{2} \mathrm{O}_{6}$ and $\mathrm{Am}_{2} \mathrm{O}_{6}$ agreed with the global minimum structure of $\mathrm{U}_{2} \mathrm{O}_{6}$ (Fig. 13a) by Yang et al. [33]. Upon dimer formation the equatorial $\mathrm{Pu}-\mathrm{O}$ bond of the monomer was increased considerably (by ca. $0.2 \AA$ ) while the Am-O bond only marginally (by $0.01 \AA$ ). The replacement of the equatorial $\mathrm{Pu}-\mathrm{O}$ formal double bond of $\mathrm{PuO}_{3}$ by two $\mathrm{Pu}-\mathrm{O}$ formal single bonds in the dimer confirmed that the hexavalent character of $\mathrm{Pu}$ is retained in $\mathrm{Pu}_{2} \mathrm{O}_{6}$. On the other hand, the $\mathrm{Am}^{\mathrm{V}}$ oxidation state in the monomer increased to $\mathrm{Am}^{\mathrm{VI}}$ in the dimer due to the two bridging Am-O single bonds attached to the americyl moieties. The structure of the heterooxide $\mathrm{PuAmO}_{6}$ resembled those of $\mathrm{Pu}_{2} \mathrm{O}_{6}$ and $\mathrm{Am}_{2} \mathrm{O}_{6}$ with the $\mathrm{D}_{2 \mathrm{~h}}$ symmetry lowered to $\mathrm{C}_{2 \mathrm{v}}$ and slight changes observed in the geometrical parameters. The calculated dissociation enthalpy was somewhat larger than the average of the respective homodimers.

In a subsequent study Zaitsevskii probed two isomer structures for $\mathrm{Pu}_{2} \mathrm{O}_{6}, \mathrm{Am}_{2} \mathrm{O}_{6}$, and $\mathrm{Bk}_{2} \mathrm{O}_{6}$ [49]. While for $\mathrm{Pu}_{2} \mathrm{O}_{6}$ the calculated enthalpy of dissociation to monomers supported the global minimum character of the above shown $\mathrm{D}_{2 \mathrm{~h}}$ isomer [40, 41], for $\mathrm{Am}_{2} \mathrm{O}_{6}$ and $\mathrm{Bk}_{2} \mathrm{O}_{6}$, a new $\mathrm{C}_{2 \mathrm{v}}$ structure (Fig. 13b) was found to be more stable. This isomer has an $\eta^{2}-\mathrm{O}_{2}$ peroxide moiety between the actinyl groups, while the geometrical parameters resemble in character those in the oxoperoxide monomers. Accordingly, the oxidation states in this dimer structure, $\mathrm{Am}^{\mathrm{V}}$ and $\mathrm{Bk}^{\mathrm{V}}$, agreed with those in their $\mathrm{T}$-shaped monomers.

Recently, Zhang et al. [88] performed a detailed survey of the potential energy surfaces of $\mathrm{Pu}_{2} \mathrm{O}_{x}(x=1-8)$ molecules using the same computational techniques like in their earlier $\mathrm{U}_{2} \mathrm{O}_{x}(x=1-6)$ paper [33], vide supra. Beyond several lowenergy structures and their energies, favorable fragmentation channels, Bader atomic charges and orbital resolved projected densities of states were reported. However, lacking appropriate information, the minimum characters of the optimized structures are unclear, similarly the characters of the obtained electronic states. The latter issue is rather critical in the case of $\mathrm{Pu}$-containing compounds, because softwares can converge from the initial guesses to low-lying excited electronic states, which can have significantly different structures from those of the ground states. In order to verify the lowest-energy structures from [88] for this review, they were reproduced in this work by B3LYP calculations (using the Gaussian 09 code). Application of the keyword Stable supported the ground-state character of the structures discussed in this review, while the frequency analyses confirmed the minimum characters on the potential energy surfaces (except for one structure, vide supra). However, a few differences were obtained in the spin multiplicities: while the $\mathrm{Pu}_{2} \mathrm{O}_{6}, \mathrm{Pu}_{2} \mathrm{O}_{7}, \mathrm{Pu}_{2} \mathrm{O}_{8}$ ground states in [88] were characterized as singlets (with the $\mathrm{M}$ values in the figure captions taken as spin polarization), the present B3LYP calculations predicted triplet ground states for $\mathrm{Pu}_{2} \mathrm{O}_{6}$ and $\mathrm{Pu}_{2} \mathrm{O}_{8}$.

The ground-state structure of $\mathrm{Pu}_{2} \mathrm{O}_{5}$ [88] agreed in character with that of the low-energy $\mathrm{U}_{2} \mathrm{O}_{5}$ isomer in Fig. $12 \mathrm{~b}$ from [33]. A triple-bridged structure, most stable for $\mathrm{U}_{2} \mathrm{O}_{5}$ (cf. Fig. 12a), was not found for $\mathrm{Pu}_{2} \mathrm{O}_{5}$. Instead, several high-energy ones were reported which contain an $\mathrm{O}_{2}$ moiety.

For $\mathrm{Pu}_{2} \mathrm{O}_{6}$, the HSE06 calculations of Zhang et al. [88] resulted in a different energy ordering with respect to the results in $[40,41]$. The lowest-energy $\mathrm{Pu}_{2} \mathrm{O}_{6}$ structure was the $\mathrm{C}_{2 \mathrm{v}}$ isomer shown in Fig. 13c, while the $\mathrm{D}_{2 \mathrm{~h}}$ one (Fig. 13a, most stable in $[40,41]$ ) proved to be slightly higher (by 13.5 $\mathrm{kJ} / \mathrm{mol}$ ) in energy. The discrepancy may be due to the different theoretical levels and the case should be clarified with more sophisticated calculations.

For $\mathrm{Pu}_{2} \mathrm{O}_{7}$, Zhang et al. [88] obtained a $\mathrm{C}_{\mathrm{s}}$ ground-state structure with two parallel actinyl moieties connected by two bridging oxygens, where one oxygen is part of a superoxo moiety (Fig. 15a). A characteristic local minimum (Fig. 15b, higher in energy by $57 \mathrm{~kJ} / \mathrm{mol}$ [88]) is composed of $\mathrm{AnO}_{4}+\mathrm{AnO}_{3}$ moieties by bonding of two $\mathrm{AnO}_{4}$ oxygens to $\mathrm{An}$ in the equatorial plane of $\mathrm{AnO}_{3}$. Zaitsevskii et al. considered only the latter local minimum structure for both $\mathrm{Pu}_{2} \mathrm{O}_{7}$ [40, 41], $\mathrm{Am}_{2} \mathrm{O}_{7}$ and the mixed $\mathrm{PuAmO}_{7}$ [41]. On the basis of the high energy of the $\mathrm{Pu}_{2} \mathrm{O}_{7}$ local minimum (vide supra), this structure may not correspond to the ground-state global minimum form of $\mathrm{Am}_{2} \mathrm{O}_{7}$ and $\mathrm{PuAmO}_{7}$ either. Zaitsevskii et al. found $\mathrm{Pu}_{2} \mathrm{O}_{7}$ to have a remarkable stability [40, 41], that of $\mathrm{Am}_{2} \mathrm{O}_{7}$ was somewhat lower [41].

For $\mathrm{Pu}_{2} \mathrm{O}_{8}$, the HSE06 calculations predicted a doublebridged structure close to $\mathrm{C}_{2 \mathrm{~h}}$ symmetry consisting of two $\mathrm{PuO}_{2}\left(\mathrm{O}_{2}\right)$ moieties (Fig. 16a) [88] as most stable. The bonding is analogous to the one observed in the $\mathrm{Pu}_{2} \mathrm{O}_{7}$ ground state, where the bridging oxygen is part of a superoxo moiety. The isomer consisting of two facing $\mathrm{PuO}_{4}$ moieties (Fig. 16b) studied in [41] was found by Zhang et al. [88] considerably higher in energy $(126 \mathrm{~kJ} / \mathrm{mol})$. In the latter study, a $\mathrm{C}_{2 \mathrm{v}}$ structure with perpendicular $\mathrm{PuO}_{4}$ arrangement (Fig. 16c) [88] was predicted to be quasi-degenerate with the ground-state structure. According 
to frequency calculations in the present study, this structure is a saddle-point on the potential energy surface.

Calculations on $\mathrm{Am}_{2} \mathrm{O}_{8}$ could not be found in the literature. For the $\mathrm{PuAmO}_{8}$ heterodimer a structure with facing $\mathrm{PuO}_{4}$ and $\mathrm{AmO}_{4}$ moieties (Fig. 16b) was reported, pointing out its very low stability [41]. The structure in Fig. 16a was not probed for $\mathrm{PuAmO}_{8}$. In addition to the structure and bonding, the thermochemistry of the formation of the presented dimers from the monomer oxides as well as from each other was evaluated in [41].

\section{Dimers from CCls}

Cation-cation interactions (CCIs) can appear between highly polarized ionic molecules, hence between actinyl cations and their derivatives too. Although the oxo ligand is usually seen as chemically inert, the negatively charged oxygens can interact with the metal cation center of another actinyl moiety. CCIs between $\mathrm{AnO}_{2}{ }^{\mathrm{n}+}$ ions (mainly $\mathrm{UO}_{2}{ }^{+}$and $\mathrm{NpO}_{2}{ }^{+}$) have been widely observed in solutions [89-95] and in inorganic solid compounds [96-99]. The sizes of CCI oligomers reach usually from dimers to tetramers in solution [100] while in the solid state up to three-dimensional frameworks [98]. The interaction strongly affects the structural and electronic properties and can well be recognized in the UV-Vis and IR spectra.

Quantum chemical modelling of CCIs in the gaseous and aqueous phases was restricted to the dications. They appear in two isomer forms, shown in Fig. 17. Selected geometrical parameters are compiled in Table 4.

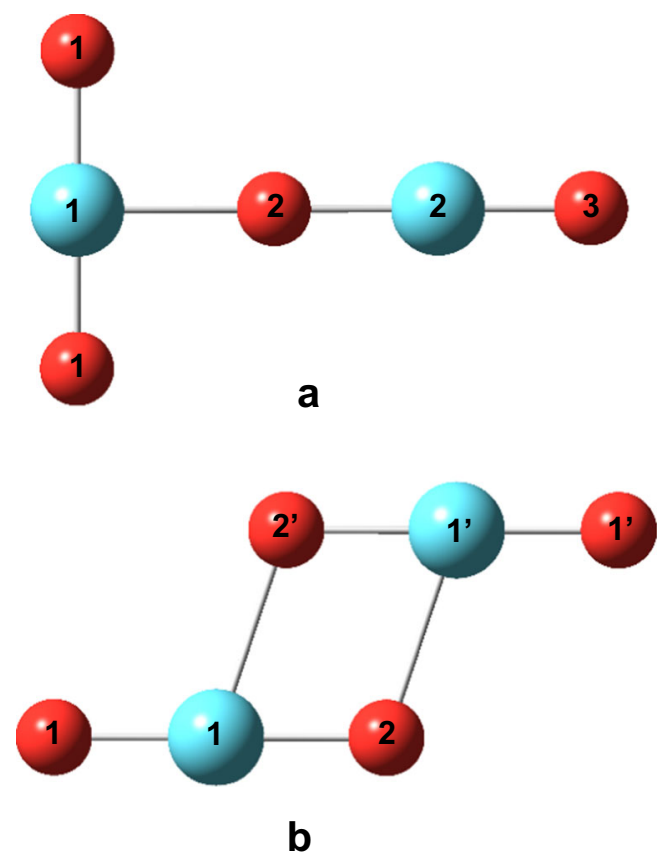

Fig. 17 The a T- $\left(\mathrm{C}_{2 \mathrm{v}}\right)$ and $\mathbf{b}$ diamond-shaped $\left(\mathrm{C}_{2 \mathrm{~h}}\right)$ structures of $\left(\mathrm{AnO}_{2}\right)_{2}{ }^{\mathrm{n}+} \mathrm{CCI}$ dimers. An atoms are depicted in cyan, $\mathrm{O}$ in red
An early quasirelativistic calculation of the $\left(\mathrm{UO}_{2}\right)_{2}{ }^{2+}$ dimer by Pyykkö and Zhao [55] predicted a week interaction between $\mathrm{U}$ and $\mathrm{O}$ of two facing cations with a distance of $2.386 \AA$ (in good agreement with the sum of covalent single bond radii of $U$ and $O, 2.33 \AA$ [101]). The probed diamondshaped structure (Fig. 17b) was subjected to a partial optimization (distances and angles between two constrained $\mathrm{UO}_{2}{ }^{+}$ monomers) only.

Isolated and solvated CCIs between various actinyl cations were modelled by DFT calculations using the COSMO solvation model [102]. Because in solution only T-shaped structures were observed [96], the geometry optimizations were restricted to this $\mathrm{C}_{2 \mathrm{v}}$ isomer (Fig. 17a). Beside the electrostatic attraction between the negatively charged oxygen and the partially positive An, a contribution to the bonding from molecular orbital interactions (in the form of donation/ backdonation) was also observed. The formation of CCI complexes in the gaseous phase proved to be endothermic in terms of absolute energies at $0 \mathrm{~K}$. Solvation favored the complexes $\left(\mathrm{NpO}_{2}\right)_{2}{ }^{2+}(\mathrm{aq})$ and $\left(\mathrm{NpO}_{2}\right)_{2}{ }^{3+}(\mathrm{aq})$ over the solvated monocations $\mathrm{NpO}_{2}{ }^{+}(\mathrm{aq})$ and $\mathrm{UO}_{2}{ }^{2+}(\mathrm{aq})$. For $\left(\mathrm{UO}_{2}\right)_{2}{ }^{4+}$, the $\mathrm{T}$-shaped structure could not be obtained as a minimum in the gas-phase calculations, explained by the large intrinsic electrostatic repulsion between the units. The large solvation effects could though stabilize the $\left(\mathrm{UO}_{2}\right)_{2}{ }^{4+}$ dimer, but its formation was still endothermic. Explicit consideration of the first solvation shell at a lower DFT level resulted in a qualitative agreement with the COSMO approach.

The CCI dimers formed by uranyl(VI) and uranyl(V) were investigated by Tecmer et al. by scalar relativistic DFT calculations using the COSMO solvation model [103]. The reported relative stabilities obtained by most functionals indicated the significant preference of the T-shaped structures (Fig. 17a) for the most stable spin multiplicities: the triplet $\left(\mathrm{UO}_{2}\right)_{2}{ }^{2+}$, doublet $\left(\mathrm{UO}_{2}\right)_{2}{ }^{3+}$, and singlet $\left(\mathrm{UO}_{2}\right)_{2}{ }^{4+}$. The structural characteristics were analyzed on the basis of BP86 calculations. The study confirmed the characteristic significant elongation of the donor UO bonds in both structures upon CCI. The general trend observed for the studied species was the increase of the inter-unit U-O bond with increasing charge. According to the calculated electronic transitions, the spectral characteristics of the $\mathrm{UO}_{2}{ }^{2+}$ and $\mathrm{UO}_{2}{ }^{+}$building blocks would largely preserved for the CCI dimers, facilitating the identification of the oxidation state of the $\mathrm{U}$ atom in solutions containing $\mathrm{CCI}$ clusters.

Compounds with diamond-shaped (Fig. 17b) neptunyl CCI dimer motifs are very rare in the nature. Examples found in the solid phase include $\left.\mathrm{Na}_{4}\left[\mathrm{NpO}_{2}\right)_{2} \mathrm{C}_{12} \mathrm{O}_{12}\right] \cdot 8 \mathrm{H}_{2} \mathrm{O}$ [104] and $\mathrm{K}\left[\left(\mathrm{NpO}_{2}\right)(\mathrm{OH})_{2}\right] \cdot 2 \mathrm{H}_{2} \mathrm{O}$, the latter being the first $2 \mathrm{D}$ neptunyl structure stabilized by side-on CCI [105]. In the latter paper, Gagliardi et al. investigated the electronic structure of various diamond-shaped neptunyl CCI dimer models including also the simple $\left(\mathrm{NpO}_{2}\right)_{2}{ }^{2+}$ ion using DFT and multiconfigurational 
Table 4 Computed geometrical parameters of ground-state T- and diamond (D)-shaped CCI dimers

\begin{tabular}{|c|c|c|c|c|c|c|c|c|c|c|c|}
\hline$\left(\mathrm{AnO}_{2}\right)_{2}{ }^{\mathrm{n}+}$ & Shape & M & Method $^{\mathrm{a}}$ & $\mathrm{An}_{1}-\mathrm{O}_{1}$ & $\mathrm{An}_{1}-\mathrm{O}_{2}$ & $\mathrm{An}_{1}-\mathrm{O}_{2}$ & $\mathrm{An}_{2}-\mathrm{O}_{2}$ & $\mathrm{An}_{2}-\mathrm{O}_{3}$ & $\mathrm{O}_{1} \mathrm{An}_{1} \mathrm{O}_{1}$ & $\mathrm{O}_{1} \mathrm{An}_{1} \mathrm{O}_{2}$ & Reference \\
\hline \multirow[t]{4}{*}{$\left(\mathrm{UO}_{2}\right)_{2}{ }^{2+}$} & $\mathrm{D}$ & 1 & $\mathrm{HF} / \mathrm{C}$ & $1.712^{\mathrm{b}}$ & $1.712^{\mathrm{b}}$ & 2.386 & - & - & $180^{\mathrm{b}}$ & 102.5 & {$[55]$} \\
\hline & $\mathrm{T}$ & 3 & BP86/A & 1.79 & 2.32 & - & 1.87 & 1.78 & 178 & 91 & [103] \\
\hline & $\mathrm{D}$ & 3 & & 1.79 & 1.92 & 2.28 & - & - & 180 & 107 & \\
\hline & $\mathrm{T}$ & 3 & $\operatorname{CCSD}(\mathrm{T}) / \mathrm{B}$ & 1.767 & 2.720 & - & 1.820 & 1.741 & 174.3 & 87.3 & [108] \\
\hline \multirow[t]{3}{*}{$\left(\mathrm{UO}_{2}{ }^{2+} \mathrm{UO}_{2}^{+}\right)$} & $\mathrm{T}$ & 2 & BP86/A & 1.75 & 2.28 & - & 1.86 & 1.75 & 179 & 91 & [103] \\
\hline & $\mathrm{D}$ & 2 & & 1.74 & 1.85 & 2.33 & - & - & 181 & 109 & \\
\hline & $\mathrm{T}$ & 2 & $\operatorname{CCSD}(\mathrm{T}) / \mathrm{B}$ & 1.710 & 2.446 & - & 1.906 & 1.727 & 180.0 & 90.0 & [108] \\
\hline \multirow[t]{3}{*}{$\left(\mathrm{UO}_{2}\right)_{2}{ }^{4+}$} & $\mathrm{T}$ & 1 & BP86/A & 1.73 & 2.49 & - & 1.77 & 1.71 & 177 & 92 & {$[103]$} \\
\hline & $\mathrm{D}$ & 1 & & 1.72 & 1.81 & 2.38 & - & - & 179 & 110 & \\
\hline & $\mathrm{T}$ & 1 & BPW91/B & 1.740 & 2.491 & - & 1.908 & 1.771 & 180.0 & 90.0 & {$[102]$} \\
\hline \multirow[t]{3}{*}{$\left(\mathrm{UO}_{2}{ }^{2+} \mathrm{NpO}_{2}^{+}\right)$} & $\mathrm{T}$ & 3 & BPW91/B & 1.730 & 2.465 & - & 1.893 & 1.727 & 180.0 & 90.0 & {$[102]$} \\
\hline & $\mathrm{T}$ & 3 & $\mathrm{c}$ & 1.748 & 2.233 & - & 1.885 & 1.773 & 180.0 & 90.0 & \\
\hline & $\mathrm{T}$ & 3 & $\operatorname{CCSD}(\mathrm{T}) / \mathrm{B}$ & 1.709 & 2.469 & - & 1.874 & 1.709 & 179.9 & 89.9 & [108] \\
\hline \multirow[t]{2}{*}{$\left(\mathrm{NpO}_{2}{ }^{2+} \mathrm{UO}_{2}^{+}\right)$} & $\mathrm{T}$ & 3 & BPW91/B & 1.728 & 2.455 & - & 1.898 & 1.729 & 180.0 & 90.0 & [102] \\
\hline & $\mathrm{T}$ & 3 & $\mathrm{c}$ & 1.748 & 2.233 & - & 1.886 & 1.773 & 180.0 & 90.0 & \\
\hline \multirow[t]{8}{*}{$\left(\mathrm{NpO}_{2}\right)_{2}{ }^{2+}$} & $\mathrm{T}$ & 5 & BPW91/B & 1.755 & 2.621 & - & 1.828 & 1.744 & 180.0 & 90.0 & {$[102]$} \\
\hline & $\mathrm{T}$ & 5 & $\mathrm{c}$ & 1.795 & 2.384 & - & 1.838 & 1.782 & 180.0 & 90.0 & \\
\hline & $\mathrm{D}$ & 5 & $\mathrm{PBE} / \mathrm{A}$ & 1.78 & 1.86 & 2.38 & - & - & 176.2 & 102.8 & {$[105]$} \\
\hline & $\mathrm{T}$ & 5 & BP86/A & 1.747 & 2.500 & - & 1.851 & 1.741 & 180 & 90 & {$[106]$} \\
\hline & $\mathrm{T}$ & 5 & $\mathrm{c}$ & 1.781 & 2.211 & - & 1.841 & 1.717 & 180 & 90 & \\
\hline & $\mathrm{D}$ & 5 & & 1.739 & 1.852 & 2.433 & - & - & 183 & 109 & \\
\hline & $\mathrm{D}$ & 5 & $\mathrm{c}$ & 1.770 & 1.860 & 2.379 & - & - & 182 & 107 & \\
\hline & $\mathrm{T}$ & 5 & $\operatorname{CCSD}(\mathrm{T}) / \mathrm{B}$ & 1.731 & 2.725 & - & 1.794 & 1.721 & 177.9 & 89.0 & [108] \\
\hline \multirow[t]{2}{*}{$\left(\mathrm{NpO}_{2}{ }^{2+} \mathrm{NpO}_{2}^{+}\right)$} & $\mathrm{D}$ & 4 & $\mathrm{BP} 86 / \mathrm{A}^{\mathrm{c}}$ & 1.735 & 1.808 & 2.453 & - & - & 180 & 109 & [106] \\
\hline & $\mathrm{T}$ & 4 & $\operatorname{CCSD}(\mathrm{T}) / \mathrm{B}$ & 1.691 & 2.450 & - & 1.874 & 1.709 & 180.0 & 90.0 & [108] \\
\hline$\left(\mathrm{NpO}_{2}{ }^{2+} \mathrm{UO}_{2}{ }^{+}\right)$ & $\mathrm{T}$ & 3 & $\operatorname{CCSD}(\mathrm{T}) / \mathrm{B}$ & 1.691 & 2.429 & - & 1.905 & 1.727 & 179.7 & 89.9 & [108] \\
\hline$\left(\mathrm{PuO}_{2}\right)_{2}{ }^{2+}$ & $\mathrm{T}$ & 7 & $\operatorname{CCSD}(\mathrm{T}) / \mathrm{B}$ & 1.724 & 2.791 & - & 1.770 & 1.705 & 178.3 & 89.2 & [108] \\
\hline$\left(\mathrm{AmO}_{2}\right)_{2}{ }^{2+}$ & $\mathrm{T}$ & 9 & $\operatorname{CCSD}(\mathrm{T}) / \mathrm{B}$ & 1.723 & 2.883 & - & 1.766 & 1.708 & 180.0 & 90.0 & {$[108]$} \\
\hline
\end{tabular}

Bond distances are given in angstroms, bond angles in degrees. The third column (M) gives the spin multiplicities. For the definition of atoms, see Fig. 17 ${ }^{\mathrm{a}}$ The abbreviations of basis sets A, B, and C mean relativistic small-core pseudopotential, all-electron, and relativistic large-core pseudopotential, respectively

${ }^{\mathrm{b}}$ Constrained at the value of the monomer

${ }^{\mathrm{c}}$ Aqueous phase using the COSMO solvation model

calculations. The neptunyl moieties proved to have $5 \mathrm{f}^{2}$ configuration and the SF-CASPT2 calculations predicted degenerate singlet, triplet and quintet states for the dimer. From them, in the SO ground state the triplet had the largest contribution. The $\mathrm{SO}$ ground state of $\left(\mathrm{NpO}_{2}\right)_{2}{ }^{2+}$ was preserved during the conversion to the T-shaped (Fig. 17a) isomer, the latter lying higher in energy by a few $\mathrm{kcal} / \mathrm{mol}$. The topological analysis of the electron densities revealed two bond critical points (BCPs) between $\mathrm{Np}$ and $\mathrm{O}$ of the other moiety. The characters of the BCPs pointed to ionic interactions with some covalent (dative) character. No Np-Np bond was found. The contribution of Lewis acid/base interaction in the CCI bond was confirmed by the extended transition state (ETS) method combined with natural orbitals for chemical valence (NOCV) theory, revealing substantial donation from the occupied $\mathrm{O}(2 \mathrm{p})$ orbitals to the empty $6 \mathrm{~d}$ orbitals of $\mathrm{Np}$. $\mathrm{OH}$ ligands tend to strengthen this donation compared to $\mathrm{H}_{2} \mathrm{O}$ and organic ligands.

A detailed DFT and multi-reference study of neptunyl dications was performed recently by Boguslawski et al. [106]. The study included both the T- (Fig. 17a) and diamond-shaped (Fig. 17b) forms for the relevant spin multiplicities of $\left(\mathrm{NpO}_{2}\right)_{2}{ }^{n+}(n=2-4)$. The electronic spectra were predicted by SO-CASPT2 calculations.

For $\left(\mathrm{NpO}_{2}\right)_{2}{ }^{2+}$, both structures were found as minima on the potential energy surface; for $\left(\mathrm{NpO}_{2}\right)_{2}{ }^{3+}$, only the diamondshaped form and only in solution, while none for $\left(\mathrm{NpO}_{2}\right)_{2}{ }^{4+}$ similarly to $\left(\mathrm{UO}_{2}\right)_{2}{ }^{4+}$ [96] (vide supra). The clusters were 
studied both in the gas and aqueous phases, in the latter phase using the COSMO solvation model as well as explicit first solvation shells $\left(9 \mathrm{H}_{2} \mathrm{O}\right.$ for the $\mathrm{T}$ - and $8 \mathrm{H}_{2} \mathrm{O}$ for the diamond-shaped forms). The two solvation models provided very similar geometries. The CCI bond distances were found to be considerably shorter in solution than in the isolated molecule.

The geometries of the diamond-shaped species differed slightly due to the different molecular charge $(+3 \mathrm{vs}+2)$. In agreement with the observation on uranyl CCIs [103] (vide supra), the increase of charge resulted in slight contraction of the intra-unit bond distances and slight increase of the interunit $\mathrm{Np}-\mathrm{O}$ ones. Accordingly, the two $\mathrm{Np}$ atoms get slightly away from each other.

The SF-CASPT2 ground state of T-shaped $\left(\mathrm{NpO}_{2}\right)_{2}{ }^{2+}$ proved to be the ${ }^{5} \mathrm{~B}_{1}$ state while several low-lying states were obtained. For diamond-shaped $\left(\mathrm{NpO}_{2}\right)_{2}{ }^{2+}$, similarly to the results in [105] (vide supra), the SF-CASPT2 calculations predicted a quasi-degeneracy of the lowest-lying quintet and triplet states. However, in disagreement with the reported preference of triplet in the SO ground state in [105], the SOCASPT2 calculations of Łachmańska et al. predicted a quintet character of the $\mathrm{SO}$ ground state of both the isolated dimer and the $\left(\mathrm{NpO}_{2}\right)_{2}{ }^{2+} \cdot 8 \mathrm{H}_{2} \mathrm{O}$ form [106]. For $\left(\mathrm{NpO}_{2}\right)_{2}{ }^{3+}$ the quasidegeneracy of two quartet states was obtained.

The limitations of the computational models for such difficult (to surroundings sensitive [107]) solvated chemical systems were shown by the computed positive binding energies at most theoretical levels and by the relative stabilities of the T- and diamondshaped isomers contradicting the experimental observations. In contrast to the exclusively observed T-shaped structure in solution, the computed relaxed binding energies of $\left(\mathrm{NpO}_{2}\right)_{2}{ }^{2+}$ with respect to the monomers predicted the preference of diamondshaped isomers at all applied levels $[105,106]$. Only a simplified model with four $\mathrm{H}_{2} \mathrm{O}$ molecules in the first solvation shell predicted the preference of the T-shaped $\left(\mathrm{NpO}_{2}\right)_{2}{ }^{2+}$ using the PBE0 and B3LYP hybrid functionals. This failure of the calculations was attributed to the lack of proper solvation modelling and an insufficient description of the active space and dynamic correlation in the multi-reference calculations.

Very recently, Feng et al. carried out a systematic study of isolated CCI homo- and heterodimers constructed from the monomers $\mathrm{UO}_{2}{ }^{2+}, \mathrm{UO}_{2}{ }^{+}, \mathrm{NpO}_{2}{ }^{2+}, \mathrm{NpO}_{2}{ }^{+}, \mathrm{PuO}_{2}{ }^{+}$, and $\mathrm{AmO}_{2}{ }^{+}$[108]. The applied CCSD(T) level can be expected to give very accurate results for systems dominated by a single electron configuration. The T-shaped dimers satisfied this requirement, but most considered diamond-shaped dimers were too multireference to reliably use the $\operatorname{CCSD}(\mathrm{T})$ method. From the latter isomers, only $\left(\mathrm{UO}_{2}\right)_{2}{ }^{2+}$ could be studied, and it proved to be thermodynamically more stable than the Tshaped $\left(\mathrm{UO}_{2}\right)_{2}{ }^{2+}$ isomer by $41 \mathrm{~kJ} / \mathrm{mol}$.

Similarly to earlier results $[105,106]$, the CCI dimer ions were determined to be metastable, because due to the
Coulomb repulsion their dissociations to the monomers were exothermic [108]. From the T-shaped dimers the largest stability was predicted for the ones when the acceptor had a +2 charge (An ${ }^{\mathrm{VI}}$ actinyl) and the donor had a +1 charge $\left(\mathrm{An}^{\mathrm{V}}\right.$ actinyl). Dimers with both donor and acceptor $\mathrm{An}^{\mathrm{VI}}$ were found to be unstable. The stability of CCI complexes decreased by the donor as $\mathrm{UO}_{2}{ }^{+}>\mathrm{NpO}_{2}{ }^{+}>\mathrm{PuO}_{2}{ }^{+}>\mathrm{AmO}_{2}{ }^{+}$, and similarly by the acceptor as $\mathrm{UO}_{2}{ }^{2+}>\mathrm{NpO}_{2}{ }^{2+}>\mathrm{PuO}_{2}{ }^{2+}>$ $\mathrm{AmO}_{2}{ }^{2+}$. A natural bond orbital analysis confirmed that the stability of the CCI complexes was largely determined by charge transfer from the $\sigma$-type $\mathrm{O}$ lone pair of the donor to the empty An valence orbitals of the acceptor.

\section{Large clusters observed in the gaseous phase}

Large charged $U$ oxide clusters were identified by their mass spectra, but hitherto no information on their molecular properties is available.

The first report was published on $\left[\left(\mathrm{UO}_{2}\right)_{4} \mathrm{O}_{3}\right]^{-}$, $\left[\left(\mathrm{UO}_{2}\right)_{4} \mathrm{O}_{4}\right]^{-}$, and $\left[\left(\mathrm{UO}_{2}\right)_{4} \mathrm{O}_{5}\right]^{-}$species obtained by electrospray ionization of uranyl citrate solutions followed by ion-molecule reactions in a $3 \mathrm{D}$ ion trap and detection by FT-ICR mass analyzer [109].

A later study of Marçalo et al. using laser ablation of solid $\mathrm{UO}_{3}$ or $\left(\mathrm{NH}_{4}\right)_{2} \mathrm{U}_{2} \mathrm{O}_{7}$ resulted in numerous uranium oxide anions with compositions ranging up to $\left[\mathrm{U}_{14} \mathrm{O}_{35}\right]^{-}$as detected by FT-ICR mass spectrometry [36]. The cluster series $\left[\mathrm{U}_{x} \mathrm{O}_{3 x}\right]^{-}$ up to $x=6$ could unambiguously be identified. For $x>5$, a gradual enhancement of compositions $\left[\mathrm{U}_{x} \mathrm{O}_{3 x-y}\right]^{-}$was observed converging towards $\left[\mathrm{U}_{x} \mathrm{O}_{2.5 x}\right]^{-}$in the largest clusters. Collision-induced dissociation (CID) experiments using $\mathrm{Ar}$ as collision gas resulted in the loss of neutral $\mathrm{UO}_{3}$ from $\left[\mathrm{U}_{3} \mathrm{O}_{9}\right]^{-}$ and $\left[\mathrm{U}_{4} \mathrm{O}_{12}\right]^{-}$, indicating that $\mathrm{UO}_{3}$ constitutes the building block in these structures. The laser ablation of solid $\mathrm{UO}_{3}$ produced also the cationic uranium oxide clusters $\left[\mathrm{U}_{x} \mathrm{O}_{n}\right]^{+}$with $x$ $=2-9$ and $n=3-24$. With increasing cluster size the composition converged towards $\left[\mathrm{U}_{x} \mathrm{O}_{2.5 x}\right]^{+}$.

\section{Conclusions}

In the past decade, there has been a considerable progress in the field of high-valent actinides by detecting and characterizing their oxides in the gaseous phase. Sophisticated experimental methods like laser ablation, photoelectron spectroscopy, laser-induced electron detachment, electrospray ionization, 3D ion trap, and Fourier transform ion cyclotron resonance mass spectrometry facilitated the synthesis, observation, and analysis of some properties of such molecules. At the same time, advanced quantum chemical techniques delivered significant information on the structure, bonding, stability, and spectroscopic properties. 
One of the main questions is the oxidation state, which was probed in oxides up to $\mathrm{AnO}_{6}$ and in clusters containing up to $\mathrm{AnO}_{4}$ moieties. Beyond the neutral oxide molecules the studies covered ionic species too, partly because they are better suited for investigations by experiment (by methods coupled with mass spectrometry) and partly because the charge could stabilize structures with higher oxidation state and result in different molecular properties. The highest stable oxidation state found up to know is $\mathrm{VII}$ in $\mathrm{NpO}_{4}{ }^{-}$and $\mathrm{PuO}_{4}{ }^{-}$. The lighter actinides are characterized from this point of view by $\mathrm{Th}^{\mathrm{IV}}$, $\mathrm{Pa}^{\mathrm{V}}$, and $\mathrm{U}^{\mathrm{VI}}$, while the heavier ones by $\mathrm{Am}^{\mathrm{V}}$ and from $\mathrm{Cm}$ as $\mathrm{An}^{\text {III }}$, in agreement with the considerable stabilization of the $5 \mathrm{f}$ subshell. An exception in the second half of the row is No, where the advantageous $\mathrm{f}^{14}$ configuration leads to $\mathrm{No}^{\mathrm{II}}$.

Small molecular clusters are interesting because they appear in solution and are the building blocks of solid structures. The new theoretical studies contributed to the understanding of the structure and An-O-An bonding in these species, and uncovered the role of solvent for their stabilization. The largest clusters detected in the gaseous phase were the $\left[\mathrm{U}_{9} \mathrm{O}_{24}\right]^{+}$cations. The modelling of such large molecules with reliable quantum chemical methods can be one of the tasks of future research.

\section{Compliance with ethical standards}

Conflict of interest The author declares that there is no conflict of interest.

Open Access This article is licensed under a Creative Commons Attribution 4.0 International License, which permits use, sharing, adaptation, distribution and reproduction in any medium or format, as long as you give appropriate credit to the original author(s) and the source, provide a link to the Creative Commons licence, and indicate if changes were made. The images or other third party material in this article are included in the article's Creative Commons licence, unless indicated otherwise in a credit line to the material. If material is not included in the article's Creative Commons licence and your intended use is not permitted by statutory regulation or exceeds the permitted use, you will need to obtain permission directly from the copyright holder. To view a copy of this licence, visit http://creativecommons.org/licenses/by/4.0/.

\section{References}

1. Greenwood NN, Earnshaw A (1997) Chemistry of the elements. Butterworth-Heinemann, Oxford. https://doi.org/10.1016/C20090-30414-6

2. Pepper M, Bursten BE (1991) The electronic structure of actinidecontaining molecules: a challenge to applied quantum chemistry. Chem Rev 91:719-741. https://doi.org/10.1021/cr00005a005

3. Dolg M, Stoll H (1996) Electronic Structure calculations for molecules containing lanthanide atoms. In: Geschneider Jr KA, Eyring L (eds) Handbook on the physics and chemistry of rare earths, Chapter 152, vol 22. Elsevier, Amsterdam. https://doi.org/ 10.1016/S0168-1273(96)22009-4

4. Dolg M (1998) Lanthanides and actinides. In: Allinger NL, Clark $\mathrm{T}$ et al (eds) Schleyer PvR. Encyclopedia of computational chemistry. Wiley, Chichester, pp 1478-1486. https://doi.org/10.1002/ 0470845015.cla001
5. Schreckenbach G, Hay PJ, Martin RL (1999) Density functional calculations on actinide compounds: survey of recent progress and application to $\left[\mathrm{UO}_{2} \mathrm{X}_{4}\right]^{2-}(\mathrm{X}=\mathrm{F}, \mathrm{Cl}, \mathrm{OH})$ and $\mathrm{AnF}_{6}(\mathrm{An}=\mathrm{U}, \mathrm{Np}$, $\mathrm{Pu}$ ). J Comput Chem 20:70-90. https://doi.org/10.1002/(SICI) 1096-987X(19990115)20:1\%3C70::AID-JCC9\%3E3.0.CO;2-F

6. Kaltsoyannis N (2003) Recent developments in computational actinide chemistry. Chem Soc Rev 32:9-16. https://doi.org/10. 1039/B204253N

7. Kaltsoyannis N, Hay PJ, Li J, Blaudeau JP, Bursten BE (2006) Theoretical studies of the electronic structure of compounds of the actinide elements. In: Morss LR, Edelstein NM, Fuger J, Katz JJ (eds) The chemistry of the actinide and transactinide elements. Springer, Dordrecht, The Netherlands, pp 1893-2012. https:// doi.org/10.1007/1-4020-3598-5_17

8. Heaven MC (2006) Probing actinide electronic structure using fluorescence and multi-photon ionization spectroscopy. Phys Chem Chem Phys 8:4497-4509. https://doi.org/10.1039/ B607486C

9. Marçalo J, Gibson JK (2009) Gas-phase energetics of actinide oxides: an assessment of neutral and cationic monoxides and dioxides from thorium to curium. J Phys Chem A 113:1259912606. https://doi.org/10.1021/jp904862a

10. Dolg M, Cao X (2009) Computational methods: lanthanides and actinides. In: Solomon EI, Scott RA, King RB (eds) Computational inorganic and bioinorganic chemistry. Wiley, Chichester, pp 503-516. https://doi.org/10.1002/0470862106. ia640

11. Heaven MC, Gibson JK, Marçalo J (2011) Molecular spectroscopy and reactions of actinides in the gas phase and cryogenic matrices. In: Edelstein NM, Fuger J, Morss LR (eds) The chemistry of the actinide and transactinide elements, vol 6. Springer, Dordrecht, pp 4079-4156. https://doi.org/10.1007/978-94-0070211-0_38

12. Wang $\bar{D}$, van Gunsteren WF, Chai Z (2012) Recent advances in computational actinoid chemistry. Chem Soc Rev 41:5836-5865. https://doi.org/10.1039/C2CS15354H

13. Konings RJM, Beneš O, Kovács A, Manara D, Sedmidubský D, Gorokhov L, Iorish VS, Yungman V, Shenyavskaya E, Osina E (2014) The thermodynamic properties of the f-elements and their compounds. Part II. The lanthanide and actinide oxides. J Phys Chem Ref Data 43:013101. https://doi.org/10.1063/1.4825256

14. Kovács A, Konings RJM, Gibson JK, Infante I, Gagliardi L (2015) Quantum Chemical calculations and experimental investigations of molecular actinide oxides. Chem Rev 115:1725-1759. https://doi.org/10.1021/cr500426s

15. Morss LR, Edelstein NM, Fuger J (eds) (2006) The chemistry of the actinide and transactinide elements. Springer, Dordrecht. https://doi.org/10.1007/1-4020-3598-5 5

16. Heaven MC, Peterson KA (2018) Probing actinide bonds in the gas phase: theory and spectroscopy. In: Gibson JK, de Jong WA (eds) Experimental and theoretical approaches to actinide chemistry. John Wiley \& Sons, Inc., Hoboken, New Jersey, pp 1-52. https://doi.org/10.1002/9781119115557.ch1

17. Dau PD, Vasiliu M, Peterson KA, Dixon DA, Gibson JK (2017) Remarkably high stability of late actinide dioxide cations: extending chemistry to pentavalent berkelium and californium. Chem Eur J 23(68):17369-17378. https://doi.org/10.1002/chem. 201704193

18. Vasiliu M, Jian T, Gibson JK, Peterson KA, Dixon DA (2020) A computational assessment of actinide dioxide cations $\mathrm{AnO}_{2}{ }^{2+}$ for $\mathrm{An}=\mathrm{U}$ to Lr: the limited stability range of the hexavalent actinyl moiety, $[\mathrm{O}=\mathrm{An}=\mathrm{O}]^{2+}$. Inorg Chem 59(7):4554-4566. https://doi. org/10.1021/acs.inorgchem.9b03690

19. Li Y, Zou J, Xiong X-G, Xie H, Tang Z, Ge M, Zhao Y, Liu H (2018) Anion photoelectron spectroscopy and chemical bonding 
of $\mathrm{ThO}_{2}{ }^{-}$and $\mathrm{ThO}_{3}{ }^{-}$. J Chem Phys 148(24):244304. https://doi. org/10.1063/1.5030142

20. Su J, Hu S, Huang W, Zhou M, Li J (2016) On the oxidation states of metal elements in $\mathrm{MO}_{3}{ }^{-}(\mathrm{M}=\mathrm{V}, \mathrm{Nb}, \mathrm{Ta}, \mathrm{Db}, \mathrm{Pr}, \mathrm{Gd}, \mathrm{Pa})$ anions. Sci China Chem 59(4):442-451. https://doi.org/10.1007/s11426015-5481-Z

21. de Jong WA, Dau PD, Wilson RE, Marçalo J, Van Stipdonk MJ, Corcovilos TA, Berden G, Martens J, Oomens J, Gibson JK (2017) Revealing disparate chemistries of protactinium and uranium. Synthesis of the molecular uranium tetroxide anion, $\mathrm{UO}_{4}{ }^{-}$. Inorg Chem 56 (6):3686-3694. doi:https://doi.org/10.1021/acs. inorgchem. $7 \mathrm{~b} 00144$

22. Gabelnick SD, Reedy GT, Chasanov MG (1973) The infrared spectrum of matrix-isolated uranium oxide vapor species. Chem Phys Lett 19(1):90-93. https://doi.org/10.1016/0009-2614(73) 87070-8

23. Gabelnick SD, Reedy GT, Chasanov MG (1973) Infrared spectra of matrix-isolated uranium oxide species. I. The stretching region. J Chem Phys 58(10):4468-4475. https://doi.org/10.1063/1. 1679009

24. Gabelnick SD, Reedy GT, Chasanov MG (1973) Infrared spectra of matrix-isolated uranium oxide species. II. Spectral interpretation and structure of $\mathrm{UO}_{3}$. J Chem Phys 59:6397-6404. https://doi. org/10.1063/1.1680018

25. Green DW (1980) Standard enthalpies of formation of gaseous thorium, uranium and plutonium oxides. Int J Thermophys 1(1): 61-71. https://doi.org/10.1007/BF00506272

26. Hunt RD, Andrews L (1993) Reactions of pulsed-laser evaporated uranium atoms with molecular oxygen: infrared spectra of $\mathrm{UO}$, $\mathrm{UO}_{2}, \mathrm{UO}_{3}, \mathrm{UO}_{2}{ }^{+}, \mathrm{UO}_{2}{ }^{2+}$, and $\mathrm{UO}_{3}-\mathrm{O}_{2}$ in solid argon. $\mathrm{J}$ Chem Phys 98(5):3690-3696. https://doi.org/10.1063/1.464045

27. Zhou M, Andrews L, Ismail N, Marsden C (2000) Infrared spectra of $\mathrm{UO}_{2}, \mathrm{UO}_{2}{ }^{+}$and $\mathrm{UO}_{2}{ }^{-}$in solid neon. J Phys Chem A 104(23): 5495-5502. https://doi.org/10.1021/jp000292q

28. Green DW, Reedy GT, Gabelnick SD (1980) Infrared spectra of matrix-isolated uranium oxides. III. Low-frequency modes. J Chem Phys 73(9):4207-4216. https://doi.org/10.1063/1.440704

29. Pyykkö P, Li J, Runeberg N (1994) Quasirelativistic pseudopotential study of species isoelectronic to uranyl and the equatorial coordination of uranyl. J Phys Chem 98(18):48094813. https://doi.org/10.1021/j100069a007

30. Privalov T, Schimmelpfennig B, Wahlgren U, Grenthe I (2002) Structure and thermodynamics of uranium(VI) complexes in the gas phase: a comparison of experimental and ab initio data. J Phys Chem A 106(46):11277-11282. https://doi.org/10.1021/ jp0260402

31. Zaitsevskii AV (2013) Molecular anions of uranium fluorides and oxides: a first-principles relativistic calculation. Radiochemistry 55(4):353-356. https://doi.org/10.1134/S1066362213040012

32. Su J, Li W-L, Lopez GV, Jian T, Cao G-J, Li W-L, Schwarz WHE, Wang L-S, Li J (2016) Probing the electronic structure and chemical bonding of mono-uranium oxides with different oxidation states: $\mathrm{UO}_{\mathrm{x}}{ }^{-}$and $\mathrm{UO}_{\mathrm{x}}(\mathrm{x}=3-5)$. J Phys Chem A 120(7):1084-1096. https://doi.org/10.1021/acs.jpca.5b11354

33. Yang Y, Liu H, Zhang P (2016) Structural and electronic properties of $\mathrm{U}_{\mathrm{n}} \mathrm{O}_{\mathrm{m}}(\mathrm{n}=1-3, \mathrm{~m}=1-3 \mathrm{n})$ clusters: a theoretical study using screened hybrid density functional theory. J Chem Phys 144(18): 184304. https://doi.org/10.1063/1.4948779

34. Kovács A (2017) Relativistic multireference quantum chemical study of the electronic structure of actinide trioxide molecules. J Phys Chem A 121:2523-2530. https://doi.org/10.1021/acs.jpca. $7 \mathrm{~b} 01344$

35. Middleton R (1977) A survey of negative ions from a cesium sputter source. Nucl Inst Methods 144(3):373-399. https://doi. org/10.1016/0029-554X(77)90001-5
36. Marçalo J, Santos M, Pires de Matos A, Gibson JK (2009) Molecular uranates: laser synthesis of uranium oxide anions in the gas phase. Inorg Chem 48(12):5055-5057. https://doi.org/ 10.1021/ic9003998

37. Ronchi C, Capone F, Colle JY, Hiernaut JP (2000) Volatile molecule $\mathrm{PuO}_{3}$ observed from subliming plutonium dioxide. J Nucl Mater 280(1):111-115. https://doi.org/10.1016/S0022-3115(00) 00058-1

38. Straka M, Dyall KG, Pyykkö P (2001) Ab initio study of bonding trends for $\mathrm{f}^{0}$ actinide oxyfluoride species. Theor Chem Accounts 106(6):393-403. https://doi.org/10.1007/s002140100295

39. Gao T, Zhu ZH, Wang XL, Sun Y, Meng DQ (2004) Molecular structures and molecular spectra for $\mathrm{PuO}_{3}$ and $\mathrm{PuO}_{3}{ }^{+}$. Acta Chim Sin 62(5):454-460

40. Zaitsevskii AV, Titov AV, Mal'kov SS, Tananaev IG, Kiselev YM (2013) On the existence of oxide molecules of plutonium in highest oxidation states. Dokl Chem 448(1):1-3. https://doi.org/ 10.1134/S0012500813010023

41. Zaitsevskii A, Mosyagin NS, Titov AV, Kiselev YM (2013) Relativistic density functional theory modeling of plutonium and americium higher oxide molecules. J Chem Phys 139(3):034307. https://doi.org/10.1063/1.4813284

42. Boguslawski K, Réal F, Tecmer P, Duperrouzel C, Gomes ASP, Legeza Ö, Ayers PW, Vallet V (2017) On the multi-reference nature of plutonium oxides: $\mathrm{PuO}_{2}{ }^{2+}, \mathrm{PuO}_{2}, \mathrm{PuO}_{3}$ and $\mathrm{PuO}_{2}(\mathrm{OH})_{2}$. Phys Chem Chem Phys 19:4317-4329. https://doi. org/10.1039/c6cp05429c

43. Legeza Ö, Noack R, Sólyom J, Tincani L (2008) Applications of quantum information in the density-matrix renormalization group. In: Fehske H, Schneider R, Weiße A (eds) Computational manyparticle physics, vol 739. Springer, Berlin/Heidelberg, pp 653664. https://doi.org/10.1007/978-3-540-74686-7_24

44. Li Q, Liu XY, Gao T, Zhu ZH, Fu YB, Wang XL, Sun Y (2000) Potential energy function and stability of $\mathrm{PuO}^{\mathrm{n}+}$. Acta Phys-Chim Sin 16(11):987-991. https://doi.org/10.3866/PKU. WHXB20001106

45. Li Q, Liu XY, Wang R, Zhu ZH, Fu YB, Wang XL (2001) Study of analytic potential energy function and stability for $\mathrm{PuO}^{\mathrm{n}+}$ with density functional theory. Chin Phys 10(6):501-504

46. Gibson JK, de Jong WA, Dau PD, Gong Y (2017) Heptavalent actinide tetroxides $\mathrm{NpO}_{4}{ }^{-}$and $\mathrm{PuO}_{4}{ }^{-}$: oxidation of $\mathrm{Pu}(\mathrm{V})$ to $\mathrm{Pu}$ (VII) by adding an electron to $\mathrm{PuO}_{4}$. J Phys Chem A 121(47): 9156-9162. https://doi.org/10.1021/acs.jpca.7b09721

47. Domanov VP, Lobanov YV (2011) Formation of volatile curium(VI) trioxide $\mathrm{CmO}_{3}$. Radiochemistry 53(5):453-456. https://doi.org/10.1134/S1066362211050018

48. Zaitsevskii A, Mosyagin NS, Titov AV, Kiselev YM Abstracts of papers. In: Russian-Nordic Symposium on Radiochemistry, Moscow, 21-24 October, 2013 2013. Idea Print, p 36

49. Zaitsevskii A (2015) Plutonium and transplutonium element trioxides: molecular structures, chemical bonding and isomers. Phys Chem Chem Phys 17:24831-24836. https://doi.org/10.1039/ C5CP02190A

50. Zaitsevskii AV, Skripnikov LV, Titov AV (2016) Chemical bonding and effective atomic states of actinides in higher oxide molecules. Mendeleev Commun 26(4):307-308. https://doi.org/10. 1016/j.mencom.2016.07.013

51. Michelini MC, Marçalo J, Russo N, Gibson JK (2010) Gas-phase reactions of uranate ions, $\mathrm{UO}_{2}^{-}, \mathrm{UO}_{3}{ }^{-}, \mathrm{UO}_{4}^{-}$, and $\mathrm{UO}_{4} \mathrm{H}^{-}$, with methanol: a convergence of experiment and theory. Inorg Chem 49(8):3836-3850. https://doi.org/10.1021/ic902550g

52. Sokalska M, Prussakowska M, Hoffmann M, Gierczyk B, Frański $\mathrm{R}$ (2010) Unusual ion $\mathrm{UO}_{4}{ }^{-}$formed upon collision induced dissociation of $\left[\mathrm{UO}_{2}\left(\mathrm{NO}_{3}\right)_{3}\right]^{-},\left[\mathrm{UO}_{2}\left(\mathrm{ClO}_{4}\right)_{3}\right]^{-},\left[\mathrm{UO}_{2}\left(\mathrm{CH}_{3} \mathrm{COO}\right)_{3}\right]^{-}$ ions. J Am Soc Mass Spectrom 21(10):1789-1794. https://doi. org/10.1016/j.jasms.2010.06.018 
53. Zhai H-J, Kiran B, Cui L-F, Li X, Dixon DA, Wang L-S (2004) Electronic structure and chemical bonding in $\mathrm{MO}_{\mathrm{n}}{ }^{-}$and $\mathrm{MO}_{\mathrm{n}}$ Clusters $(M=M o, W ; n=3-5)$ : a photoelectron spectroscopy and ab initio study. J Am Chem Soc 126(49):16134-16141. https://doi.org/10.1021/ja046536s

54. Chen Z-Y, Yang J-L (2007) Atomic and molecular chemisorption of oxygen in $\mathrm{WO}_{4}{ }^{-}$clusters. Chin J Chem Phys 20(1):78-82. https://doi.org/10.1360/cjcp2007.20(1).78.5

55. Pyykko P, Zhao Y (1991) The large range of uranyl bond lengths: ab initio calculations on simple uranium-oxygen clusters. Inorg Chem 30(19):3787-3788. https://doi.org/10.1021/ic00019a046

56. Bolvin H, Wahlgren U, Gropen O, Marsden CJ (2001) Ab Initio study of the two iso-electronic molecules $\mathrm{NpO}_{4}{ }^{-}$and $\mathrm{UO}_{4}{ }^{2-}$. J Phys Chem A 105 (46):10570-10576. https://doi.org/10.1021/ jp011240j

57. Huang W, Xu W-H, Su J, Schwarz WHE, Li J (2013) Oxidation states, geometries, and electronic structures of plutonium tetroxide $\mathrm{PuO}_{4}$ isomers: is octavalent $\mathrm{Pu}$ viable? Inorg Chem 52(24): 14237-14245. https://doi.org/10.1021/ic402170q

58. Groenewold GS, Cossel KC, Gresham GL, Gianotto AK, Appelhans AD, Olson JE, Van Stipdonk MJ, Chien W (2006) Binding of molecular $\mathrm{O}_{2}$ to di- and triligated $\left[\mathrm{UO}_{2}\right]^{+}$. J Am Chem Soc 128(9):3075-3084. https://doi.org/10.1021/ja0573209

59. Leavitt CM, Bryantsev VS, Jong WA, Diallo MS, Goddard III WA, Groenewold GS, Stipdonk MJV (2009) Addition of $\mathrm{H}_{2} \mathrm{O}$ and $\mathrm{O}_{2}$ to acetone and dimethylsulfoxide ligated uranyl(V) dioxocations. J Phys Chem A 113(11):2350-2358. https://doi. org/10.1021/jp807651c

60. Bryantsev VS, de Jong WA, Cossel KC, Diallo MS, Goddard III WA, Groenewold GS, Chien W, Van Stipdonk MJ (2008) Twoelectron three-centered bond in side-on $\left(\eta^{2}\right)$ uranyl(V) superoxo complexes. J Phys Chem A 112:5777-5780. https://doi.org/10. 1021/jp804202q

61. Rios D, Michelini MC, Lucena AF, Marçalo J, Bray TH, Gibson JK (2012) Gas-phase uranyl, neptunyl, and plutonyl: hydration and oxidation studied by experiment and theory. Inorg Chem 51(12):6603-6614. https://doi.org/10.1021/ic3001625

62. Ricks AM, Gagliardi L, Duncan MA (2011) Uranium oxo and superoxo cations revealed using infrared spectroscopy in the gas phase. J Phys Chem Lett 2(14):1662-1666. https://doi.org/10. 1021/jz2006868

63. Momenteau M, Reed CA (1994) Synthetic heme-dioxygen complexes. Chem Rev 94(3):659-698. https://doi.org/10.1021/ cr00027a006

64. Dau PD, Maurice R, Renault E, Gibson JK (2016) Heptavalent neptunium in a gas-phase complex: $\left(\mathrm{Np}^{\mathrm{VII}} \mathrm{O}_{3}{ }^{+}\right)\left(\mathrm{NO}_{3}{ }^{-}\right)_{2}$. Inorg Chem 55:9830-9837. https://doi.org/10.1021/acs.inorgchem. $6 \mathrm{~b} 01617$

65. Jové J, He L, Proust J, Pagès M, Pyykkö P (1991) Mössbauer spectroscopy as a nuclear probe for solid state transuranium chemistry. J Alloys Compd 177(2):285-309. https://doi.org/10.1016/ 0925-8388(91)90083-8

66. Domanov VP, Buklanov GV, Lobanov YV (2002) Formation of unusual $\mathrm{U}, \mathrm{Pu}$, and $\mathrm{Cf}$ oxide species under conditions of gas thermochromatography. Radiochem 44(2):114-120. https://doi. org/10.1023/a:1019654825664

67. Domanov VP, Buklaeov GV, Lobanov YV (2002) Exotic new oxides of plutonium found by using gas thermochromatography. J Nucl Sci Technol 39 (sup3):579-584. https://doi.org/10.1080/ 00223131.2002.10875535

68. Pershina V, Bastug T, Fricke B, Varga S (2001) The electronic structure and properties of group 8 oxides $\mathrm{MO}_{4}$, where $\mathrm{M}=\mathrm{Ru}, \mathrm{Os}$, and Element 108, Hs. J Chem Phys 115(2):792-799. https://doi. org/10.1063/1.1379579

69. Hübener S, Taut S, Vahle A, Bernhard G, Fanghänel T (2008) Thermochromatographic studies of plutonium oxides.
Radiochim Acta 96:781-785. https://doi.org/10.1524/ract.2008. 1522

70. Nikonov MV, Kiselev YM, Tananaev IG, Myasoedov BF (2011) Plutonium volatility in ozonization of alkaline solutions of $\mathrm{Pu}(\mathrm{VI})$ hydroxo complexes. Dokl Chem 437(1):69-71. https://doi.org/10. 1134/S0012500811030104

71. Antonio MR, Williams CW, Sullivan JA, Skanthakumar S, Hu YJ, Soderholm L (2012) Preparation, stability, and structural characterization of plutonium(VII) in alkaline aqueous solution. Inorg Chem 51(9):5274-5281. https://doi.org/10.1021/ic300205h

72. Shilov VP, Fedoseev AM, Gogolev AV (2017) Stability of tetraoxides of chemical elements. Russ J Gen Chem 87(10): 2265-2268. https://doi.org/10.1134/S1070363217100036

73. Tsushima S (2008) Quantum chemical calculations of the redox potential of the $\mathrm{Pu}(\mathrm{VII}) / \mathrm{Pu}(\mathrm{VIII})$ couple. J Phys Chem B 112(41): 13059-13063. https://doi.org/10.1021/jp804856z

74. Zaitsevskii A, Schwarz WHE (2014) Structures and stability of $\mathrm{AnO}_{4}$ isomers, $\mathrm{An}=\mathrm{Pu}, \mathrm{Am}$ and $\mathrm{Cm}$ : a relativistic density functional study. Phys Chem Chem Phys 16:8997-9001. https://doi. org $/ 10.1039 / \mathrm{C} 4 \mathrm{CP} 00235 \mathrm{~K}$

75. Huang W, Pyykkö P, Li J (2015) Is octavalent Pu(VIII) possible? Mapping the plutonium oxyfluoride series $\mathrm{PuO}_{\mathrm{n}} \mathrm{F}_{8-2 \mathrm{n}}(\mathrm{n}=0-4)$. Inorg Chem 54:8825-8831. https://doi.org/10.1021/acs. inorgchem. $5 \mathrm{~b} 01540$

76. Huang W, Xu W-H, Schwarz WHE, Li J (2016) On the highest oxidation states of metal elements in $\mathrm{MO}_{4}$ molecules $(\mathrm{M}=\mathrm{Fe}, \mathrm{Ru}$, Os, Hs, Sm, and Pu). Inorg Chem 55:4616-4625. https://doi.org/ 10.1021/acs.inorgchem.6b00442

77. Domanov VP (2013) Possibility of generation of octavalent curium in the gas phase in the form of volatile tetraoxide $\mathrm{CmO}_{4}$. Radiochem 55(1):46-51. https://doi.org/10.1134/ S1066362213010098

78. Pyykkö P, Runeberg N, Straka M, Dyall KG (2000) Could uranium(XII)hexoxide, $\mathrm{UO}_{6}(\mathrm{Oh})$ exist? Chem Phys Lett 328(46):415-419. https://doi.org/10.1016/S0009-2614(00)00958-1

79. Xiao H, Hu H-S, Schwarz WHE, Li J (2010) Theoretical investigations of geometry, electronic structure and stability of $\mathrm{UO}_{6}$ : octahedral uranium hexoxide and its isomers. J Phys Chem A 114(33):8837-8844. https://doi.org/10.1021/jp102107n

80. Burns PC, Hughes K-A (2003) Studtite, $\left[\left(\mathrm{UO}_{2}\right)\left(\mathrm{O}_{2}\right)\left(\mathrm{H}_{2} \mathrm{O}\right)_{2}\right]\left(\mathrm{H}_{2} \mathrm{O}\right)_{2}$ : the first structure of a peroxide mineral. Am Mineral 88(7):11651168. https://doi.org/10.2138/am-2003-0725

81. Serezhkina LB, Savchenkov AV, Serezhkin VN (2017) Stereochemistry of thorium in oxygen-containing compounds. Russ J Inorg Chem 62(5):633-638. https://doi.org/10.1134/ s0036023617050217

82. Serezhkin VN, Karasev MO, Serezhkina LB (2013) Causes of uranyl ion nonlinearity in crystal structures. Radiochemistry 55(2):137-146. https://doi.org/10.1134/s106636221302001x

83. Serezhkin VN, Serezhkina LB (2018) Stereochemistry of neptunium in oxygen-containing compounds. Radiochemistry 60(1):112. https://doi.org/10.1134/s1066362218010010

84. Serezhkin VN, Pushkin DV, Serezhkina LB (2018) Stereochemistry of plutonium in oxygen-containing compounds. Radiochem 60(3):221-232. https://doi.org/10.1134/ s1066362218030013

85. Serezhkin VN, Serezhkina LB (2018) Stereochemistry of americium and curium in oxygen-containing compounds. Radiochem 60(4):335-344. https://doi.org/10.1134/s106636221804001x

86. Serezhkina LB, Serezhkin VN (2018) Stereochemistry of Bk, Cf, and Es in Oxygen-containing compounds. Radiochemistry 60(5): 488-497. https://doi.org/10.1134/s106636221805003x

87. Kresse G, Furthmüller J (1996) Efficient iterative schemes for ab initio total-energy calculations using a plane-wave basis set. Phys Rev B 54:11169-11186. https://doi.org/10.1103/PhysRevB.54. 11169 
88. Zhang C, Hu S-X, Liu H-T, Yang Y, Zhang P (2018) Bonding properties and oxidation states of plutonium in $\mathrm{Pu}_{2} \mathrm{O}_{n}(\mathrm{n}=1-8)$ molecules studied by using screened hybrid density functional theory. J Phys Chem A 122(16):4085-4091. https://doi.org/10. 1021/acs.jpca.7b12324

89. Sullivan JC, Hindman JC, Zielen AJ (1961) Specific interaction between $\mathrm{Np}(\mathrm{V})$ and $\mathrm{U}(\mathrm{VI})$ in aqueous perchloric acid media. J Am Chem Soc 83(16):3373-3378. https://doi.org/10.1021/ ja01477a004

90. Newton TW, Baker FB (1965) A uranium(V)-uranium(VI) complex and its effect on the uranium $(\mathrm{V})$ disproportionation rate. Inorg Chem 4(8):1166-1170. https://doi.org/10.1021/ ic50030a017

91. Guillaume B, Begun GM, Hahn RL (1982) Raman spectrometric studies of "cation-cation" complexes of pentavalent actinides in aqueous perchlorate solutions. Inorg Chem 21(3):1159-1166. https://doi.org/10.1021/ic00133a055

92. Guillaume B, Hahn RL, Narten AH (1983) Investigations of "cation-cation' complexes of $\mathrm{NpO}_{2}{ }^{+}$solutions by large-angle X-ray scattering. Inorg Chem 22(1):109-111. https://doi.org/10.1021/ ic00143a024

93. Stoyer NJ, Hoffman DC, Stoyer NJ, Hoffman DC, Stoyer NJ, Hoffman DC, Silva RJ (2000) Cation-cation complexes of $\mathrm{PuO}_{2}{ }^{+}$and $\mathrm{NpO}_{2}{ }^{+}$with $\mathrm{Th}^{4+}$ and $\mathrm{UO}_{2}{ }^{2+}$. Radiochim Acta 88(36647):279-282. https://doi.org/10.1524/ract.2000.88.5.279

94. Gregoire-Kappenstein AC, Moisy P, Cote G, Blanc P (2003) Dimerization of $\mathrm{Np}(\mathrm{V})$ and media effects in concentrated solutions. Radiochim Acta 91(11):665-672. https://doi.org/10.1524/ ract.91.11.665.23472

95. Den Auwer C, Grégoire-Kappenstein AC, Moisy P (2003) Np(V) cation-cation interactions. A new contribution from EXAFS spectroscopy? Radiochim Acta 91(12):773-776. https://doi.org/10. 1524/ract.91.12.773.23419

96. Krot NN, Grigoriev MS (2004) Cation-cation interaction in crystalline actinide compounds. Russ Chem Rev 73(1):89-100. https://doi.org/10.1070/RC2004v073n01ABEH000852

97. Forbes TZ, Wallace C, Burns PC (2008) Neptunyl compounds: polyhedron geometries, bond-valence parameters, and structural hierarchy. Can Mineral 46(6):1623-1645. https://doi.org/10.3749/ canmin.46.6.1623

98. Jin GB (2013) Mixed-valent neptunium(IV/V) compound with cation-cation-bound six-membered neptunyl rings. Inorg Chem 52(21):12317-12319. https://doi.org/10.1021/ic4021492

99. Serezhkin VN, Sidorenko GV, Pushkin DV, Serezhkina LB (2014) Cation-cation interactions between uranyl(VI) ions. Radiochem 56(2):115-133. https://doi.org/10.1134/ s1066362214020015

100. Mougel V, Horeglad P, Nocton G, Pécaut J, Mazzanti M (2009) Stable pentavalent uranyl species and selective assembly of a polymetallic mixed-valent uranyl complex by cation-cation interactions. Angew Chem Int Ed 48(45):8477-8480. https://doi.org/ 10.1002/anie. 200903457

101. WebElements. Copyright 1993-2019, Mark Winter (The University of Sheffield and WebElements Ltd, UK). http:/ www.webelements.com . Accessed 20 May 2020

102. McKee ML, Swart M (2005) Study of $\mathrm{Hg}_{2}{ }^{2+}$ and complexes of $\mathrm{NpO}_{2}{ }^{+}$and $\mathrm{UO}_{2}{ }^{2+}$ in solution. Examples of cation-cation interactions. Inorg Chem 44(20):6975-6982. https://doi.org/10.1021/ ic050224o

103. Tecmer P, Hong SW, Boguslawski K (2016) Dissecting the cation-cation interaction between two uranyl units. Phys Chem Chem Phys 18(27):18305-18311. https://doi.org/10.1039/ C6CP03542F

104. Cousson A, Dabos S, Abazli H, Nectoux F, Pagès M, Choppin G (1984) Crystal structure of a neptunyl cation-cation complex $\left(\mathrm{NpO}_{2}{ }^{+}\right)$with mellitic acid: $\mathrm{Na}_{4}\left(\mathrm{NpO}_{2}\right)_{2} \mathrm{Cl}_{12} \mathrm{O}_{12} \cdot 8 \mathrm{H}_{2} \mathrm{O}$. J Less Common Met 99(2):233-240. https://doi.org/10.1016/00225088(84)90220-0

105. Vlaisavljevich B, Miró P, Ma D, Sigmon GE, Burns PC, Cramer CJ, Gagliardi L (2013) Synthesis and characterization of the first 2D neptunyl structure stabilized by side-on cation-cation interactions. Chem Eur J 19(9):2937-2941. https://doi.org/10.1002/ chem. 201204149

106. Łachmańska A, Tecmer P, Legeza Ö, Boguslawski K (2019) Elucidating cation-cation interactions in neptunyl dications using multi-reference ab initio theory. Phys Chem Chem Phys 21(2): 744-759. https://doi.org/10.1039/c8cp04267e

107. Madic C, Guillaume B, Morisseau JC, Moulin JP (1979) "Cationcation" complexes of pentavalent actinides-I. Spectrophotometric study of complexes between neptunium (V) and $\mathrm{UO}_{2}{ }^{2+}$ and $\mathrm{NpO}_{2}{ }^{2+}$ ions in aqueous perchloric and nitric solutions. J Inorg Nucl Chem 41(7):1027-1031. https://doi.org/10.1016/00221902(79)80082-2

108. Feng R, Glendening ED, Peterson KA (2019) Actinyl cationcation interactions in the gas phase: an accurate thermochemical study. Phys Chem Chem Phys 21(15):7953-7964. https://doi.org/ 10.1039/c9cp00760a

109. Somogyi Á, Pasilis SP, Pemberton JE (2007) Electrospray ionization of uranyl-citrate complexes: adduct formation and ionmolecule reactions in 3D ion trap and ion cyclotron resonance trapping instruments. Int J Mass Spectrom 265(2):281-294. https://doi.org/10.1016/j.ijms.2007.02.050

Publisher's note Springer Nature remains neutral with regard to jurisdictional claims in published maps and institutional affiliations. 